\title{
ANALYTICAL STUDY FOR THE IMPACT OF ECONOMIC REFORM ON ATTRACTING FOREIGN DIRECT INVESTMENT TO EGYPTIAN AGRICULTURE SECTOR
}

\author{
EKRAM AHMED EL SAYED ABDELRAHMAN \\ Agricultural Economic Research Institute, Agricultural Research Center, Giza, Egypt \\ corresponding author :Ekram 9375@yahoo.com
}

(Manuscript received 12 February 2019)

\begin{abstract}
$\mathrm{E}$ gypt has natural resource base and large market size, qualifies to be a major recipient of FDI in Africa and indeed, it is one of the top three leading African countries that consistently received FDI in the past decade. However, the level of FDI attracted especially to agriculture is small compared to the resource base and potential need, the percentage of FDI inflow to the agricultural sector in Egypt decreased from $4.68 \%$ during 1982 to $3.37 \%$ during 2017/2016 which reflected negatively on agricultural sector contribution on gross national product from $19.9 \%$ during 1982 to $11.6 \%$ during 2016/2017. This research aims at highlighting the impact of economic reform on Attracting Foreign Direct Investment to Egyptian Agriculture Sector, and examined the impact of FDI on the agricultural sector growth in Egypt during the period (19902016), known as the economic reforms. The research is based on the descriptive and analytical methodology and the econometric methodology in determining the relationship, the research employs secondary time series data which spanned $(1990$ - 2016). The result obtained in the analysis; there exist a positive relationship between foreign direct investment and agricultural sector of Egypt foreign direct investment, it hasn't significant impact on agriculture in Egypt due to the nature, risk and uncertainty of agriculture activity, The $\mathrm{R}^{2}$ is 0.93 showing that the explanatory variable explains $93 \%$ of changes in the dependent variable. Other factors that contribute to agriculture apart from foreign direct investment are captured by the remaining $7 \%$ which are not included in the model, from the regression analysis carried out; The questionnaire cleared that, There are many obstacles facing the investor when investing, which limits the attractiveness of investment, such as, unstable political and economic policies, weak infrastructure, global competition for FDI flows as impediments standing in the way of attracting significant FDI flows, political regime, , rate of inflation, interest rate, credit rating and debt service,.. In the light of the above findings, the followings recommendations are proposed to encourage and improve the inflow of foreign direct investment in Egypt:
\end{abstract}

- Economic reform policies encouraged and attract more FDI into Egypt; also Egypt needs to juxtapose foreign investment with domestic investment in order to maintain high levels of income and employment.

- Foreign investment can be effective if it is directed at improving labor skills. Foreign direct investments into Egypt will not on its own lead to sustainable economic growth. 
906 ANALYTICAL STUDY FOR THE IMPACT OF ECONOMIC REFORM ON ATTRACTING FOREIGN DIRECT INVESTMENT TO EGYPTIAN AGRICULTURE SECTOR

- focus on the Policies' stability of the economy' which enhancement of the internal economy,

- monitoring of benchmarks and business practice, voluntary guidelines, and transfer of Environmentally sound technology

- Government should provide adequate infrastructure and policy framework that will be conducive for doing business in Egypt, so as to attract the inflow of FDI.

- The necessity of activating inter-Arab investments.

- Promoting Agriculture should be the top-most priority of administration in Egypt.

Keyboard: Egypt economy, economic reform, foreign direct investment (FDI), investment climate. 


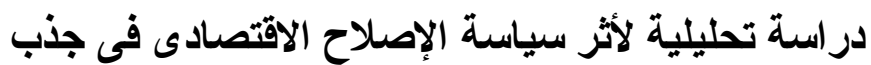

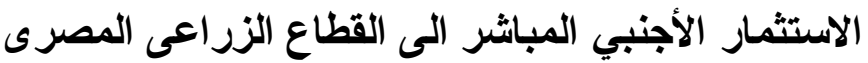

\author{
إكرام أحمد السيد عبدالرحمن \\ قسم السياسة الزر اعية وتقييم المشروعات، معهُ بحوث الإقتصاد الزراعي - مركز البحوث الزر اعية-
}

الجيزة، مصر، Ekram9375@yahoo.com

\section{الملخص و التوصيات}

بدأت الحكومة المصرية برنامج للإصلاح الاقتصادى و التكيف الهيكلى عام 1991، ثم قامت

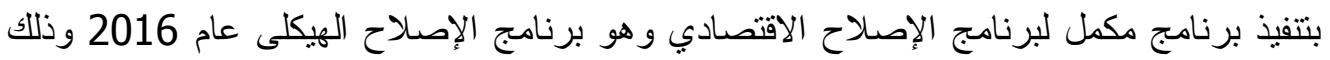

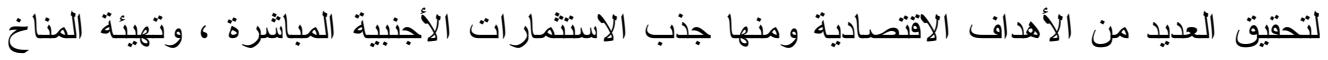

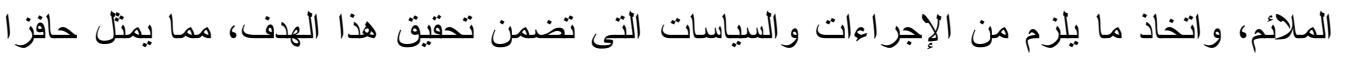

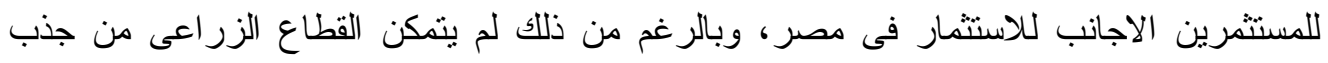

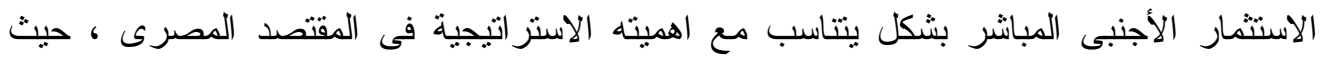

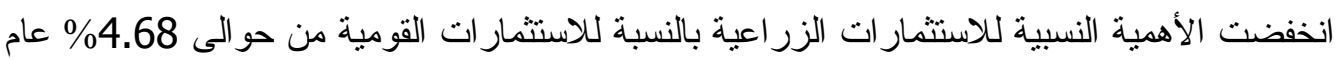

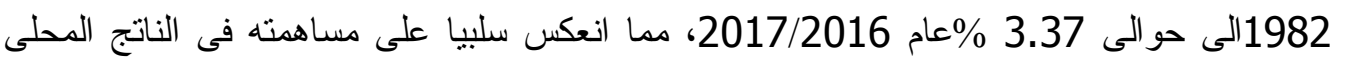

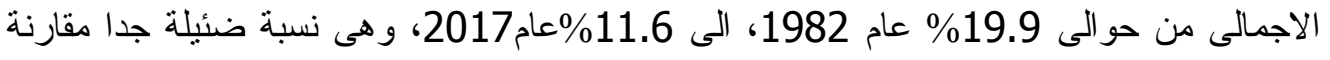

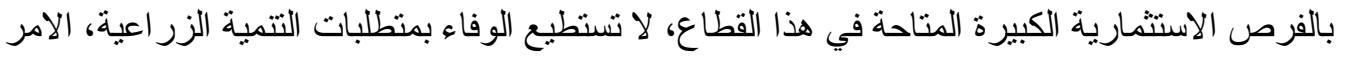

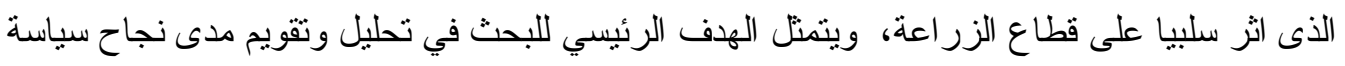

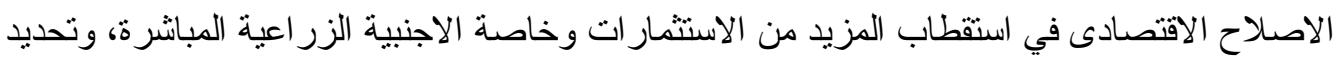

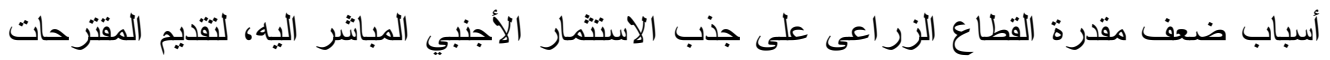

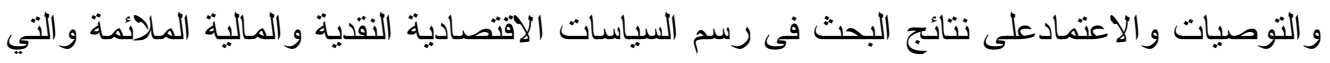

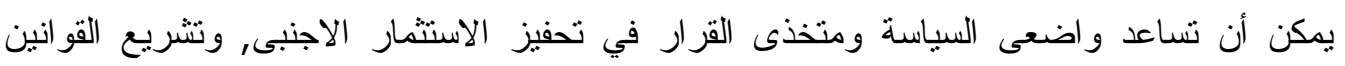

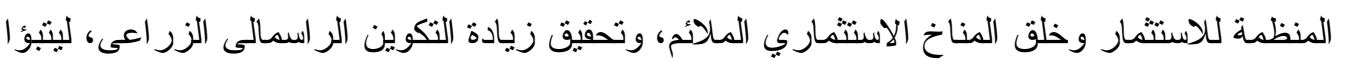

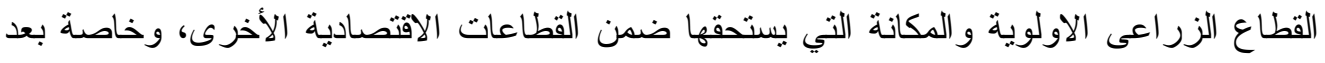

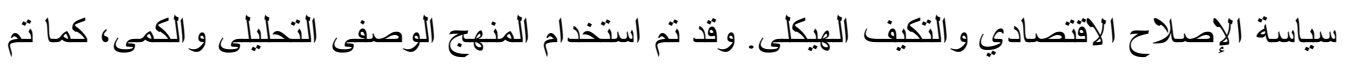
تصميم استمارة استبيان لفئتين (المستثرين وذوى الخبرة و الاهتمام بمجال الاستثمار)، لضمان

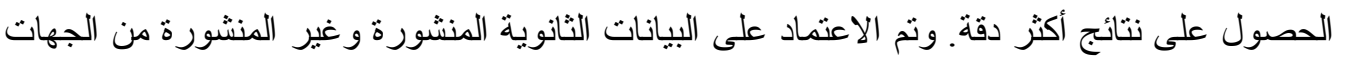

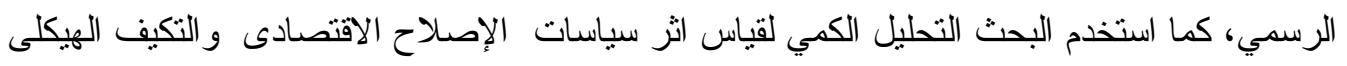
على جذب الإستثمار الاجنبى المباثر في القطاع الزراعي من خلال قياس أنز الاستئمار الأجنبي

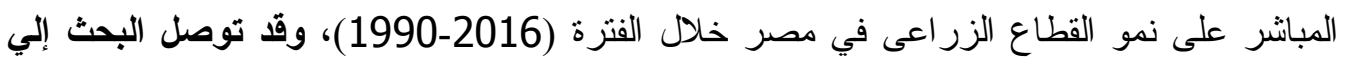
النتائج الأتية: اوضحت نتائج دراسة العلاقة بين المتغير التابع (Y) الذي يمنل نمو القطاع الزراعى، والمتغير ات

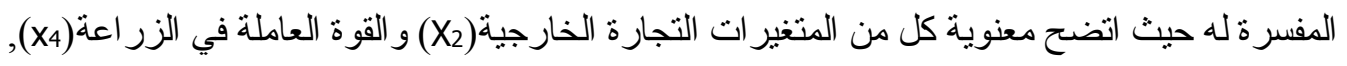

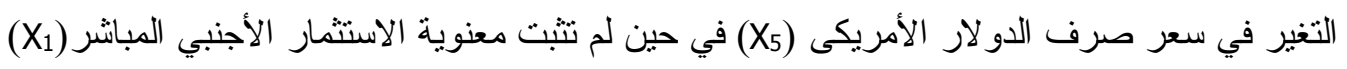


بالر غم من الإشارة الموجبة المتفقة مع الفرضية، و هذا يعنى رفض فرضية الدر اسة، كما لم تتبت معنوية

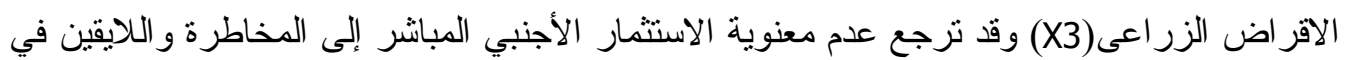

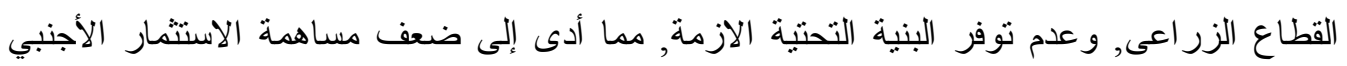

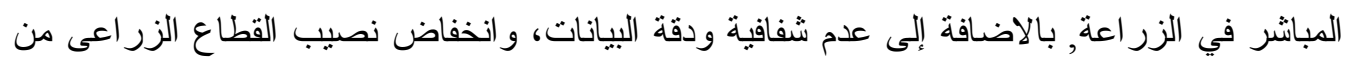

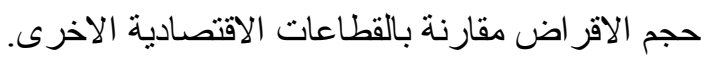

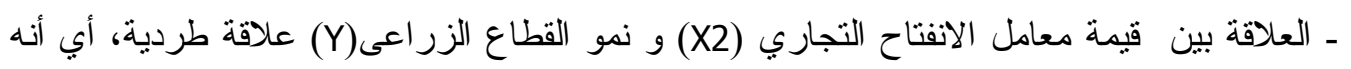

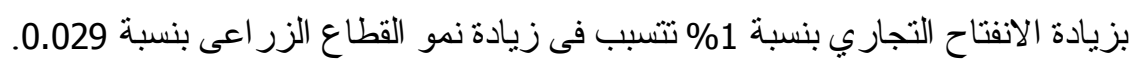

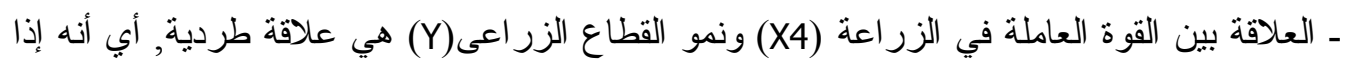

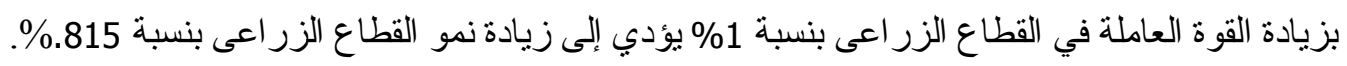

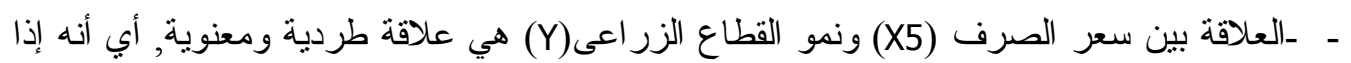

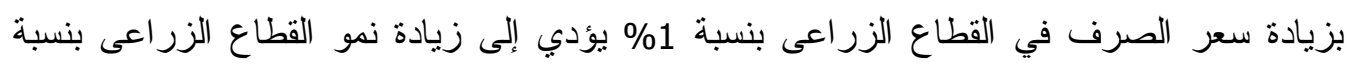

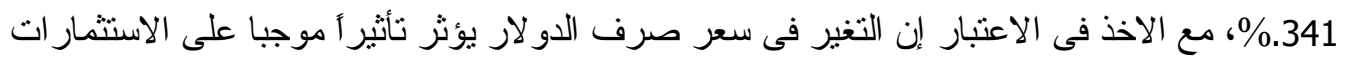

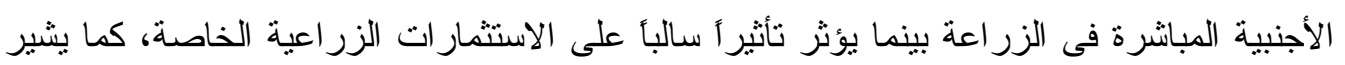

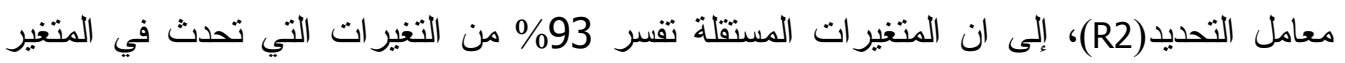

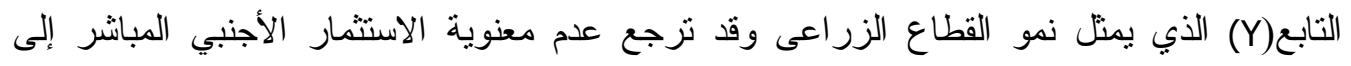

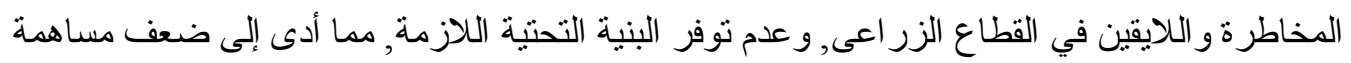

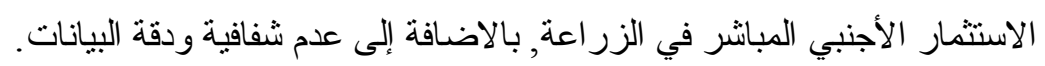

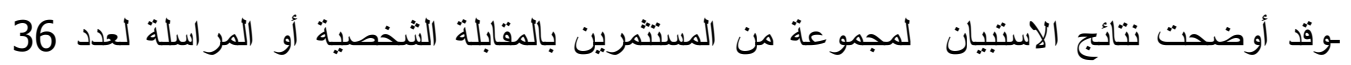
مستثمر ا من جنسيات متعددة عام 2017/2016 ، 64 من ذوى الخبرة و الاهتمام بمجال الاستثمار

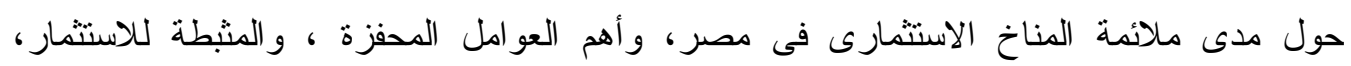

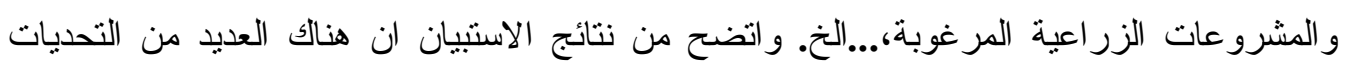

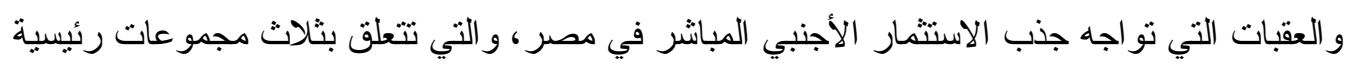
و هي قاعدة الموارد الطبيعية، إصلاح السياسات، و المؤسسات. وتتعلق المجموعة الأولى الألى بمحدودية

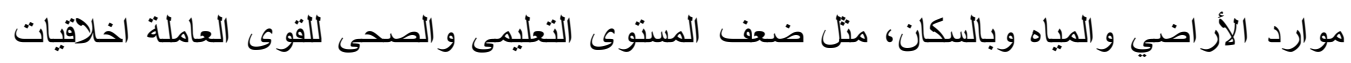

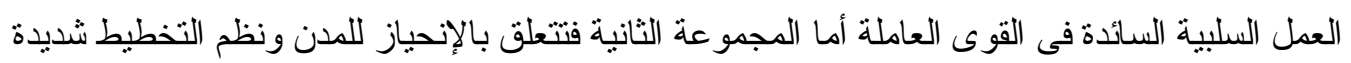
المركزية، صعوبة تحديد المسئوليات الوظيفية لبعض الأجهزة الحكومية، عدم تفعيل مكاتب الاستثمار

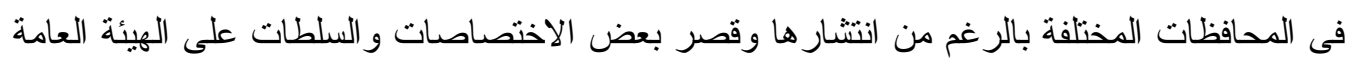

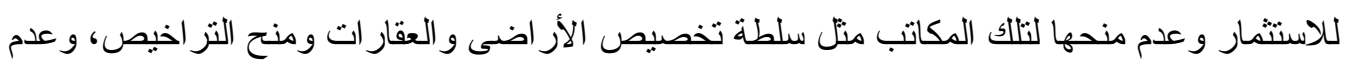

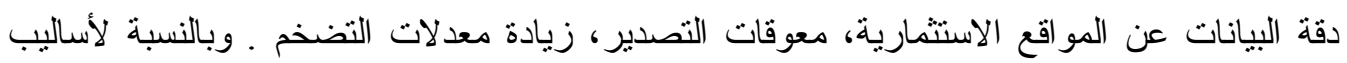

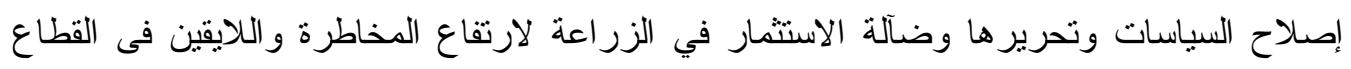

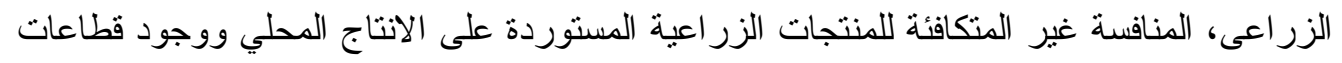

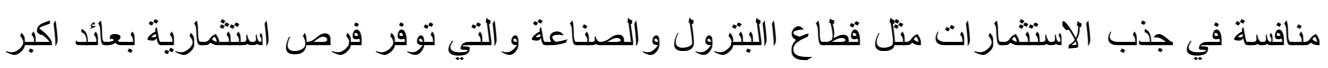

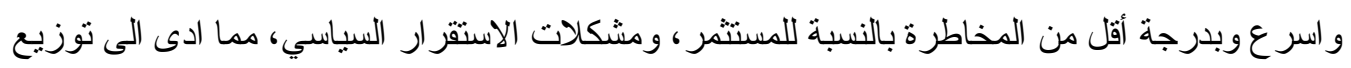

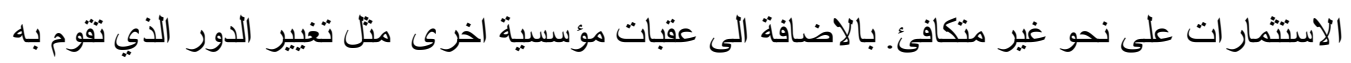

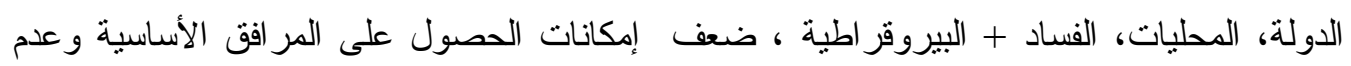

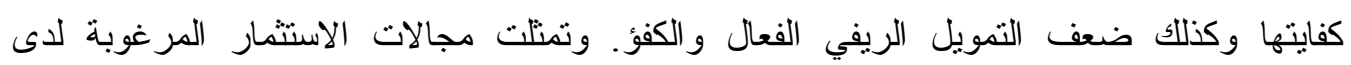
المستثمرين فى مجالات البنرول، الصناعة، وبالنسبة للقطاع الزر اعى مثل الصناعات الغذائية كصناعة التهات 


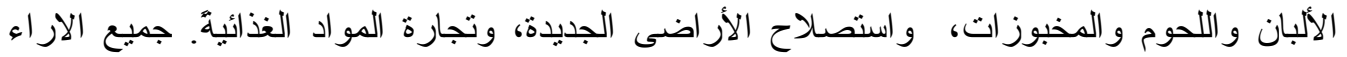

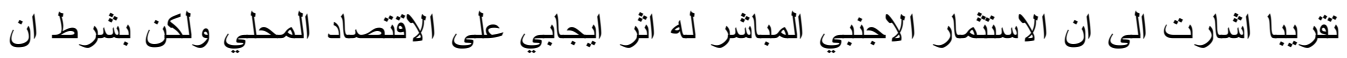

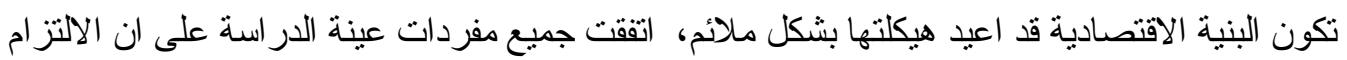

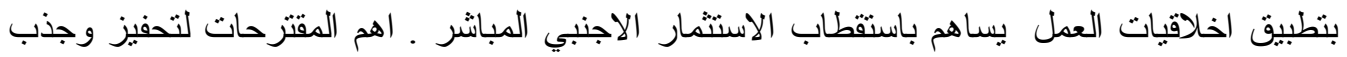

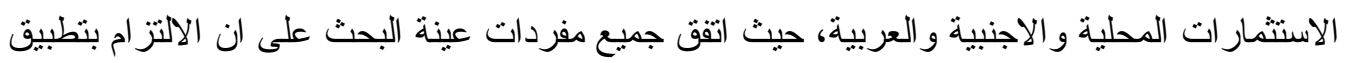

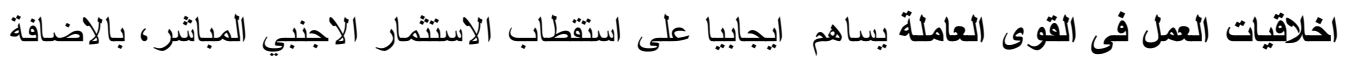

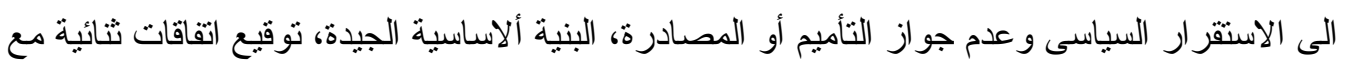

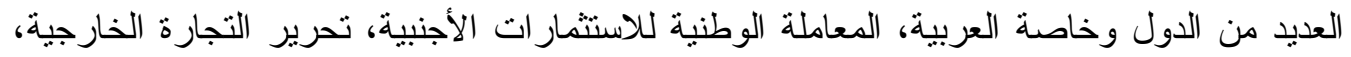

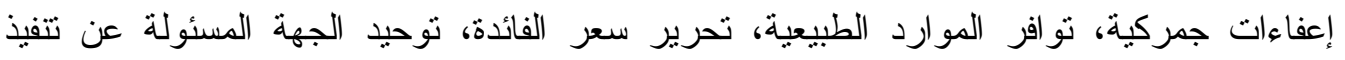

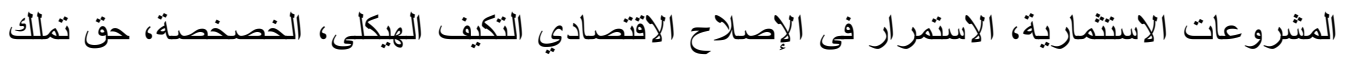

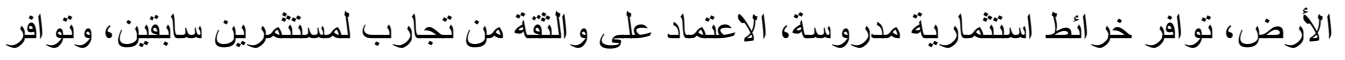

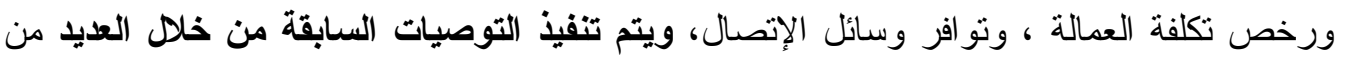

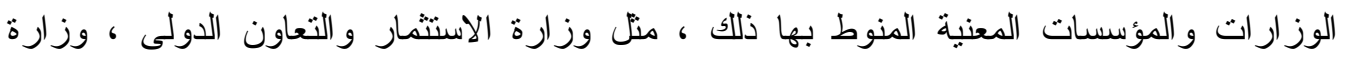

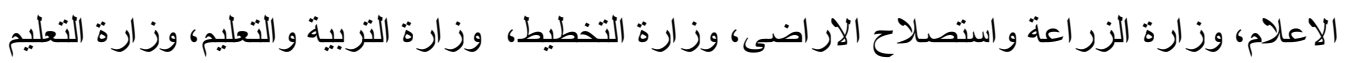

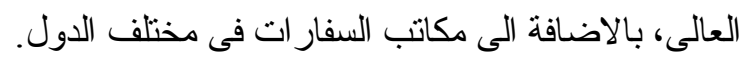

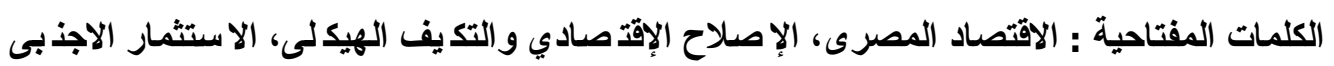

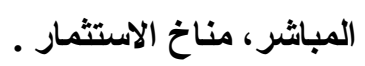

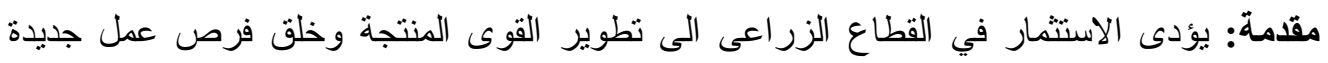

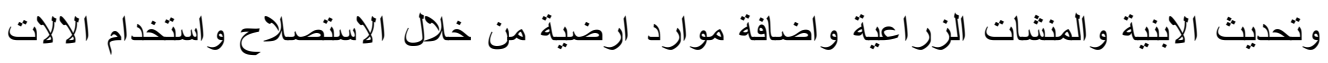

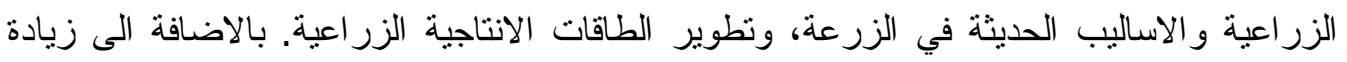

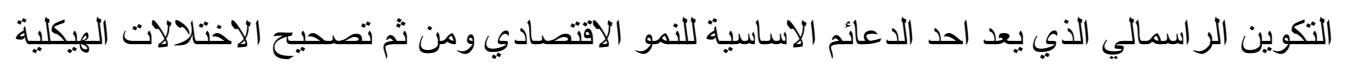

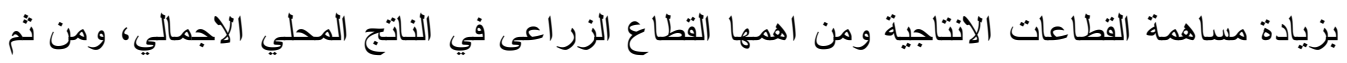

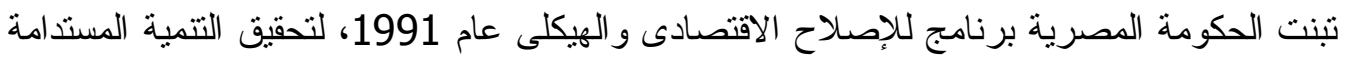

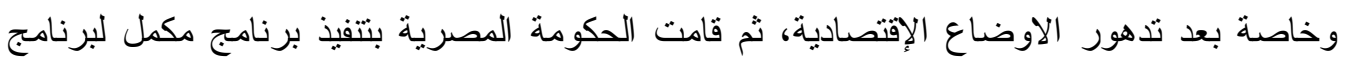

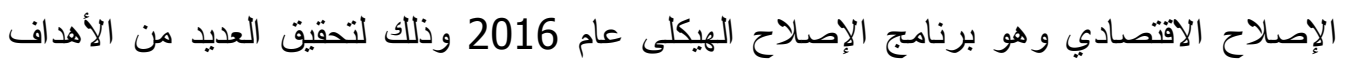

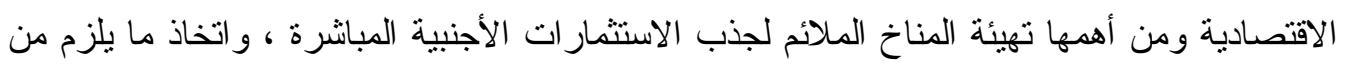

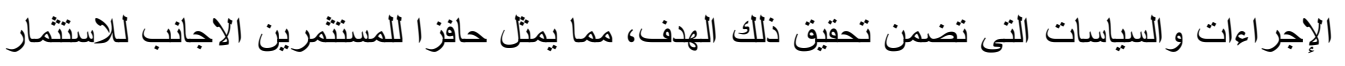

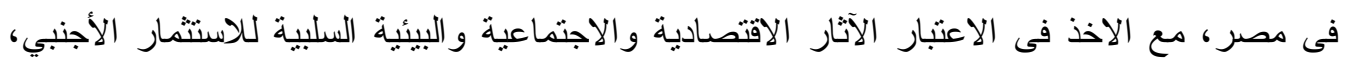

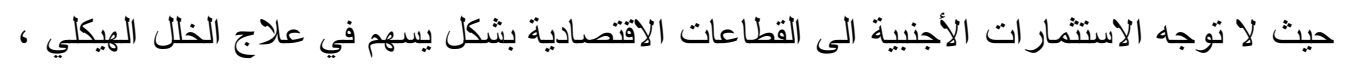

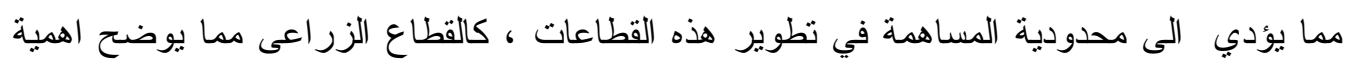

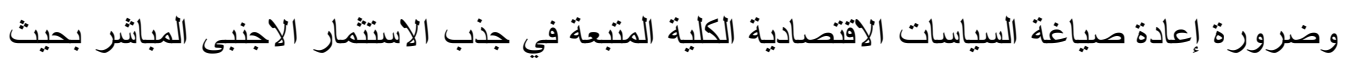

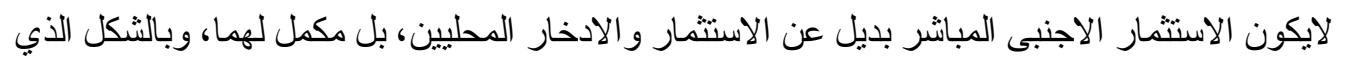

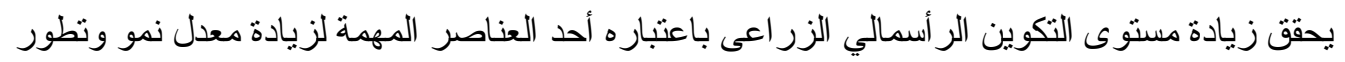

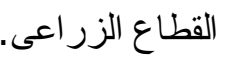

\section{مشكلة البحث}

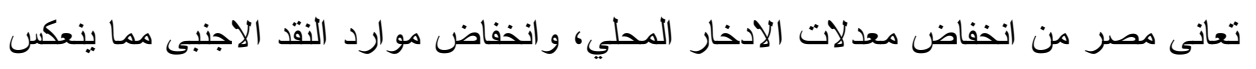

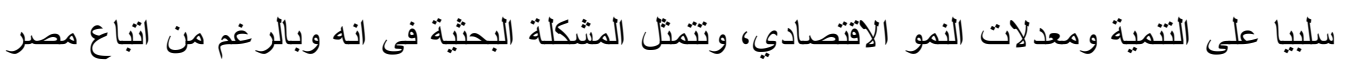


برنامج الاصلاح الاقتصادى و التكيف الهيكلى 1991، و المجهودات المبذولة لتحسين بيئة الأعمال

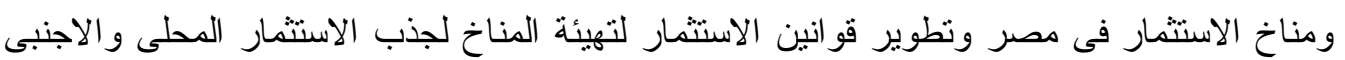
المباشر و إصدار قو انين لحماية المنافسة و الملكية وتقديم الضمانات و النسهيلات للمستثمرين المحليين

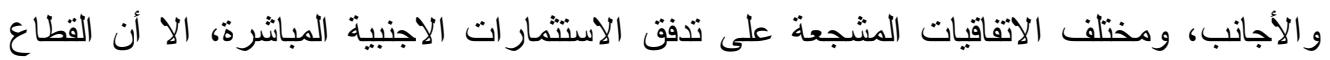
الزر اعى لم يحظ بنصيب يتناسب مع أهميته الاستر اتيجية فى المقتصد المصرى لـى بل و انخفضت الأهمية

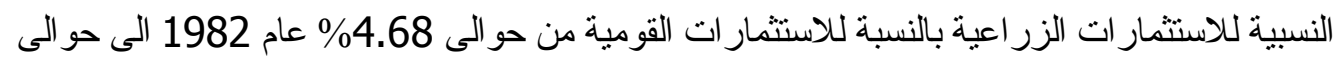

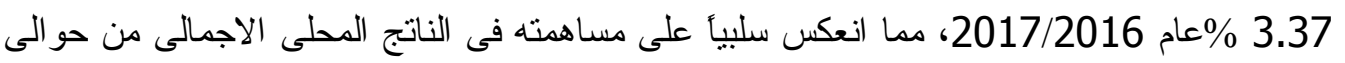

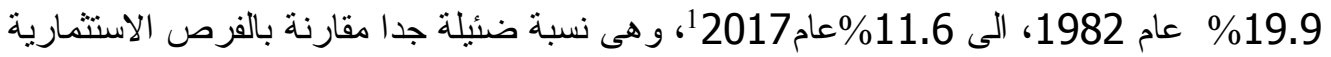

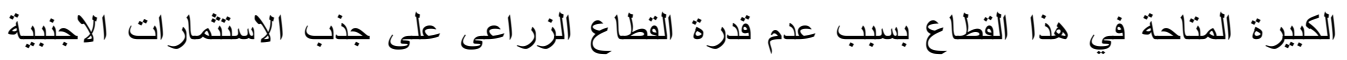

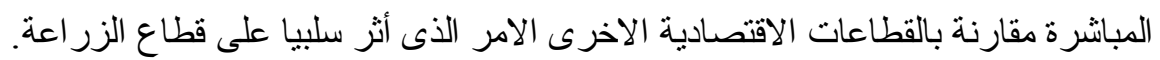

\section{هدف البحث}

يتمنل الهدف الرئيسي للبحث في تحليل وتقويم مدى نجاح سياسة الاصداح الاقتصادى في

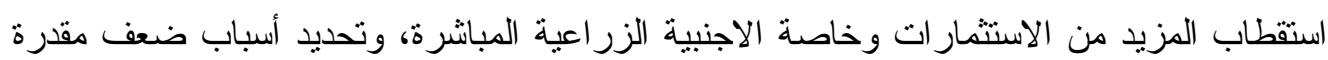

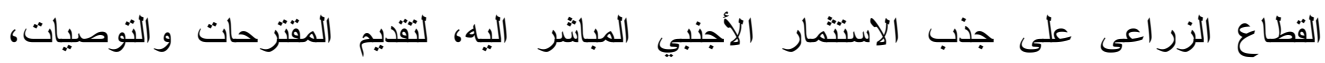

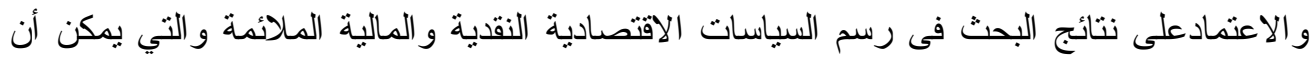

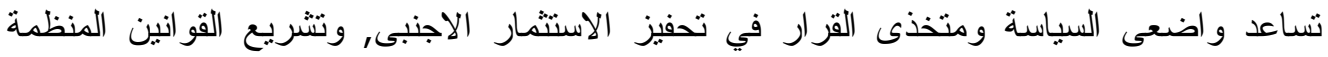

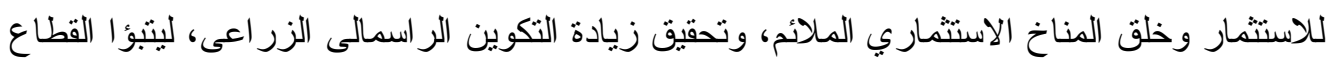

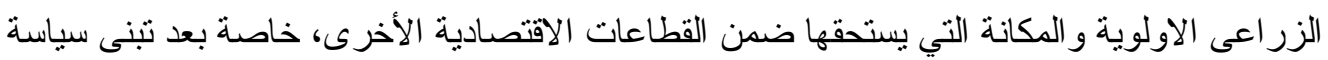

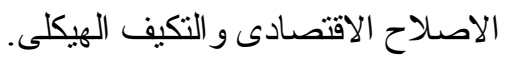

\section{الطريقة البحثية ومصادر البيانات}

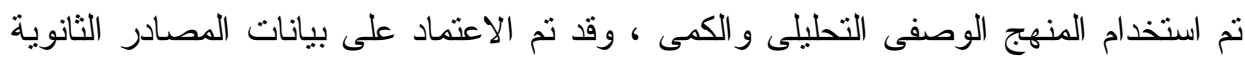
و الأولية، وقد تم تصميم استمارة استبيان لفيتتي (المستتمرين وذوى الخبرة و الاهتمام بمجال الاستثمار)،

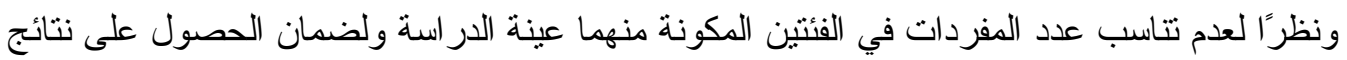

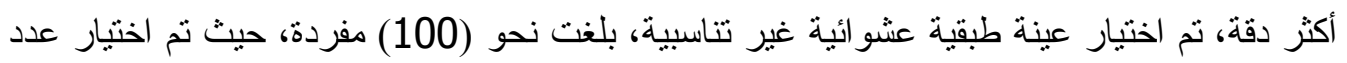

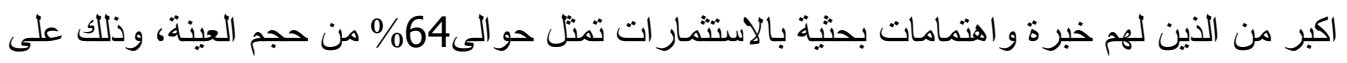

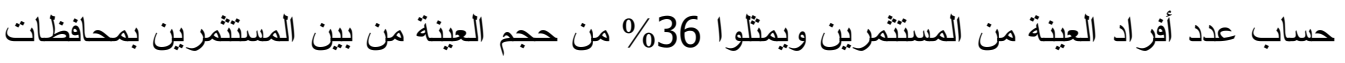
القاهرة الكبرى عام 2017/2016. وقد تم الاعتماد على بيانات منظمة الأونكتاد، العيئة العامة للاستثمار و المناطق الحرة ، البنك المركزى المصرى...الخ، بالإضافة الى عدد من التقارير ، الدر اسات

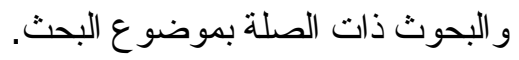

\section{النتائج البحثية ومناقشتها}

يقصد بالإصلاح الاقتصادي مجموعة من الجهود المدروسة الني تبذلها الدولة لمعالجة وضع ميزانهان المدفوعات و تعزيز فرص النمو وزيادة الكفاءة في استخدام الموارد2، كما يقصد بالاصدلاح الهيكلى 3 ،

1 وز ارة التتمية الاقتصادية ، تقارير المتابعة السنوية للخطة ، أعداد متقرقة ، القاهرة.

2 احمد ابو اليزيد الرسول-السياسات الاقتصادية الزراعية "رؤى معاصرة" مكتبة بستان المعرفة للطبع و النشر -مصر - 
مجموعة من السياسات و الإجر اءات الهادفة إلى رفع الطاقة الإنتاجية ودرجة مرونة الاقتصاد، وهى سياسات اقتصادية جزئية ، هدفها الأساسى تحسين كفاءة تخصيص الموارد بنقليص مختلف الأسباب الإنس التى تعيق عمل الأسواق. ومن اهم مبررات الإصلاح الاقتصادي4 الاختلالات الهيكلية و المشاكل

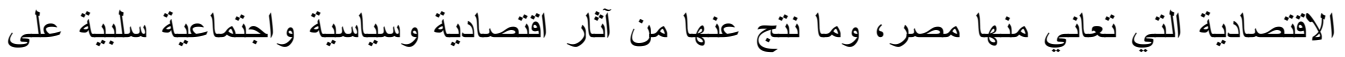
المجتمع، ومن أهم أهداف الإصلاح الإقتصادي زيادة الانتاج و الانتاجية من ناحية وكذللك التحكم بالطلب

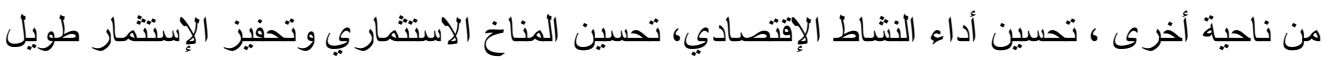
الاجل، تثجيع الإستثمار الأجنبي المباشر وفق أولويات التتمية المحلية وزيادة عائد الاستثمار من خلال

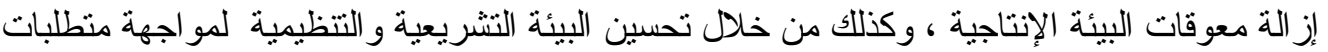

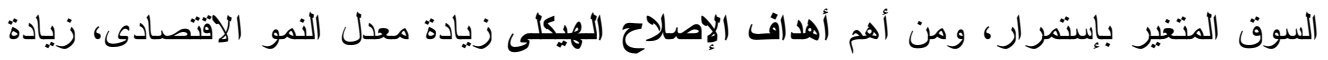

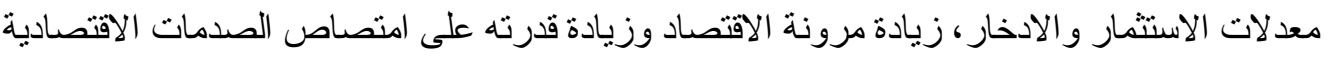

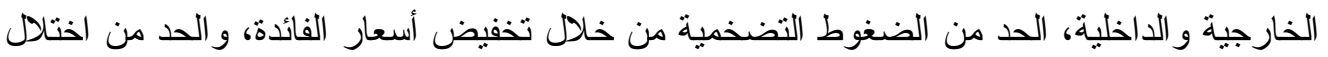

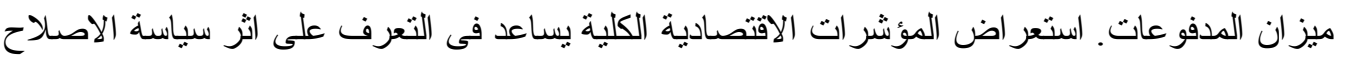

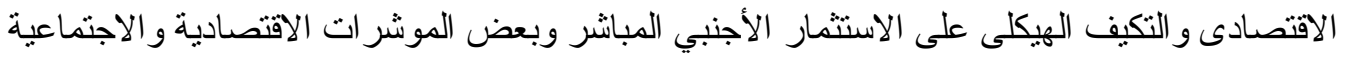

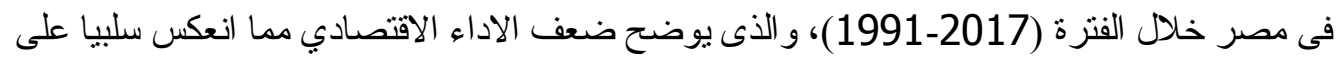

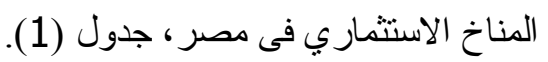

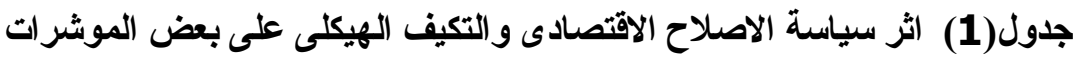

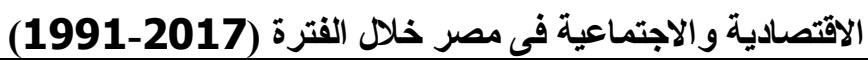

\begin{tabular}{|c|c|c|c|c|c|c|c|}
\hline 2017 & 2016 & 2015 & 2011 & 2010 & 1997 & 1991 & البيان \\
\hline 4.2 & 4.35 & 4.4 & 1.8 & 5.1 & 5.46 & 1.08 & معدل نمو الناتج المحلى الاجمالى\%\% \\
\hline 29.5 & 13.8 & 10.4 & 11.15 & 10.11 & 9.88 & 14.48 & التضخ \\
\hline 33.3 & 16.8 & 14.5 & 14.8 & 15.4 & 37.92 & 89.12 & نسبة المديونية الخارجية من الناتج \\
\hline (35.4) & $(38.7)$ & $(39.1)$ & $(34.0)$ & $(27.2)$ & $(8.6)$ & - & الميز ان التجارى(مليون دو لار) \\
\hline 17.75 & 10.03 & 7.69 & 5.93 & 5.6 & 3.39 & 3.14 & سعر الصرف(جنيه/دولار) \\
\hline 12.4 & 13.03 & 13.1 & 12.1 & 9 & 8.4 & 9.60 & معدل البطالة\% \\
\hline
\end{tabular}

المصدر: البنتك المركزى المصرى، التقريز السنوى ،وزراة المالية، اعداد مختلفة.

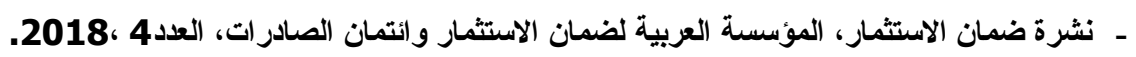

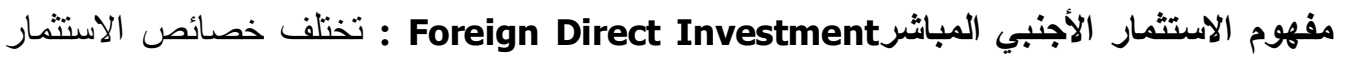

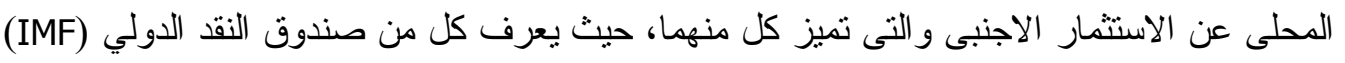

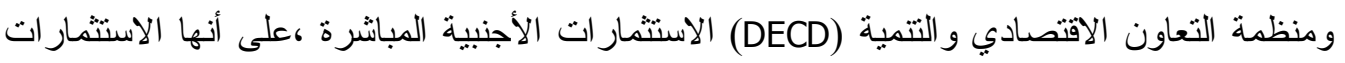

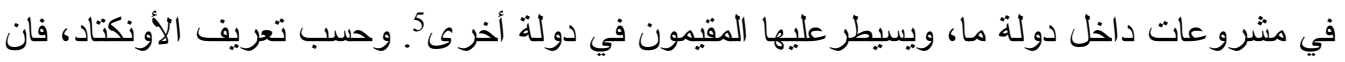
الاستثمار الأجنبي المباثر هو ذللك الاستثمار الذي يفضى إلى علاقة طويلة الأمد ويعكس منفعة وسيطرة

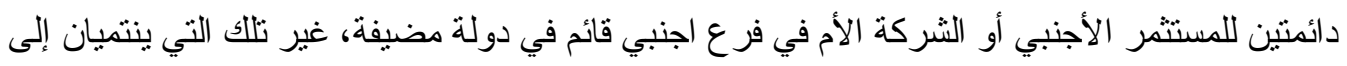

4 احمد حسين عبدالحميد الغنيمى- الاصلاح الاقتصادى فى الزراعة المصرية -كلية الزر اعة-قشم الاقتصاد الزر اعى جامعة الاسكندرية-2007. 5 على عبد الوهاب إبر اهيم نجا، الاستثمار الأجنبي المباشر وأثره على التثمية الاقتصادية في مصر خلا الفترة

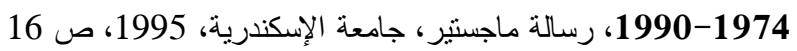


جنسيتها6. يمكن التمييز 7 ما بين الاستثمار الأجنبي المباثر وغير المباشر حيث ان الاستثمار الأجنبي

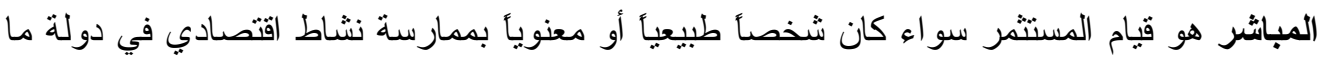

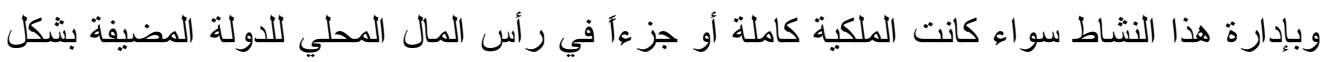

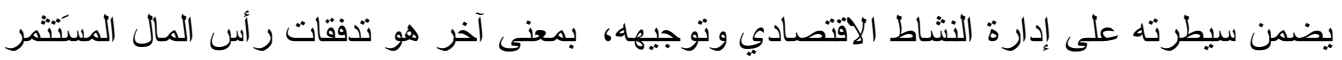

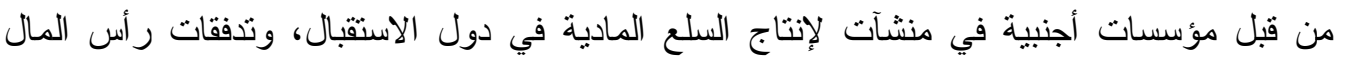
الأجنبي المباشر هي عادة طويلة الأجل، وتطبق نسبة 10\% أو أكثر من ملكية الحقوق (رأس مال

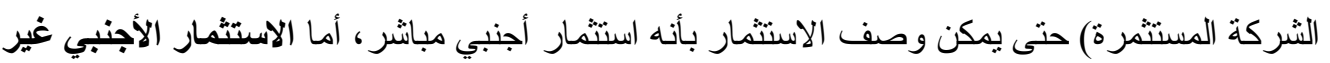

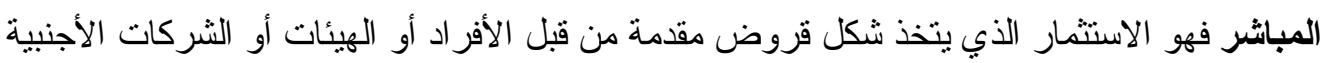

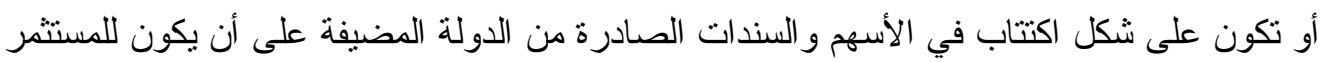

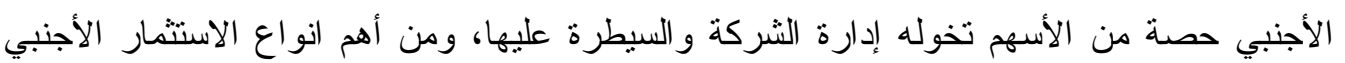

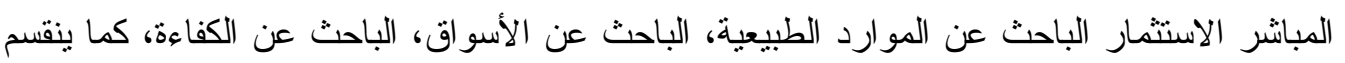

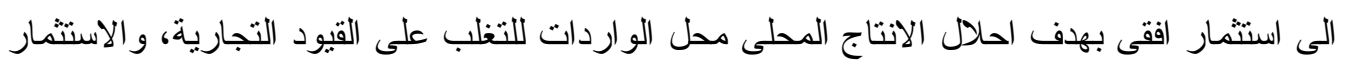

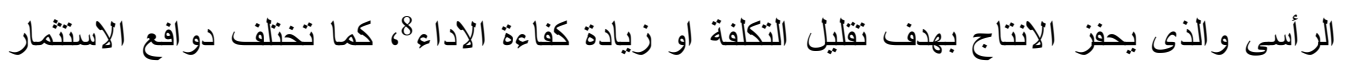

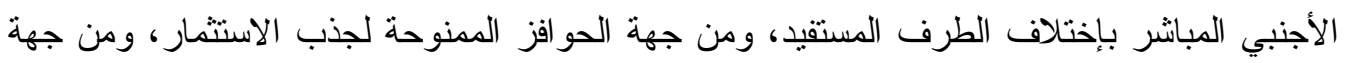

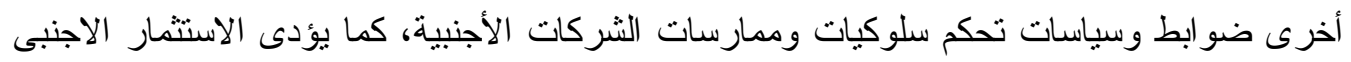

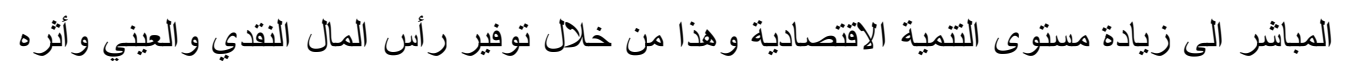

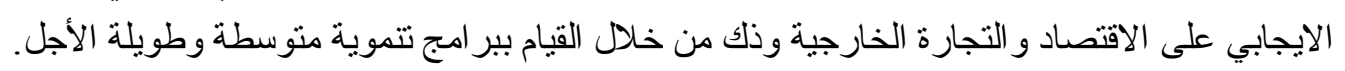

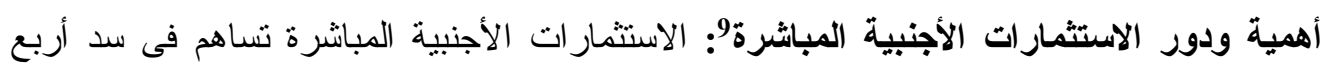

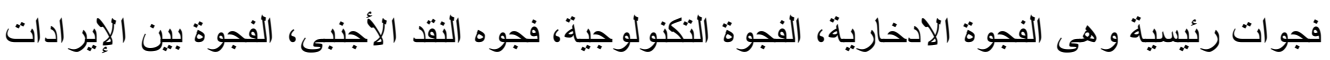

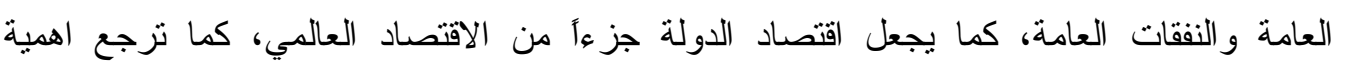

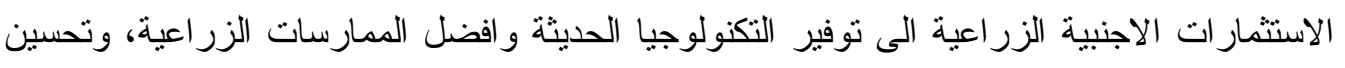

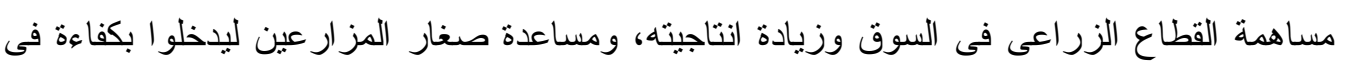

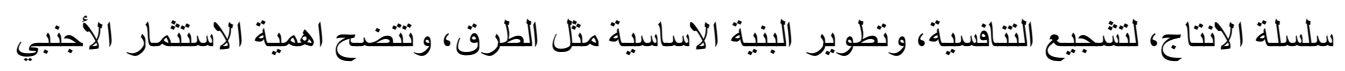

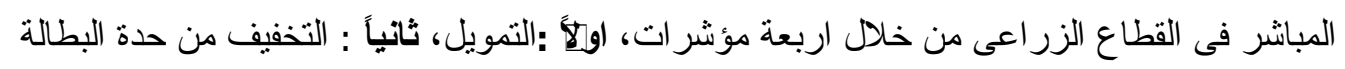

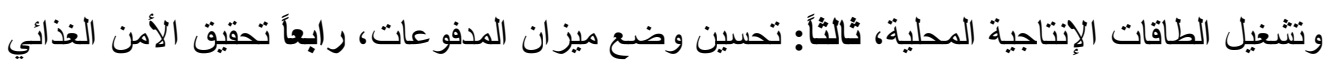

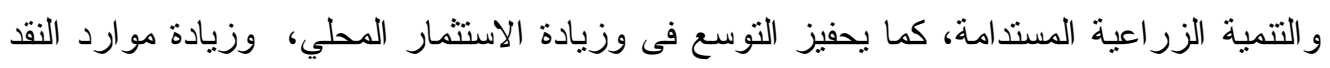

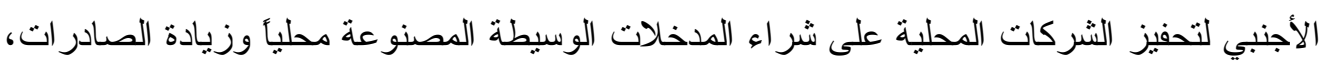

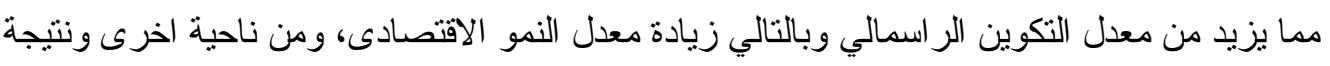

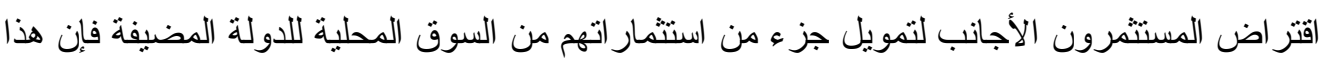
يؤدي إلى تتاقص نصيب المستثرين المحليين من المبلغ المخصص لتمويل استثمار اتهم، ونتيجة لذلك التك

6 المؤسسة العربية لضمان الاستثمار ،الاستثمار الأجنبي المباشر والتتمية، سلسلة الخلاصات المركزة،السنة

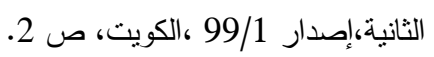

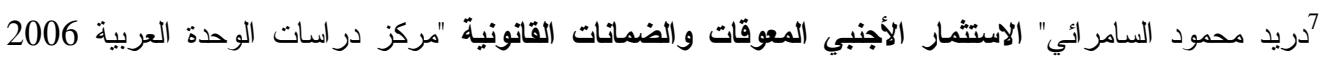

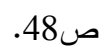

8 Elizabeth Asiedu (2002), "On the Determinants of Foreign Direct Investment to Developing Countries: Is Africa Different?", World Development, Vol. 30, No. 1, P. 109.

9 Alasrag, Hussien. "Foreign Direct Investment Development Policies in the Arab Countries". Munich Personal RePEc Archive, no. 2230 (December 2005), http://mpra.ub.uni-muenchen .de/2230/1/MPRA_paper_2230.pdf 


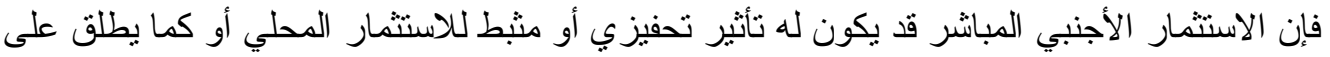

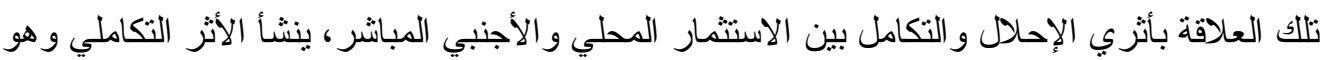

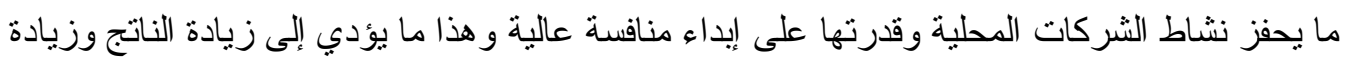
عدد المؤسسات المحلية ، وبالتالي تحسين معدلات النمو الاقتصادي في الدول المضيفة.يينما إذا اعتمدت

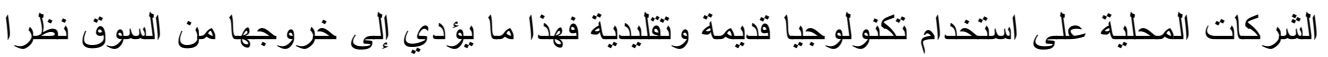

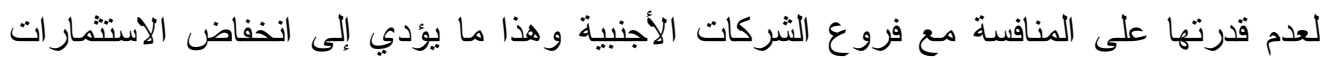

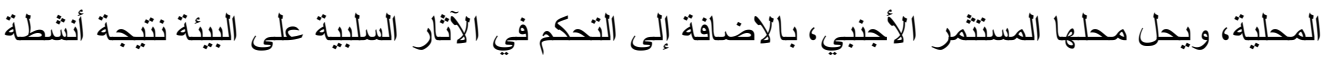

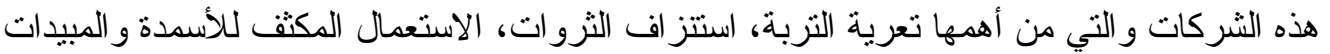

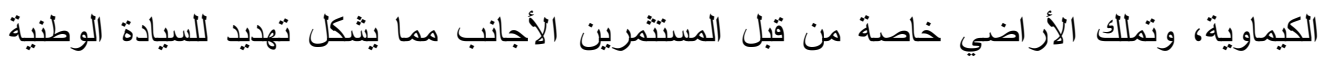
بالإضافة إلى التأثير على كم ونوع المحاصيل المحلية، مما يستلزم العمل على تعظيم المنافع و القضاء أو الحد من آثاره السلبية. اثر سياسة الاصلاح الاقتصادى على المناخ الاستثماري فى مصر 10: تتضح الهية التعرف على اثر الثرار

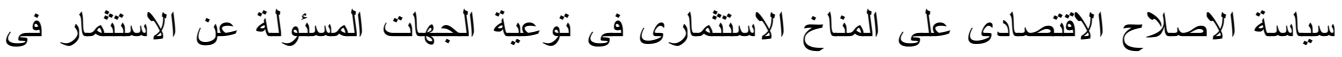

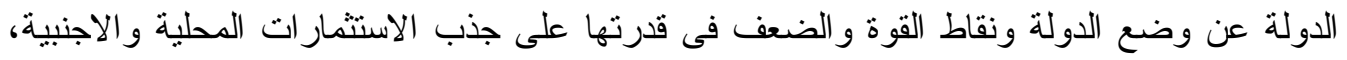

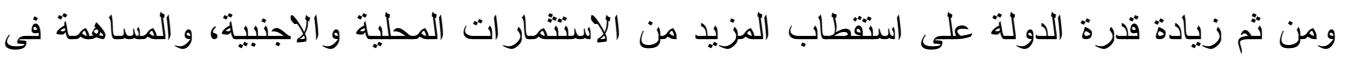

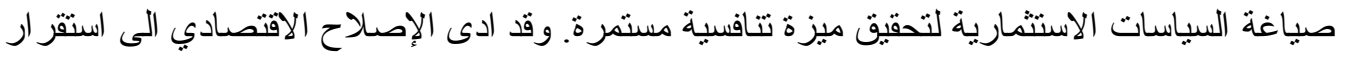

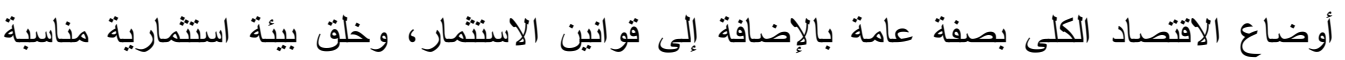

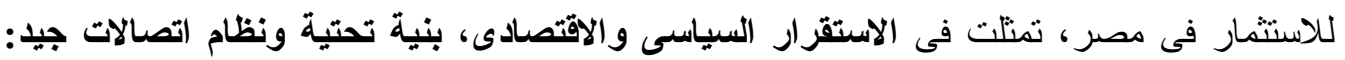

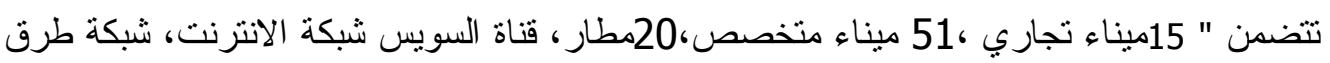
محلية..الخ، التشريعات الضريبية مشجعة على الاستثمار من ناحية ومحافظة على حقوق الدولة من

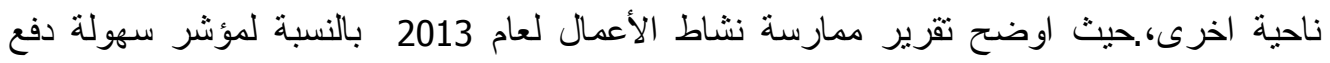

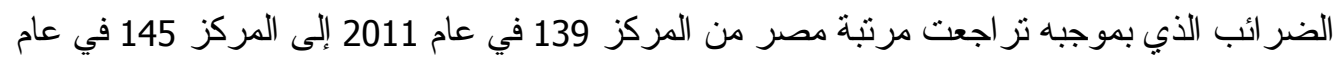
2013من بين 185 دولة، فيجب تفعيل الاقفاقيات والتكتلات الاقتصادية الإقليمية والعربية والدولية،

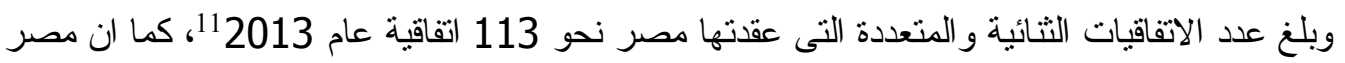

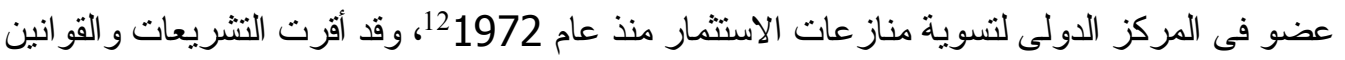

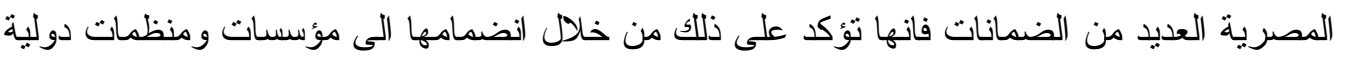
و عقدها للاتفاقيات مثل اتفاقية تحرير التجارة بين الدول العربية ،و المناطق الصناعية المؤهلة (الكويز)

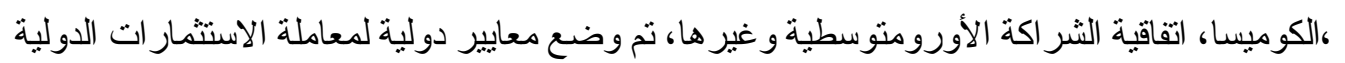

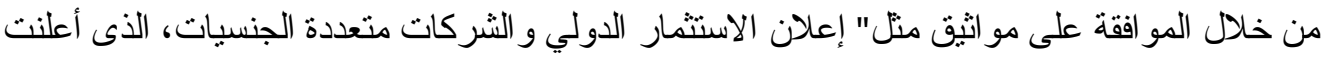
مصر انضمامها إليه في عام2007، كما يعانى المقتصد المصرى من فجوة هيكلية بين الادخار

10 أميره حسب اله محمد، محددات الاستثمار الاجنبي المباثر في البنية الاقتصادية العربية دراسة مقارنة (تركيا -

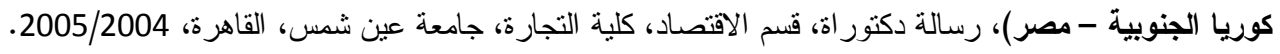

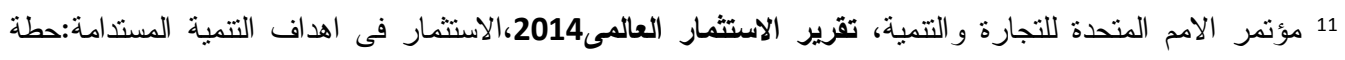

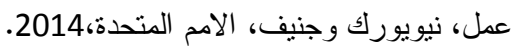

${ }^{12}$ Centre International pour le Règlement des Différends Relatifs aux Investissements CIRDI,Rapport annuel 2014, Washington, DC : Banque Mondiale, 2014, p 9-13. 
و الاستثمار في الاقتصاد المصري مما يعكس عدم كفاية حجم الادخار المحلي لتمويل الإنفاق

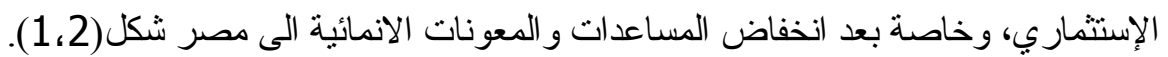

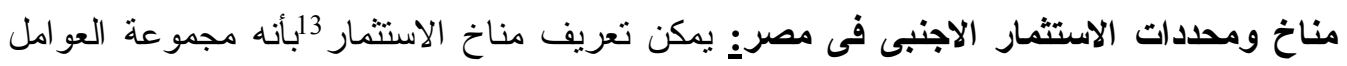
الخاصة التي تحدد شكل الفرص و الحوافز التي تتاح للمؤسسات الاستتمارية بطريقة منتجة، وإيجاد فرص عمل، وخفض تكاليف مزاولة الأعمال، وتتمثل اهم محددات الإستثمار الأجنبي المباشر 14 فى

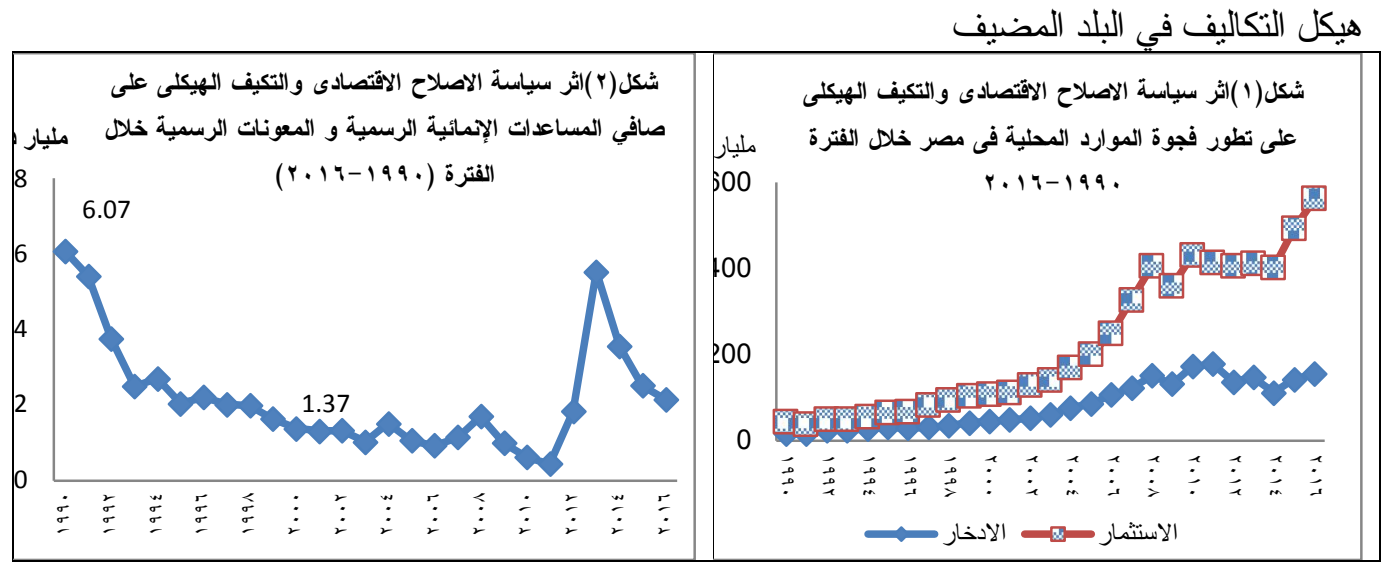

المصدر: جمعت من موقع البنك الدولي على شبكة المعلومات الدولية

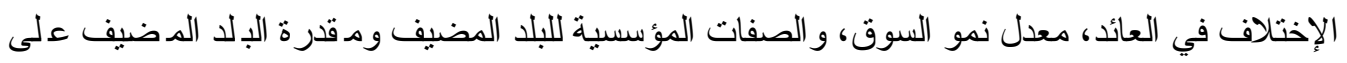

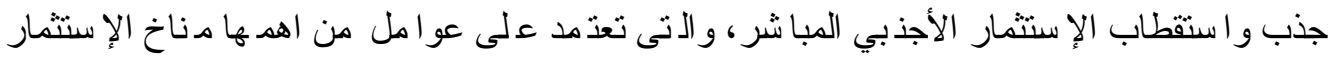

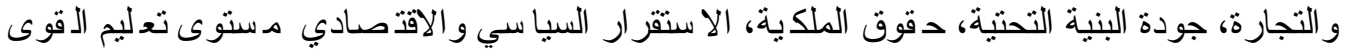

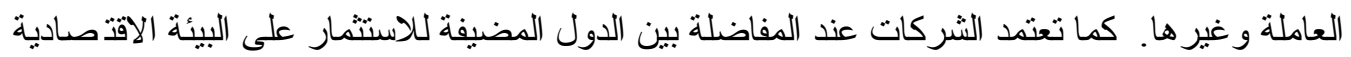

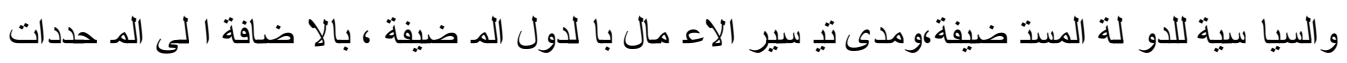

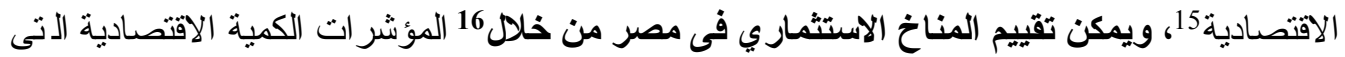

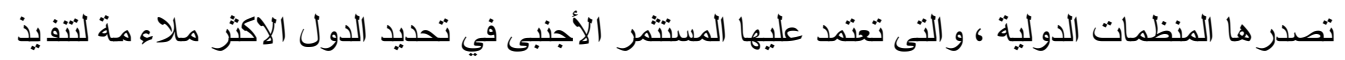

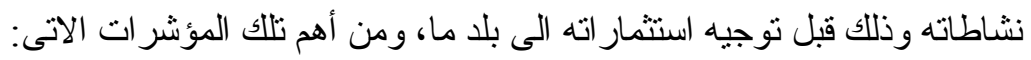

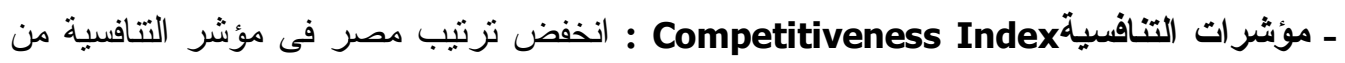

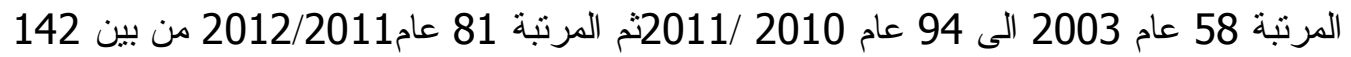
دولة ، ثم استمر الانخفاض حتى بلغ المرنبة 100 خلام عام 2017 علم 17 جدول(2).

13 رئاسة الجمهورية ،المجالس القومية المتخصصة،" موسوعة المجالس القومية المتخصصة" ،المجلد الثاني

و الثلاثون،الكتاب السنوي، ـ 2005-2006صهـ 22

14 De Mello, L. (1997) "Foreign Investment in Developing Countries and Growth: A Selective Survey", Journal of Development Studies, October.1997.

15 UNCTAD, World Investment Report: Trends and Determinants, Overview (New York and Geneva ,1998, p. 91

${ }^{16}$ World Bank Doing Business 2013. *Ranked out of 185 economies around the world.

17 World Economic Forum, Global Competitiveness Reports, 2002- 2018.

$$
\text { ـ المنتدى الاقتصادي العالمي، تقرير التنافسية العالمي. اعداد مختلفة. }
$$


جدول (2) اثر سياسة الاصلاح الآتصادى والتكيف الهيكلى على تنافسية الاقتصاد المصري

\begin{tabular}{|c|c|c|}
\hline & (التزي| \\
\hline$\downarrow$ & 58 & $2004 / 2003$ \\
\hline$\downarrow$ & $142 / 81$ & $2011 / 2010$ \\
\hline$\downarrow$ & 94 & $2012 / 2011$ \\
\hline$\downarrow$ & $144 / 107$ & $2013 / 2012$ \\
\hline$\downarrow$ & $148 / 118$ & $2014 / 2013$ \\
\hline$\downarrow$ & $144 / 119$ & $2015 / 2014$ \\
\hline$\uparrow$ & $140 / 116$ & $2016 / 2015$ \\
\hline$\wedge$ & $138 / 115$ & $2017 / 2016$ \\
\hline$\wedge$ & $137 / 100$ & $2018 / 2017$ \\
\hline
\end{tabular}

Source:The World Economic Forum," The Global Competitiveness Report".2017.

ـ مؤشر اداء الدولة فى جذب الاستثمار الاجنبى المباشر 18: انخفض ترتيب مصر فى مؤشر اداء الدولة فى جذب الأب

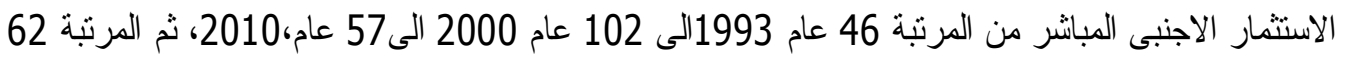
عام 2011. ـمؤشر سهولة ممارسة أنثطة الأعمال 19 : انخفض نرتيب مصر في سهولة ممارسة أنشطة الأعمال من المرنبة

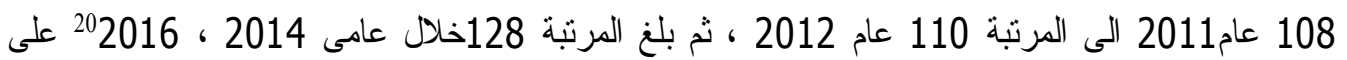
التزتيب. ـمؤشر التنمية البشرية: احتلت مصر المرتبة120عام 1997، ( 115 ) عام 2000، ثم 110عام 2010 بينما انخفضت الى المرنبة (112) (110 ) عام2012، 201421.

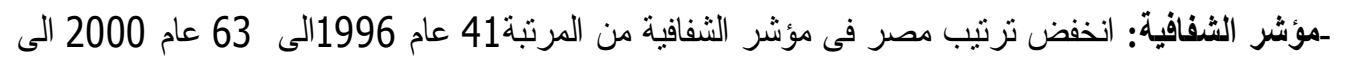

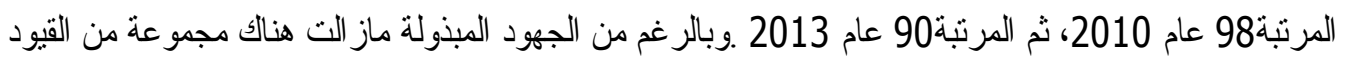
و المشاكل التى تحد من تز ايد معدلات الاستثمار وتؤثر بشكل سلبى على كفاءته وقدرته التنافسية جدول (3) ومن

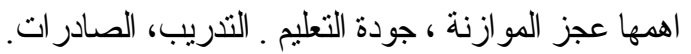

\begin{tabular}{|c|c|c|c|}
\hline \multicolumn{4}{|c|}{ جدول(3) أهم أسباب تأخر ترتيب مصر في تقرير التنافسية } \\
\hline 2018-2017 & $2017-2016$ & $2016-2015$ & البيان \\
\hline $137 / 132$ & $138 / 134$ & $140 / 137$ & بيئة الإقتصاد الكلي \\
\hline 128 & 132 & 139 & GDP\%ة عجز الهو از GDن \\
\hline 121 & 117 & 124 & GDP\% الدين الحكومى \\
\hline 133 & 134 & 139 & جودةً التُعليم الإبكاندي \\
\hline 130 & 135 & 139 & جودةُ نظام النعليم العالي \\
\hline 135 & 136 & 139 & النمريب \\
\hline 128 & 132 & 131 & الصادر اتGOPP \\
\hline 107 & 126 & 126 & الاجر والانتاجيه \\
\hline
\end{tabular}

Source: The World Economic Forum," The Global Competitiveness Report" , Different issues.

اثر السياسات الاقتصادية المصرية على تدفقات الاستثمار الاجنبى المباثر الى مصرخلا

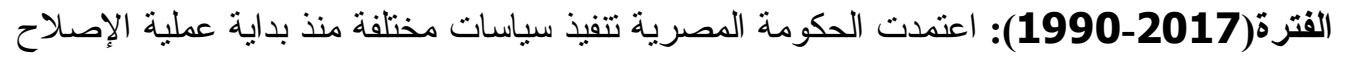

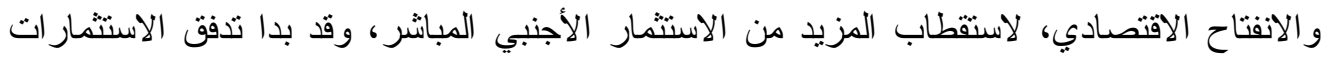

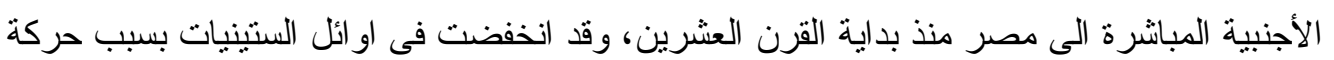

UNCTAD, Inward FDI Performance and Potential Index Rankings, 1990 - 2010, www.unctad.org/fdistatistics 19 Egypt in the global economy: strategic choices for savings,investments, and long term growth", doing business, 1st march 1998. 
التاميمات 22 لكل الانشطة الاقتصادية التى يز اولها مصرى او اجنبى، وسيطرت الدولة على مؤسسات الاعمال واعتبرت تدفق رؤوس الأمو ال الأجنبية وبر امج حرية التجارة على أنها طرق إنتعمارية الأنية جديدة، لم تكن الحكومة المصرية ترحب كثير ا خلال السبعينيات بالاستثمار الأجنبى المباثر بسبب اتجاه

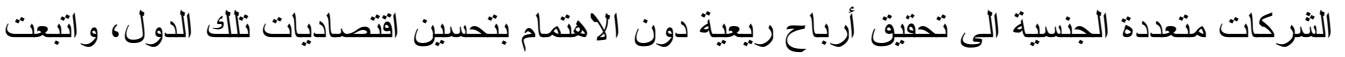

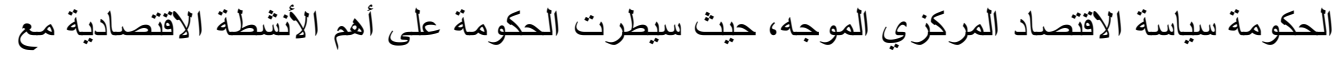

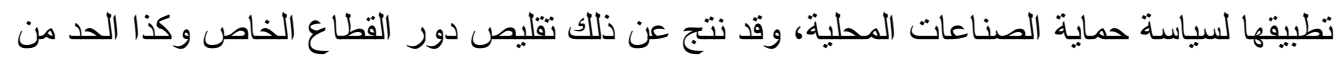

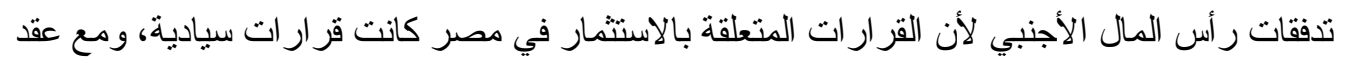

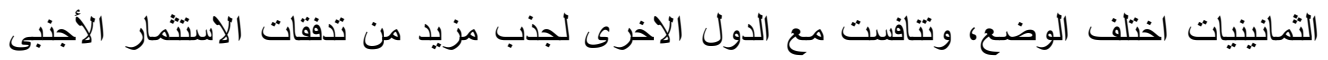

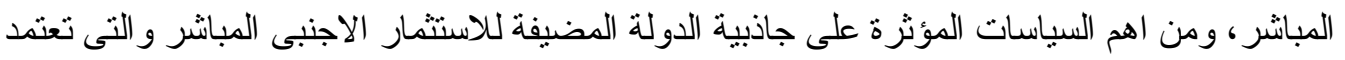

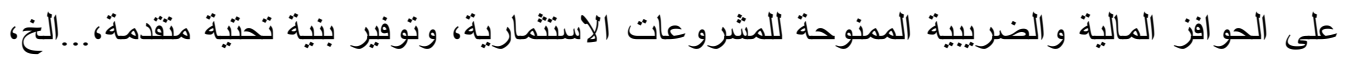

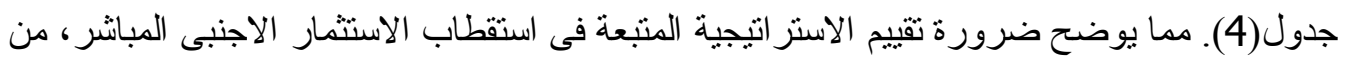

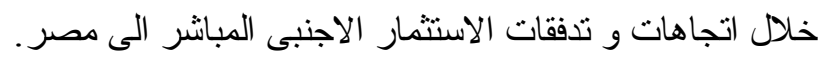
جدول(4) السياسات المؤثرة على جاذبية الدولة المضيفة للاستثمار الاجنبى المباثر الأبر

\begin{tabular}{|c|c|c|}
\hline 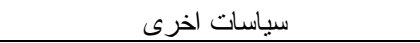 & السياسات الصناعية & السياسات الكلية \\
\hline - النفاذ الى اسواق ،وتطوير وسائل & - تطوير القطاع الصناعى & - التحكم فى الديون الخارجية \\
\hline 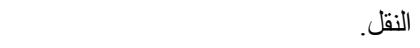 & - الحو افز المالية والتمويلية & - تطوير سوق العمل \\
\hline - الاندماج فى الاقتصاد العالمى & - تسهيل الاجر اءات الادارية & ـ تعزيز السياسات التجارية و البنية التحتية \\
\hline - تفعيل الاتفاقيات و المعاهدات & - - تشجيع البحث العلمى واستخدام & - تحرير التجارة \\
\hline - محاربة الفساد & التكنولوجيا الحديثة فى التصنيع & ـ تطبيق بر امج الإصلاحات الاقتصادية التي \\
\hline 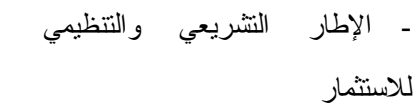 & 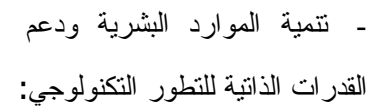 & تعمل على التحكم في التضخم و وعزز \\
\hline - توفير الموارد الطبيعية & & \\
\hline
\end{tabular}

Source : Dirk Willem te Velde(2002) : Government policies for inward foreign direct investment in developing countries: implications for human capital formation and income inequality, OECD development center, Working Paper No. 193. P18.

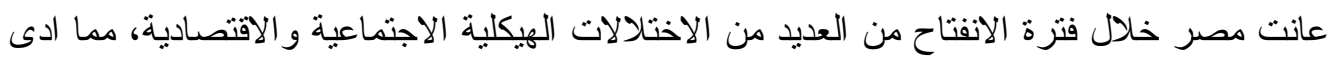

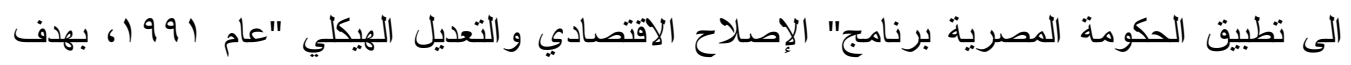

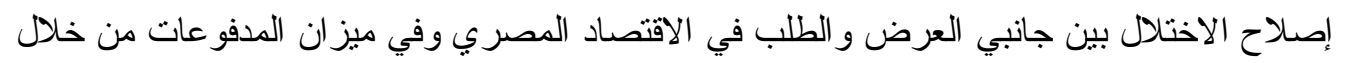

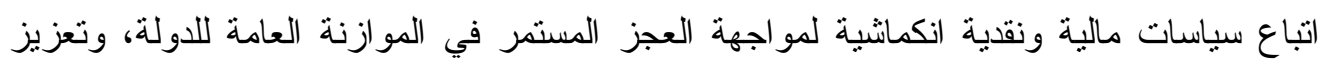

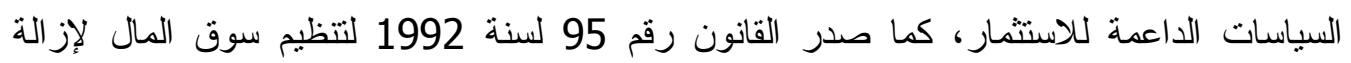
المعوقات أمام المستثمرين، وتتظيم تأسيس الشركات، مع اعطاء حو افز للمستثمرين فى الأور اق المالية،

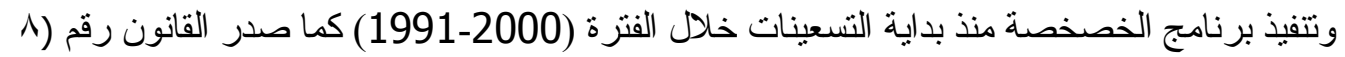

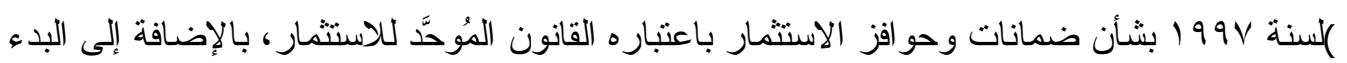

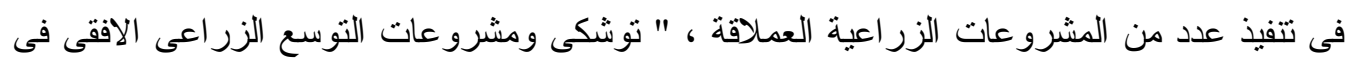


كل من سيناء وشرق وغرب الدلتا" ، كذللك تم إنشاء الهيئة العامة للاستثمار و المناطق الحرة بموجب

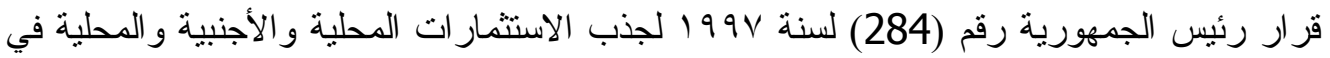
قطاعات اقتصادية ، ومناطق جغر افية جديدة ، و ازدادت مساهمة القطاع الخاص فى مشرو عات الات البنية

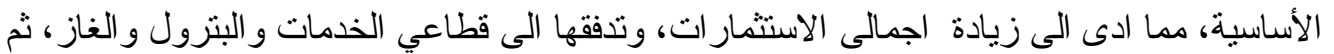

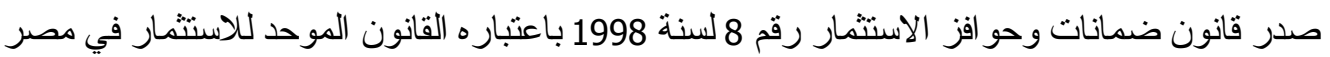

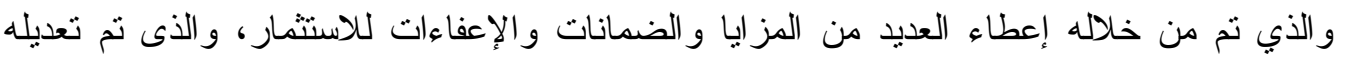

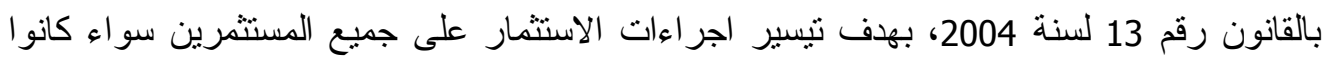
مصريين أو أجانب لنتجيع الاستثمار و التغلب على معوقاته، وقدمت قو انين نتجيع الاستثمار المتعاقبة

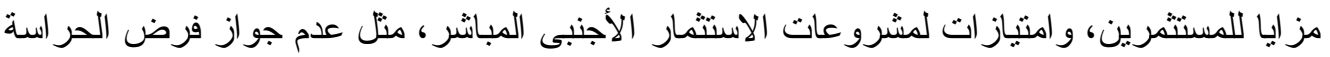

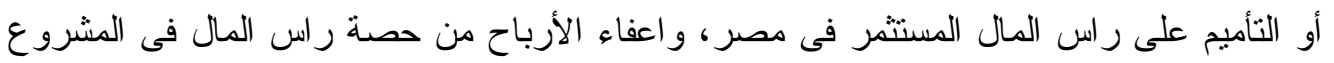

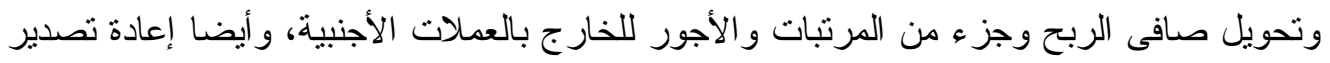
المال المنتفع بأحكام القانون عينا أو نقدا،...الخ. و اعتمدت مصر فى تمويل خطط التنمية على تحويلات

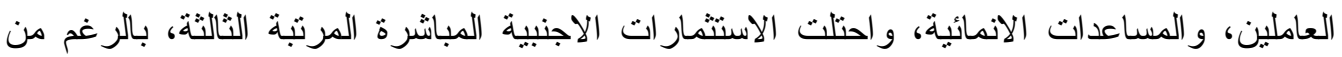

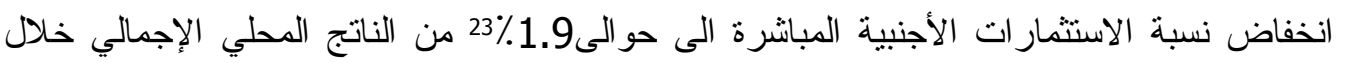

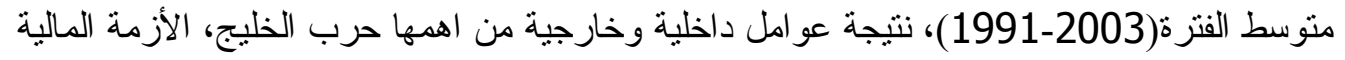

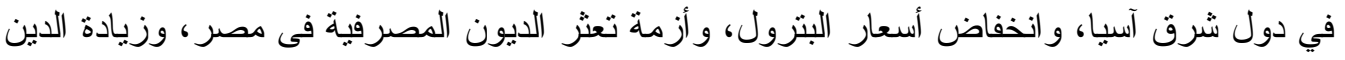

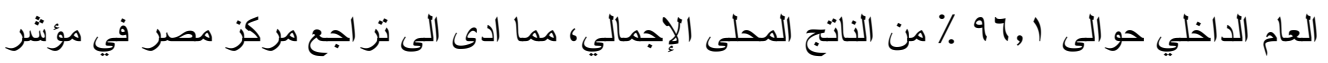

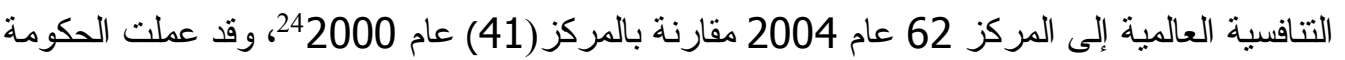

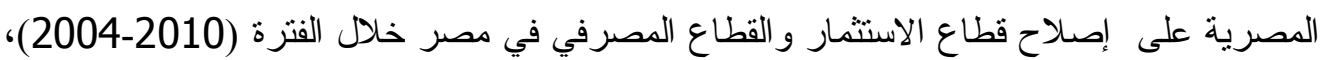

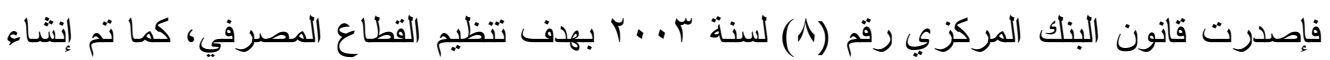

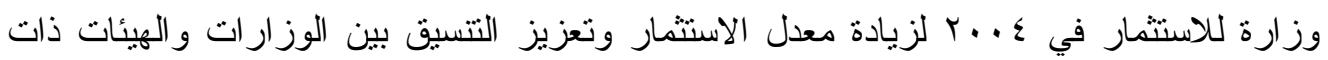

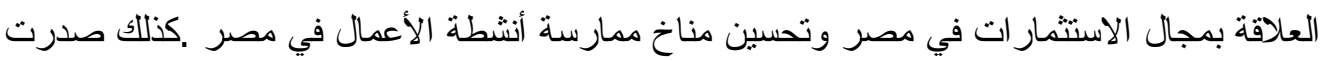

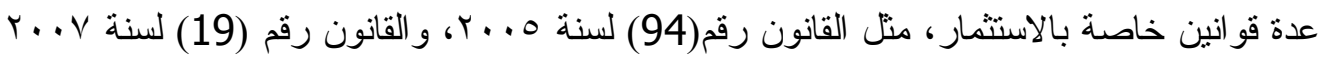

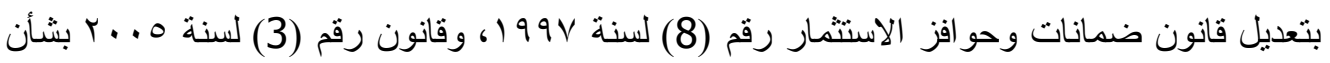

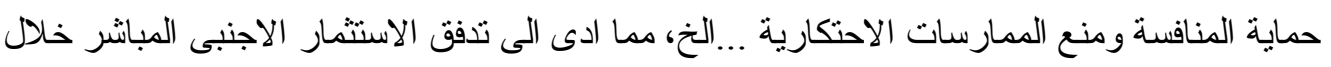

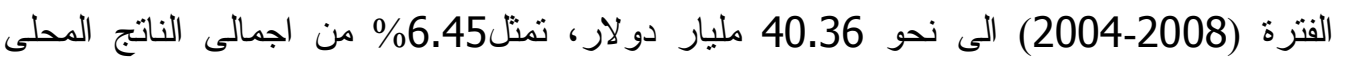

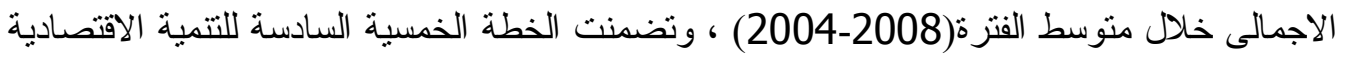

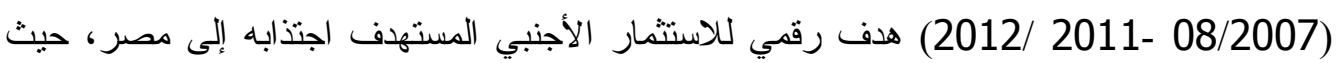

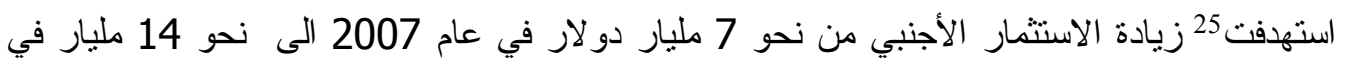

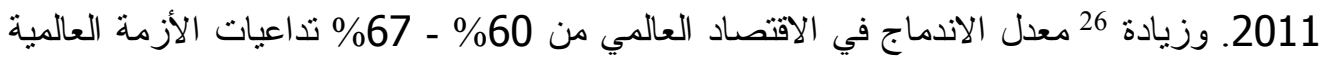
2008، و الاحداث السياسية عام 2011 حالت دون تحقق هذا الهدف، كما نم العمل على نطوير وتتظيم

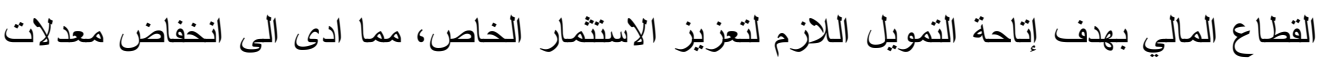

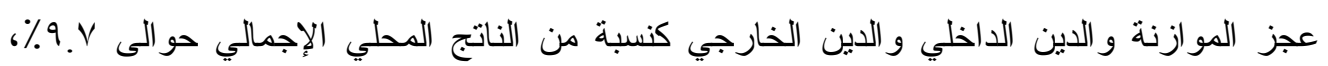

23 Unctad : World Investment Report, 2004

24 World Economic Forum, Global Competitiveness Reports, 2000- 2007

25 وز ارة النتمية الاقتصادية ، الخطة الخمسية السادسة2007/2007 -2011 /2012) ، ص 60. 26 وز ورة الثتمية الاقتصادية ، الخطة الخمسية السادسة(2007/2007 -2012 /2012) ص ص 88 - 89. 


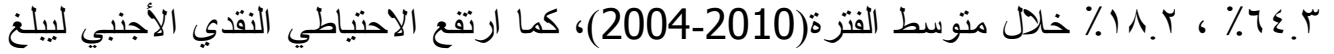

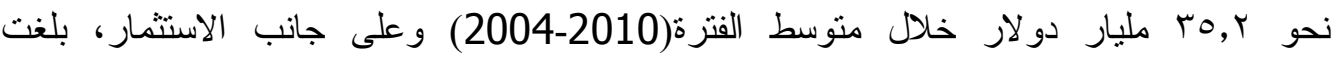

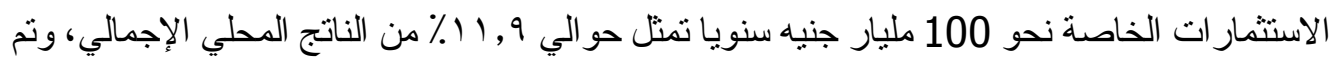

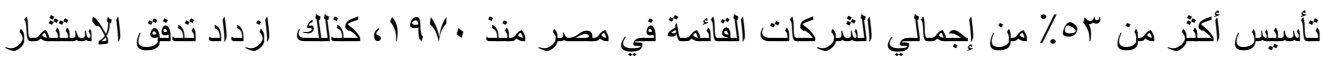

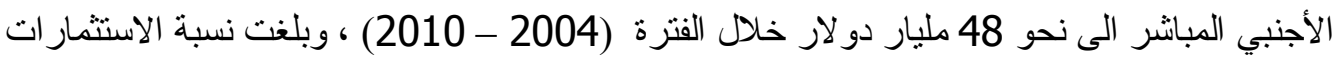

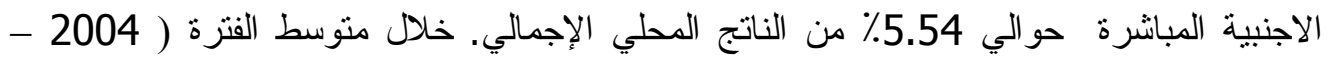

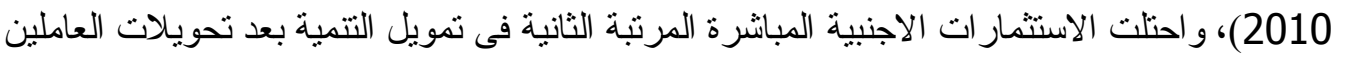
خلال منوسط الفترة(2010-2004). و واوضح نقرير ممارسة أنثطة الأعمال فى الدول العربية عام

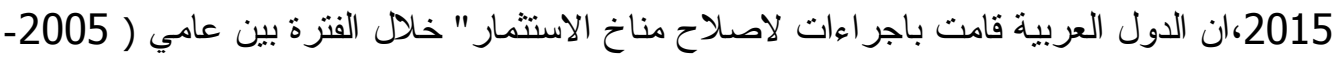

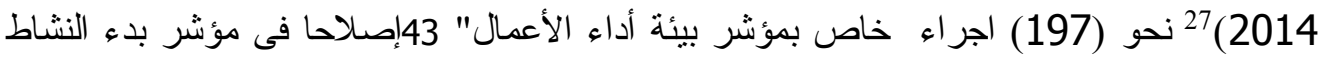
التجاري و36 إصلاحا في مؤشر الحصول على الائتمان، و33 إصلاحا في مؤشر التجارة عبر الحدود، التهاء ثم 27 إصلاحا في مؤشر دفع الضر ائب"، قامت مصر بنحو (24) إصلاحا، الإمار ات( 20) إصلاحا،

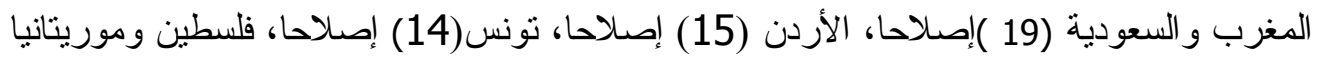

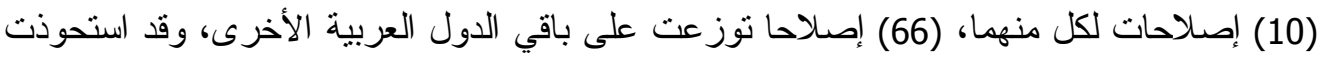
قطاعات البترول و الغاز و النقل و المو اصلات و الصناعة و التعدين على معظم تلك الاستثمار ات، عانت مصر من انخفاض فى تدفق الاستثمار الأجنبي، وهروب رؤؤس الامو ال المحلية

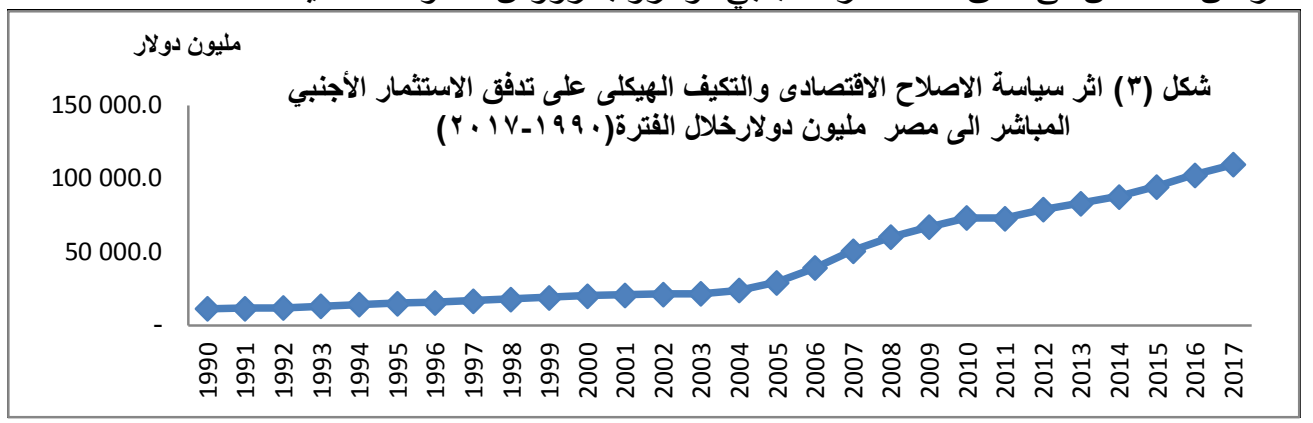

و الاجنبية الى الخارج، و انخفاض حصيلة النقد الأجنبي لاستير اد المو اد الخام اللازمة للإنتاج في أعقاب

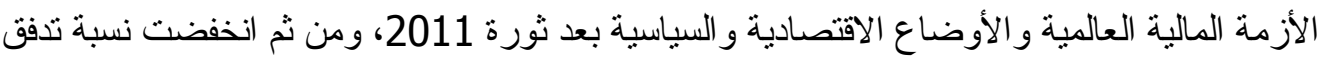

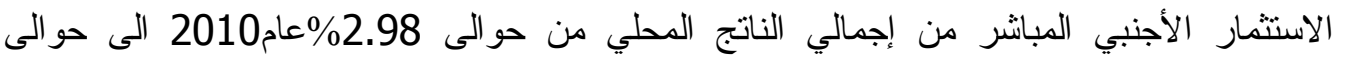

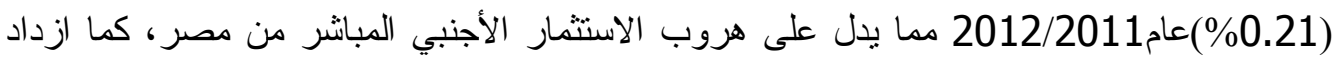

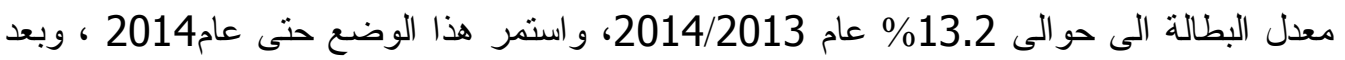

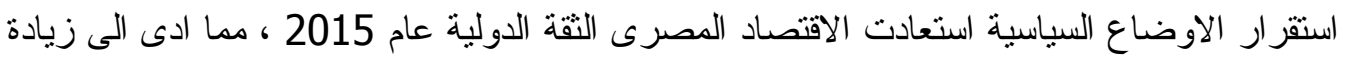

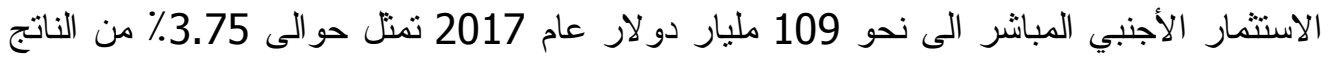
المحلي الإجمالي، شكل(4). 


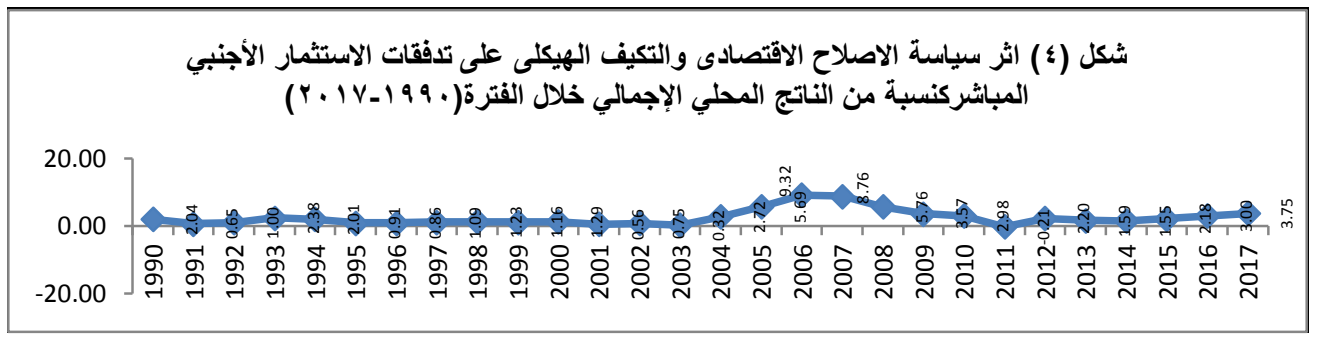

\section{Source: UNCTAD, FDI/MNE database (www.unctad.org/fdistatistics)}

وبدراسة الاهمية النسبية للاستمار الاجنبى الزراعى بالنسبة لاجمالى الاستثمار الاجنبى المباشر

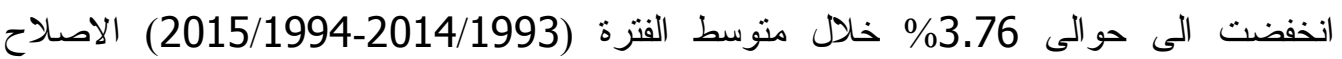

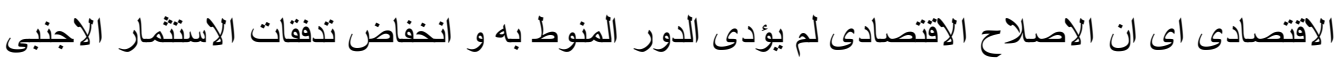

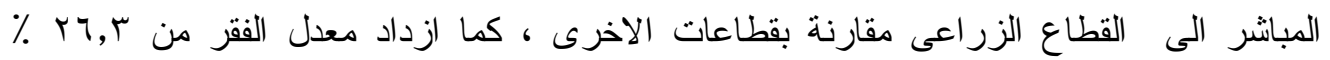

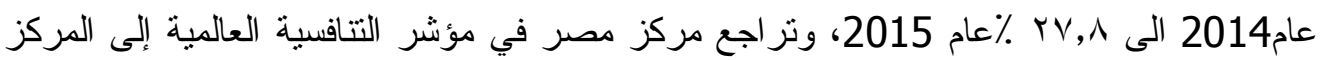

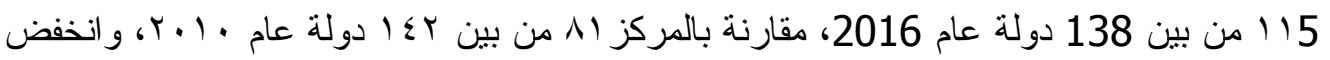

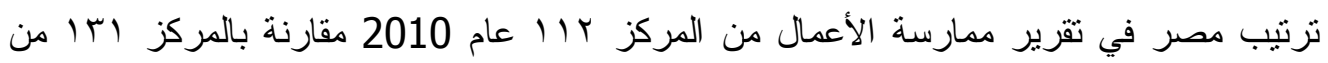

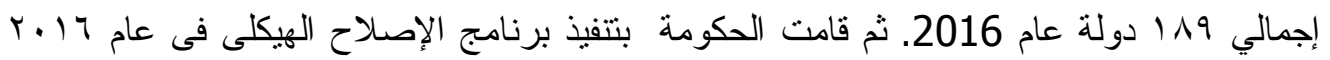

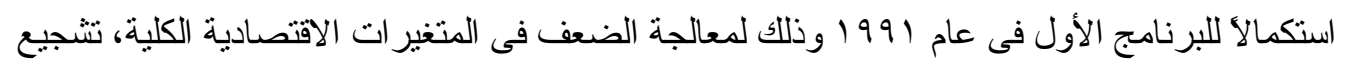

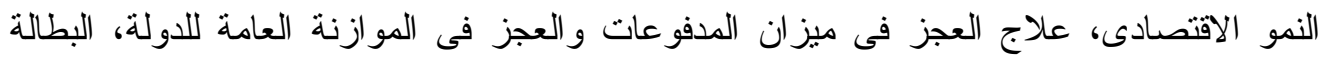

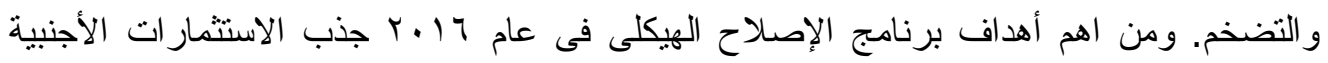
المباثرة وتهيئة المناخ الملائم لذلك و اتخاذ ما يلزم من الإجر اءات و السياسات التى تكفل تحقيق هذا الهذف، واحتلت مصر في مؤشر التتافية العالمية المركز 100 من بين 137 دولة الأنة عام

اثر سياسة الاصلاح الاقتصادى والتكيف الهيكلى على مشروعات الاستثمار الاجنبي المباشر خلا

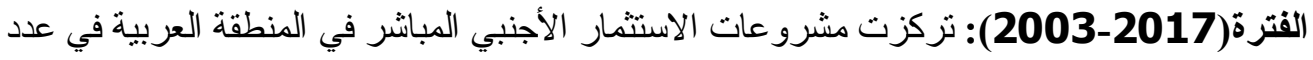

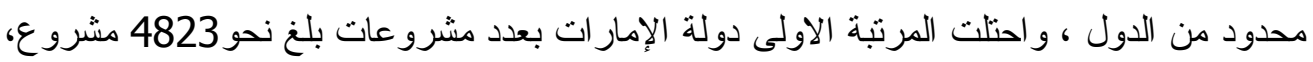

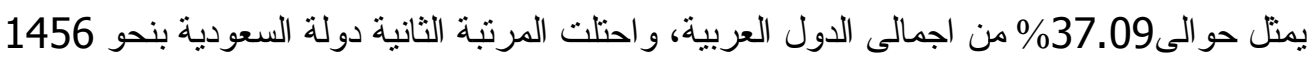

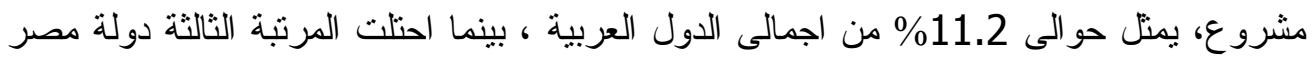

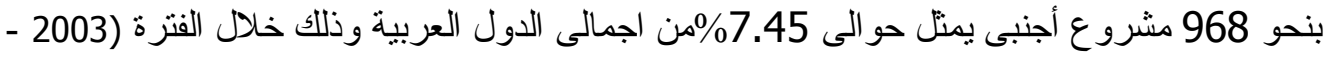

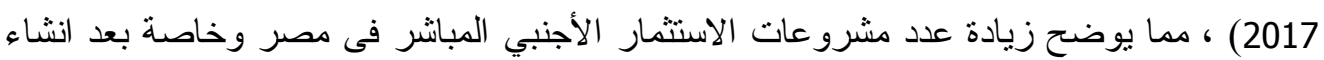

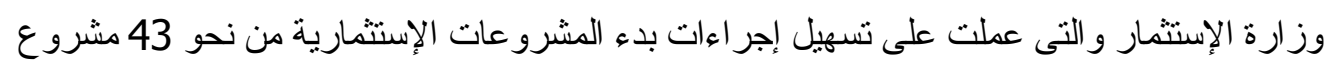

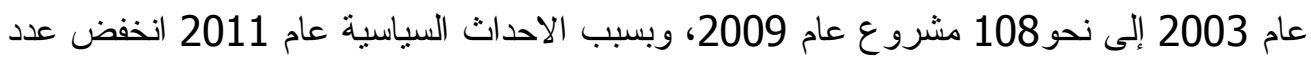
مشروعات الاستثمار الأجنبي المباشرفى مصر الى نحو 54 مشروع عام 113 عام 2011 ، ثم ازداد الى نحو 113 مشروع عام 2017 ، وقد بلغت قيمة التكلفة الاستثمارية الإجمالية لمشروعات الإن الإن الاستثمار

الأجنبي المباشر في مصر نحو 223391 مليون دو لار خلال الفترة(2003 - 2017) جدول (5). 


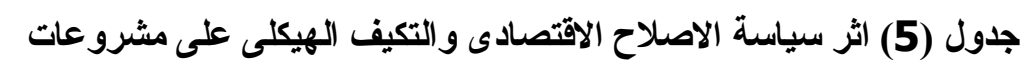

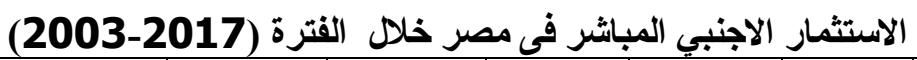

\begin{tabular}{|c|c|c|c|c|c|c|c|c|}
\hline معدل & $\begin{array}{c}\text { الاستثمار الاجنبى المباتر } \\
\text { المباتر }\end{array}$ & معدل التغير & عدد الوظائف & معدل التغير & التكلفة مليون & معدل & 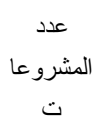 & \\
\hline- & 41 & - & 14338 & - & 4199.4 & - & 43 & 2003 \\
\hline-17.07 & 34 & -49.94 & 7178 & -61.95 & 1598 & -18.60 & 35 & 2004 \\
\hline 32.35 & 45 & 136.58 & 16982 & 647.63 & 11947.1 & 34.29 & 47 & 2005 \\
\hline 11.11 & 50 & 38.00 & 23436 & -7.83 & 11012.2 & 19.15 & 56 & 2006 \\
\hline 4.00 & 52 & -41.82 & 13635 & 7.73 & 11863.6 & -3.57 & 54 & 2007 \\
\hline 50.00 & 78 & 114.34 & 29225 & -14.47 & 10147.5 & 55.56 & 84 & 2008 \\
\hline-2.56 & 76 & -25.79 & 21688 & 82.05 & 18473.9 & 28.57 & 108 & 2009 \\
\hline-9.21 & 69 & -12.34 & 19011 & -48.58 & 9499.8 & -26.85 & 79 & 2010 \\
\hline-27.54 & 50 & -30.76 & 13163 & -42.98 & 5417 & -31.65 & 54 & 2011 \\
\hline-2.00 & 49 & 13.03 & 14878 & 68.45 & 9124.7 & 14.81 & 62 & 2012 \\
\hline-16.33 & 41 & -58.95 & 6107 & -64.97 & 3196.7 & -22.58 & 48 & 2013 \\
\hline 12.20 & 46 & 273.72 & 22823 & 468.55 & 18174.8 & 22.92 & 59 & 2014 \\
\hline-2.17 & 45 & -43.76 & 12835 & -19.47 & 14636.2 & 11.86 & 66 & 2015 \\
\hline 13.33 & 51 & 9.79 & 14091 & 179.54 & 40913.7 & -9.09 & 60 & 2016 \\
\hline 23.53 & 63 & 114.14 & 30174 & -7.93 & 37669 & 88.33 & 113 & 2017 \\
\hline 4.97 & 52.67 & 31.16 & 17304.27 & 84.70 & 13858.24 & 11.65 & 64.53 & المتوسط \\
\hline
\end{tabular}

FDi Intelligence From The Financial Times المصدر: جمعت وحسبت من بيانات - أثر الإستثمار الأجنبي المباشر على العمالة: استوعبت مشروعات الاستثمار الاجنبي المباشر فى أنى

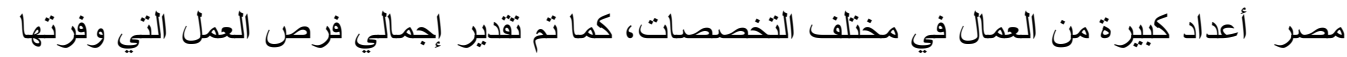

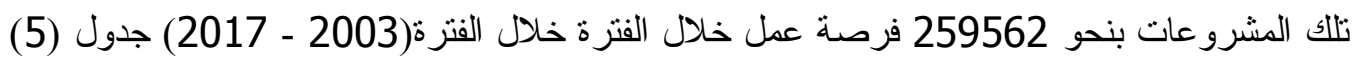

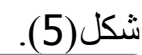

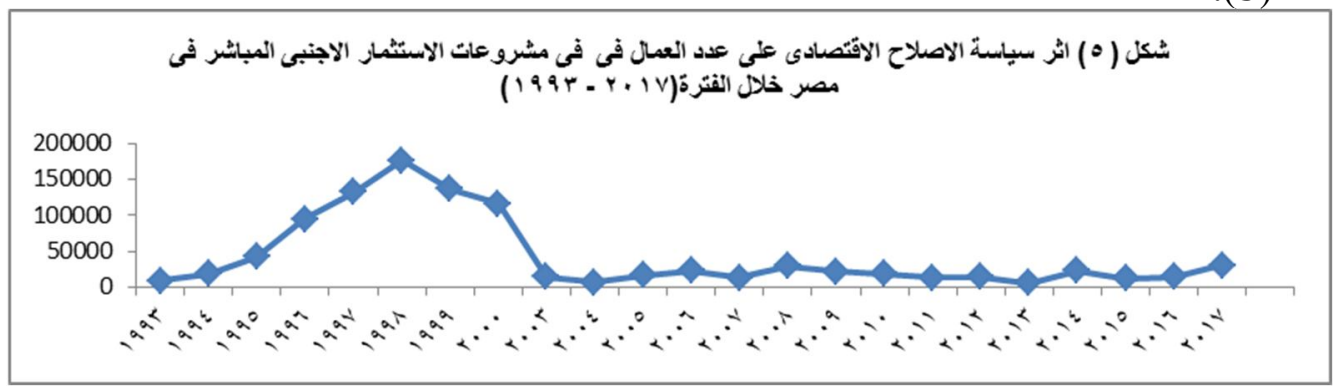

المصدر: اميرة حسب الله محمد، محدات الاستثمار الاجنبى المباشر وغير المباشر فى البيئة الاقتصادية العربية، الدار

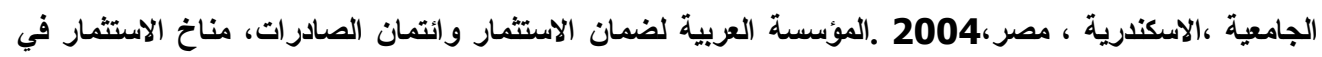
الدول العربية ،الكويت، اعداد مختلفة. التوزيع الاقليمى لتكلفة الاستثمارات الواردة الى مصر حسب الأقاليم المستثمرة خلا الفترة

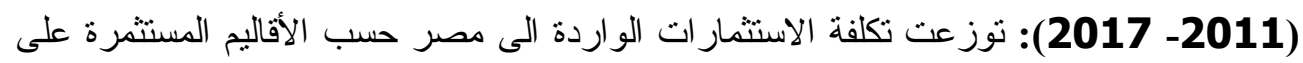
اوروبا ، الثرق الاوسط، اسياو المحيط الهادى، امريكا الثمالية، افريقيا، حيث تمنل حو الى 49.7\%؛ 40.8\%، 5.6\%، 3.2\%، 0.7\% على الترنيب خلال الفترة (2011 - 2017) شكل(6). 


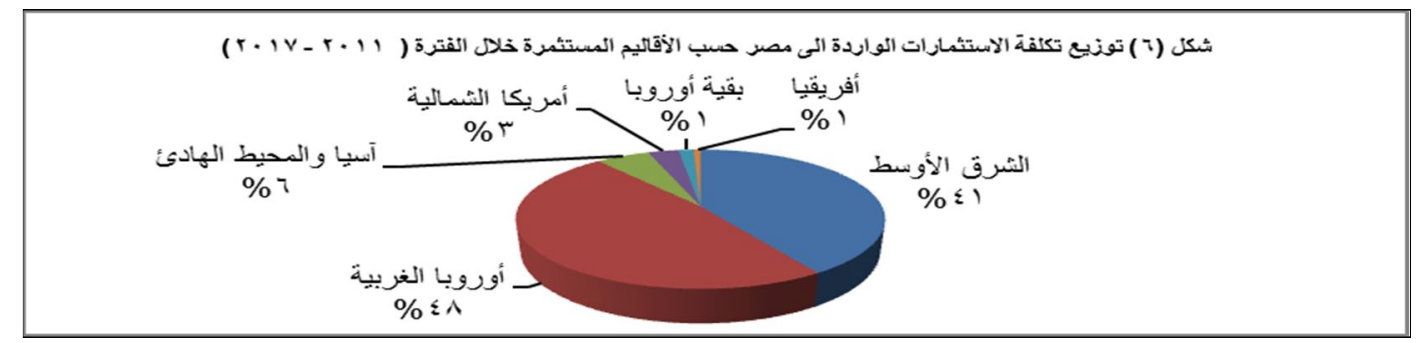

التوزيع القطاعي للاستثمار ات الأجنبية المباشرة فى مصر:

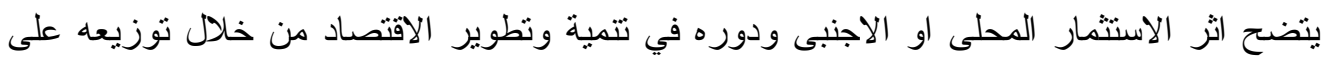

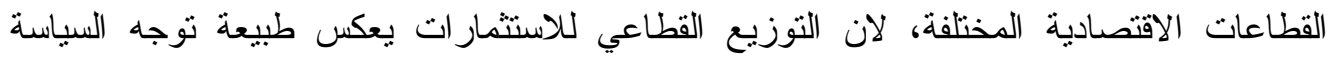

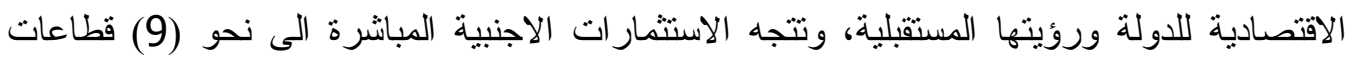
رئيسية الثكل (7) وقد هيمنت قطاعات البنرول ، التمويل، الصناعة على معظم تلك التدفقات خلال التاليه

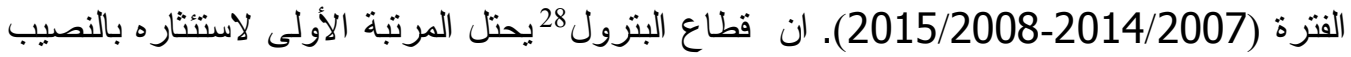
الاكبر من الاستثمار ات الأجنبية المباشرة حوالى 58,34\% من اجمالى التدفقات كمنوسط للفترة

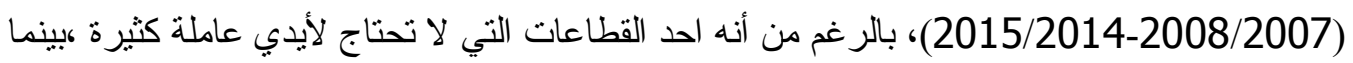
يأني قطاع الزر اعة في اخر قائمة الجاذبية الاستثمارية من حيث اجتذابه للاستثمار ات الأجنبية المباثرة

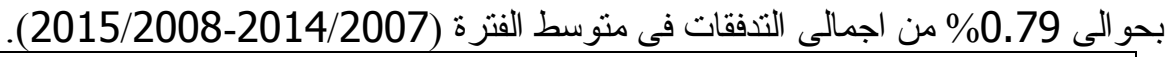
شكل (7-1) الهيكل القطاعي للاستثمار ات الأجنبية المباثرة المنفذة خلال متوسط الفترة(2097) (2015/2014-

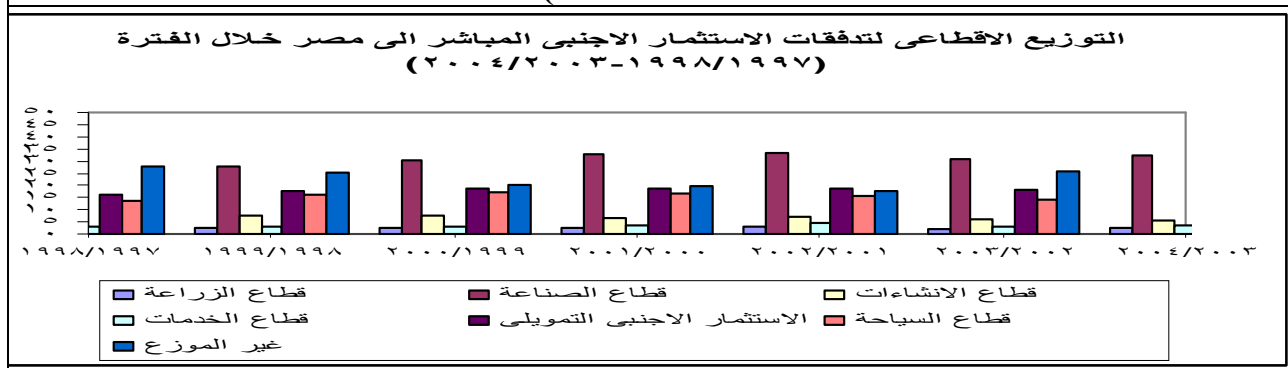

المصدر: البنك المركزي المصري، المجلة الاقتصادية، المجلد التاسع والأربعون، العدد الرابع 2008 /2009 ،

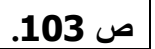

شكل (-2-2 ) الهيكل القطاعي للاستثمار ات الأجنبية المباشرة المنفذة خلال متوسط

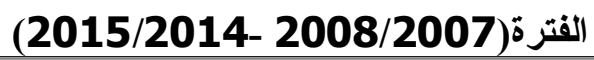

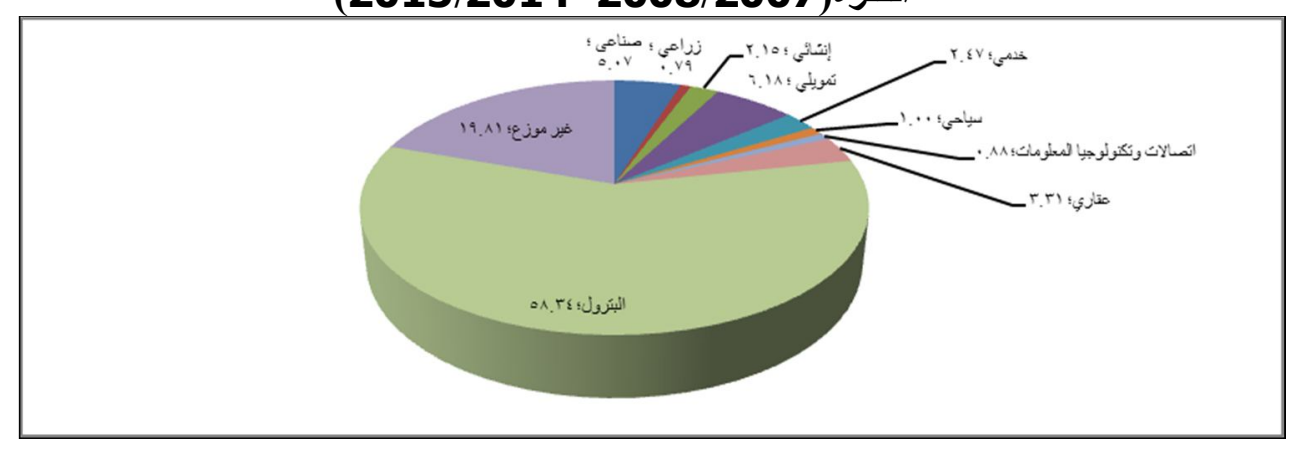

ـ البنك المركزي المصري، التقرير ، اعداد مختلفة. 
اثر سياسة الاصلاح الاقتصادى على توزيع الاستثمار ات الأجنبية الزراعية فى أهم مجالات وأنشطة

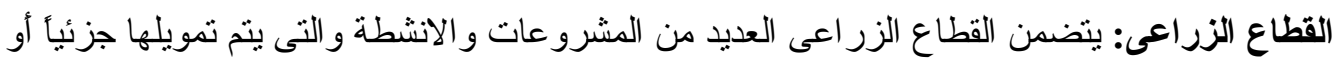

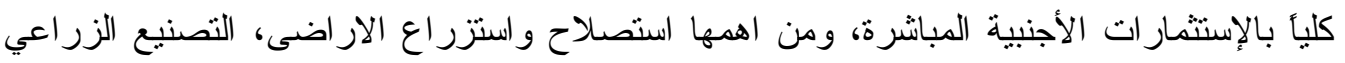
ومشروعات التكامل الصناعى الزراعى، مشروعات الانتاج الحيو انى و الداجنى السمكى و المجازر

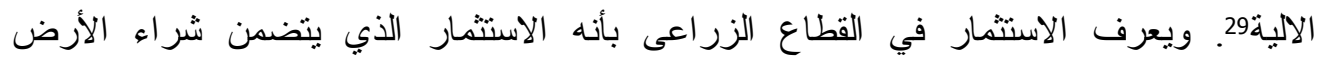

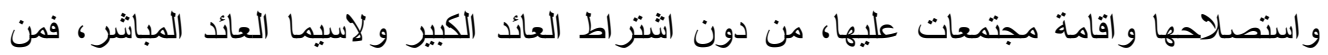
المعروف أن العائد الكبير لايظهر الاعلى المدى الطويل، فأستصلاح الأر اضى لا يأتي بعائد إلا بعد مدة

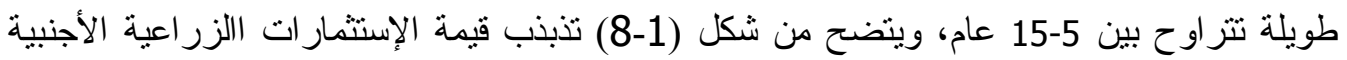

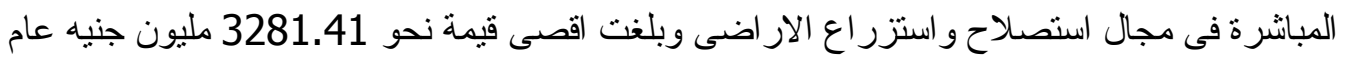

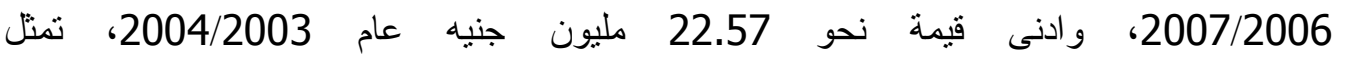

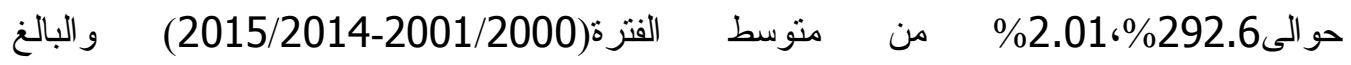
نحو 1121.44 نمليون جنيه، وبالنسبة لمجال الإنتاج الحيو انى و الداجنى و الثروة السمكية، بلغت اقصى قيمة نحو 580.26 مليون جنيه عام 2009/2008، و ادنى قيمة نحو 6.53 مليون جنيه عام بليه

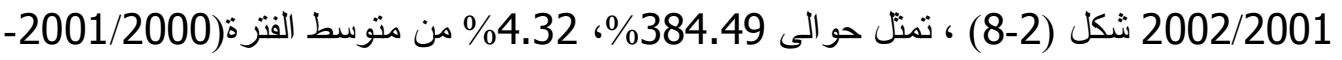

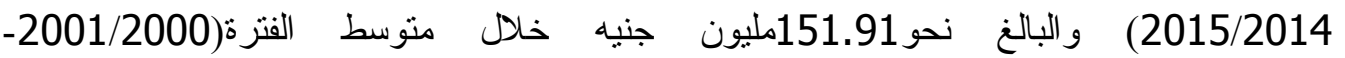

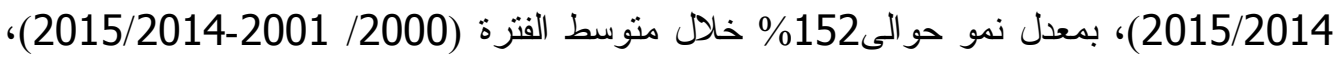

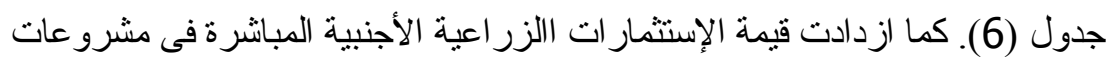

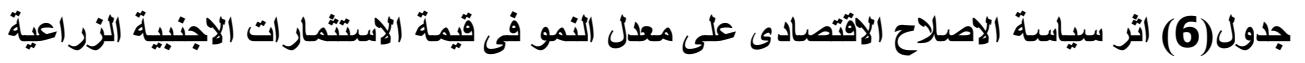

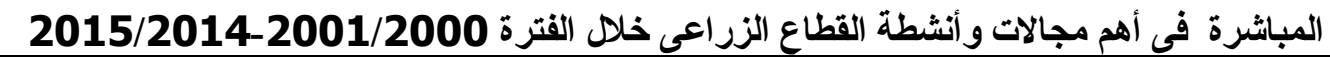

\begin{tabular}{|c|c|c|c|c|c|}
\hline انشطة زدر اعبة اذرى في & مجازل الثمو فى & مشرو عات تكامل صناعى زر اعى في & انتاج حبو انيى وداجنى وسكى النمو في & استصلاحو استزر النوع الازار اضى & السنة \\
\hline 6.99 & -20.68 & - & -85.52 & 207.35 & $2002 / 2001$ \\
\hline-74.55 & -84.15 & -94.32 & 307.87 & 152.68 & $2003 / 2002$ \\
\hline 4675.19 & 10.07 & -5738.78 & 155.19 & -89.80 & $2004 / 2003$ \\
\hline-35.82 & -100.00 & -122.87 & -51.01 & 623.46 & $2005 / 2004$ \\
\hline-48.56 & 0.00 & -70.96 & 1157.83 & 156.45 & $2006 / 2005$ \\
\hline-27.38 & -68.75 & -97.39 & -67.22 & 683.76 & $2007 / 2006$ \\
\hline 38.33 & -86.24 & 17163.30 & 22.74 & -17.29 & $2008 / 2007$ \\
\hline 233.82 & -23.36 & -7.76 & 244.44 & -72.82 & $2009 / 2008$ \\
\hline-99.64 & -73.39 & -516.57 & -91.54 & 855.49 & $2010 / 2009$ \\
\hline 22804.68 & -100.00 & -184.88 & 67.40 & -89.23 & $2011 / 2010$ \\
\hline-98.83 & - & -137.43 & 562.72 & -91.54 & 2012/2011 \\
\hline 17964.99 & 6592.63 & -207.21 & -89.51 & 1331.44 & $2013 / 2012$ \\
\hline-89.03 & -98.28 & 816.06 & -69.43 & -88.16 & $2014 / 2013$ \\
\hline-28.10 & 2991.57 & -100.00 & 66.34 & 125.39 & $2015 / 2014$ \\
\hline 3230.15 & 638.53 & 823.17 & 152.17 & 263.37 & المتوسط \\
\hline
\end{tabular}

المصدر : قطاع نظم المعلومات، الهيئة العامة للاستثمار و المناطق الحرة ، وزارة الاستثمار ، بيانات غير منشورة . SOURCE: Mohamed Hamdy Salem, International Investments in Agriculture in the Near East' Evidence from Egypt,Morocco and Sudan' , FAO Regional Office for the Near East, Cairo, Egypt,2011,PP36-38.

${ }^{29}$ FAO International investments in agriculture in the Near East. Evidence from Egypt,Morocco and Sudan. Rome: FAO. (2011).

$$
30 \text { قطاع نظم المعلومات، الهيئة العامة للاستثمار و المناطق الحرة ، وزارة الاستثمار ، بيانات غير منشورة . }
$$


شكل(8) بيان بتوزيع الاستثمار ات الأجنبية الزراعية|لمباثرة فى أهم مجالات و أنثطة القطاع

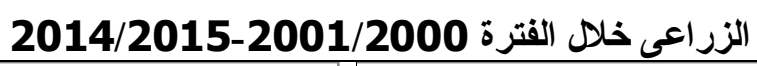

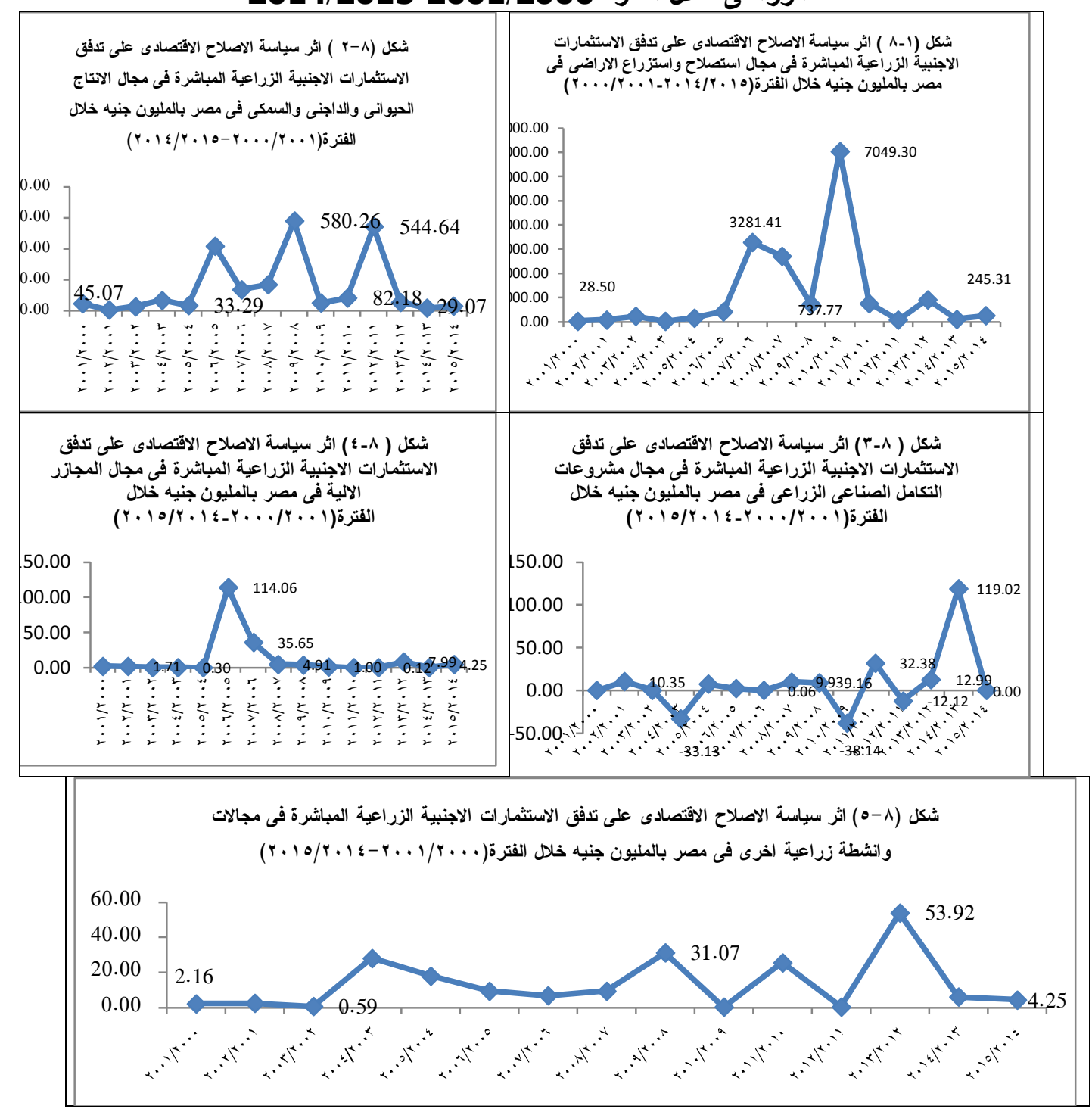

المصدر: قطاع نظم المطلومات، الهيئة العامة للاستثمار و المناطق الحرة ، وزارة الاستثمار ، بياتات غير منشورة .

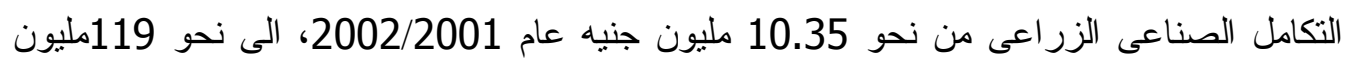

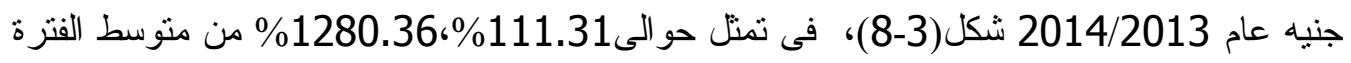

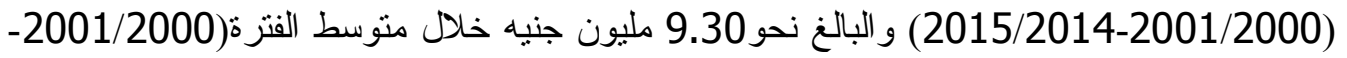

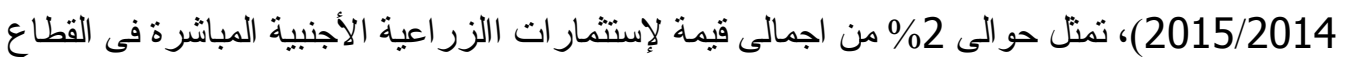

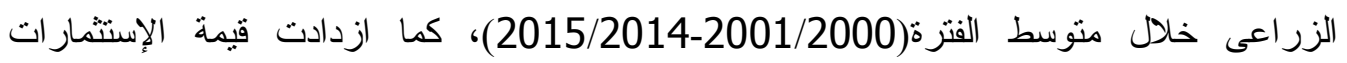

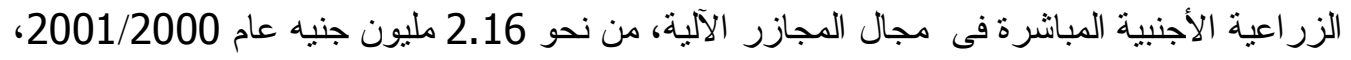

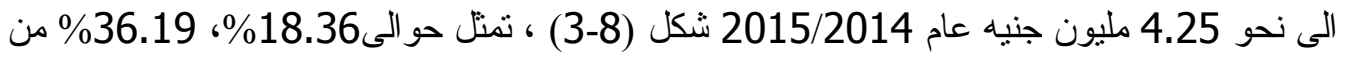

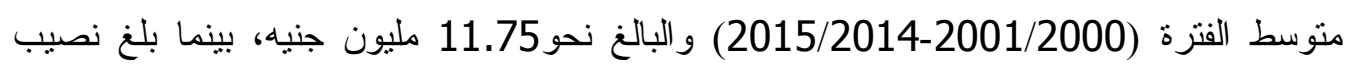

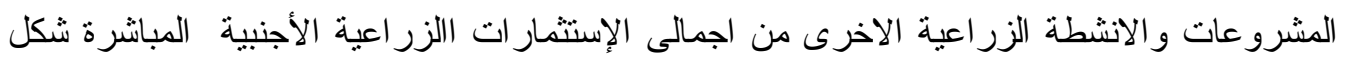
(4-8) نحو13.16مليون جنيه تمثل 1.01\% من من متوسط الفترة (2001/2000- 
يتضح مما سبق ان الاستثمار الاجنبي المباشر يتجه نحو القطاعات و الانشطة التي ينوقع ان تحقق عائد

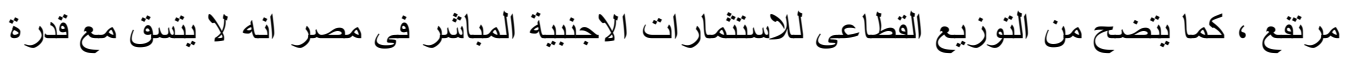
القطاعات الاقتصادية على نوفير فرص العمل، بالاضافة الى انخفاض الاهمية النسبية للاستثمار الاجنبى الزر اعى المباشر من اجمالى الاستثمار الخاص فى القطاع الزراعى من حوالى 22.15\% خلال الفترة (1989-1972) وتمتل فترة ما قبل الاصلاح الاقتصادى، الى حو الى 20.3\% خلاعل

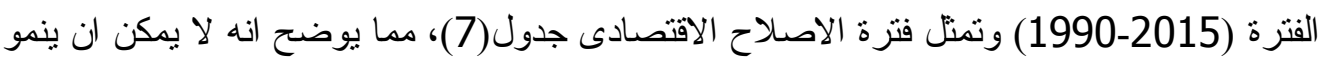

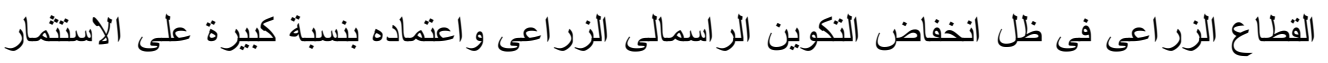

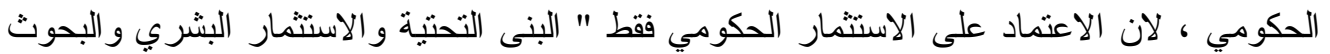
العلمية و التدريب و التعليم "، ليس كافيا بل يجب تفعيل الاستثمار الخاص المحلى و الاجنبى وزيادة مساهمته في التكوين الر اسمالي. جدول(7) الاهمية النسبية للاستثمار الاجنبى المباشر من اجمالى الاستثمار الخاص فى القطاع

الزر اعى خلا الفترة (2015-1972)

\begin{tabular}{|c|c|}
\hline \multirow{2}{*}{ 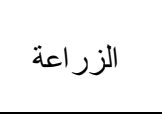 } & القطاع \\
\hline & 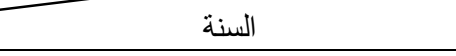 \\
\hline$\% 27.6$ & 1979-1972 \\
\hline$\% 16.7$ & $1989-1980$ \\
\hline$\% 16.2$ & $1999-1990$ \\
\hline$\% 30.6$ & $2009-2000$ \\
\hline$\% 13.3$ & $2015-2010$ \\
\hline$\% 22.15$ & متوسط فترة ما قبل الاصلاح الاقتصادى \\
\hline$\% 20.3$ & متوسط فترة الاصلاح الاقتصادى \\
\hline$(\% 2.12)$ & اثر سياسة الاصلاح الاقتصادى \\
\hline
\end{tabular}

ـ المصدر: جمعت وحسبت من بياتات وزارة التخطيط ، والمتابعةوالاصلاح الادارى، البنك المركزي المصري، التقرير،

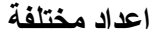

Shima'a Hanafy, Patterns of Foreign Direct Investment in Egypt,Descriptive Insights from a Novel Panel Dataset at the Governorate Level, Joint Discussion Paper Series in Economics, University Marburg ,2015, p21.

التوزيع المكانى للاستثمار الاجنبى فى القطاع الزراعى: تعنمد سياسة الإصلاح فى مصر على ثلاث

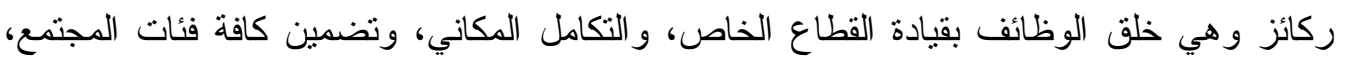

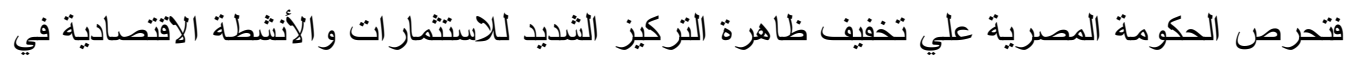

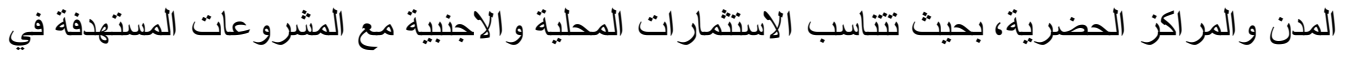

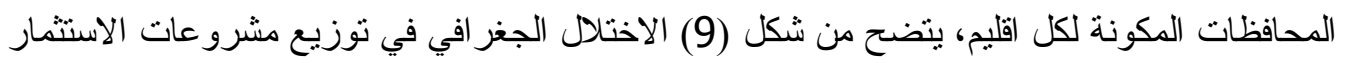

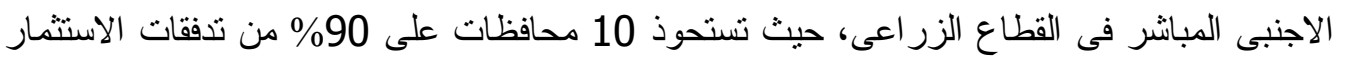

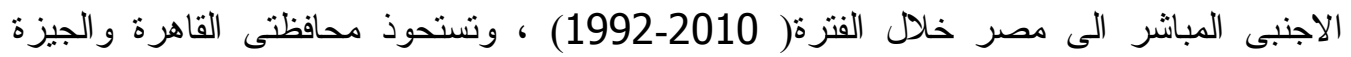

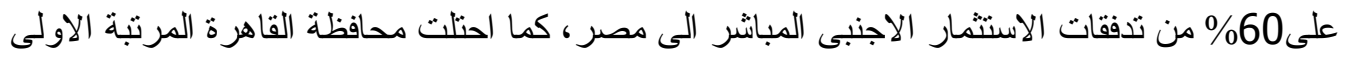
من حيث حجم الاستمار الاجنبى فى قطاع استصلاح الار اضى بها، بالرغم من كونها محافظة الأفئ

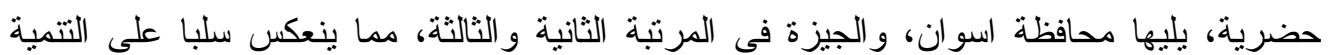


الاقليمية بشكل يؤدي الى النمو غير المنوازن بين محافظات الاقاليم المختلفة ، ويوضح التوزيع

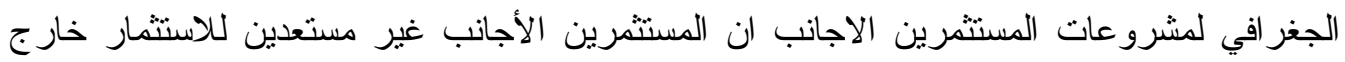

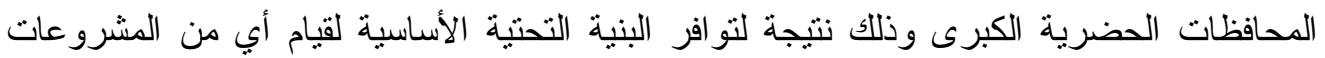

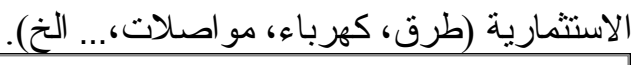

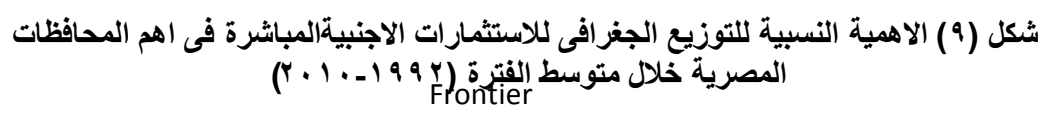

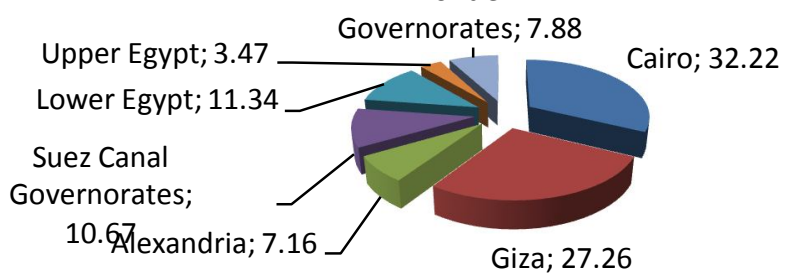

\section{Source: calculations based on GAFI data.}

الهم العوامل المحفزة للاستثمار الاجنبى المباثر فى القطاع الزراعى: تتمثل فى الحاجة الى البحث عن

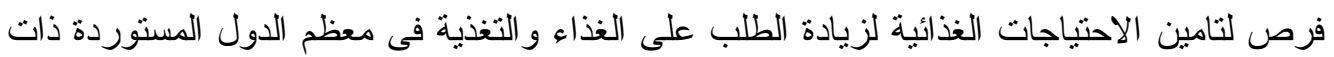

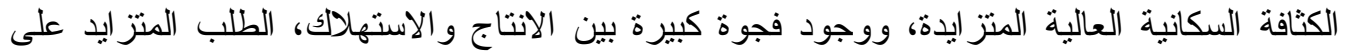
الوقود الحيوى وتحول الدول المتقدمة لأنتاج بدائل الطاقة الحيوية من المحاصيل الغذائية مثل استخر اج

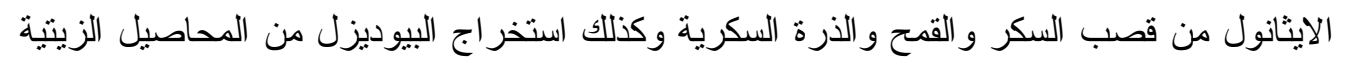

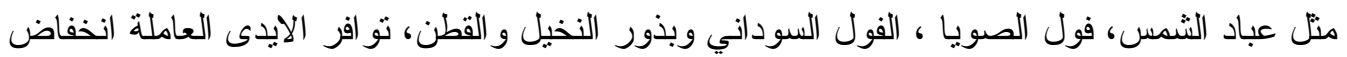
تكلفة الايدى العاملة، حجم السوق، و اتساع السوق الاستهلاكية المحلي، الانظمة الزر اعية المناسبة للاول

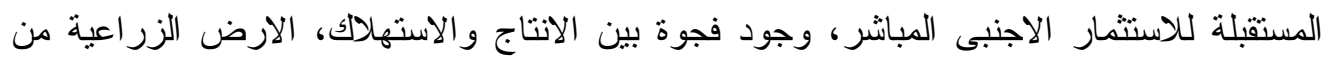

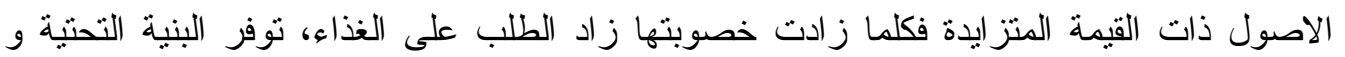
انخفاض تكاليف النقل، الاستقرار السياسى، كما تتوفر فى مصر فرصة للاستفادة من ظروف تفضيلية

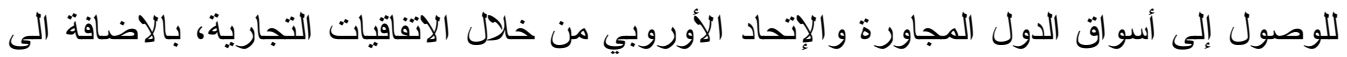

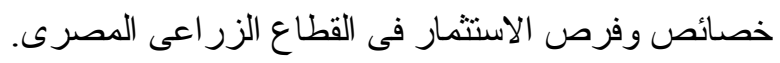

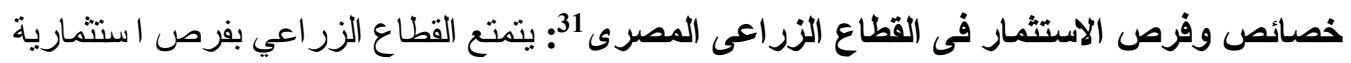

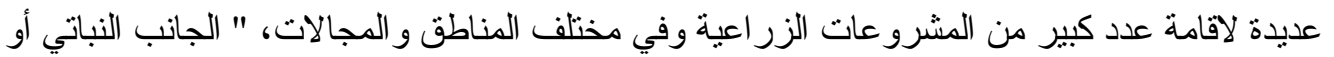

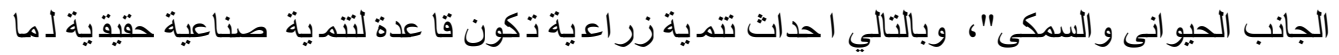

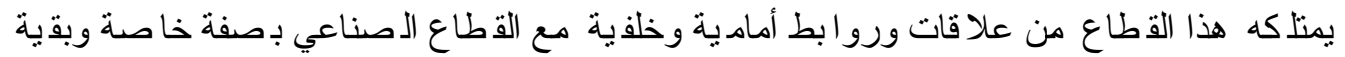

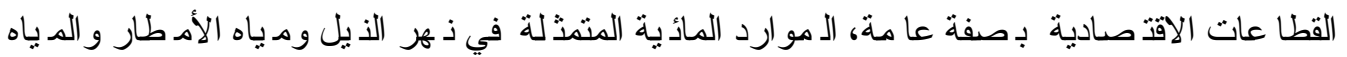

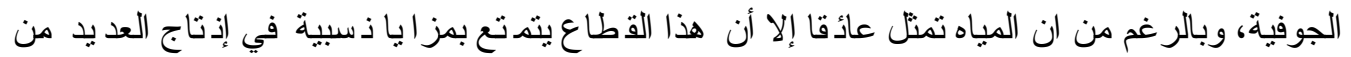

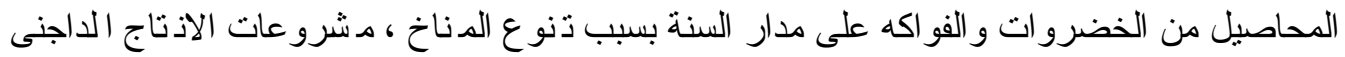

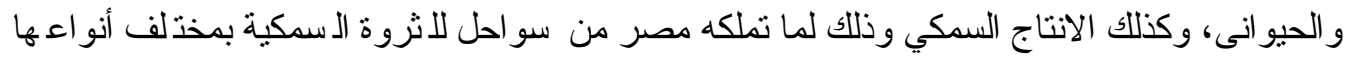

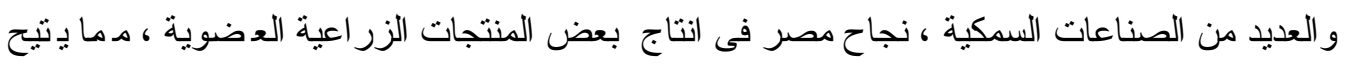
فرص تصديرية وخاصة فى إذتاج محاصيل الذضر و الفاك هة و غير ها من المحاصيل ذات القي مة

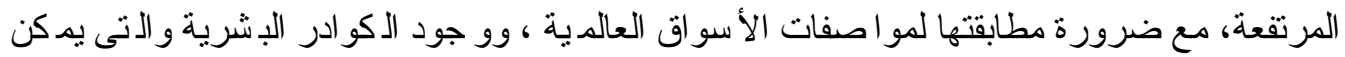

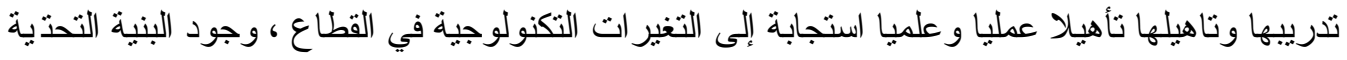


المناسبة ـ الاتصالات أو المو اصلات و الدخازن المبردة و أسواق الجملة ومر اكز التدريج و التعبئةـ،

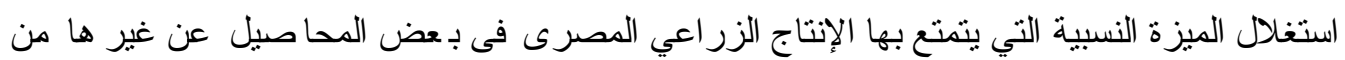

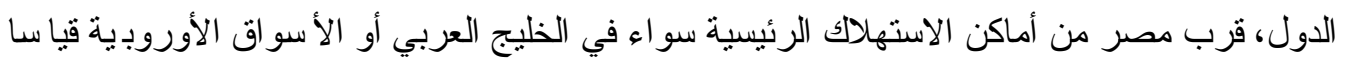

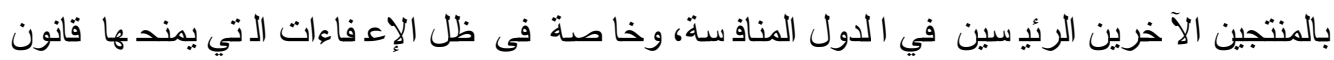

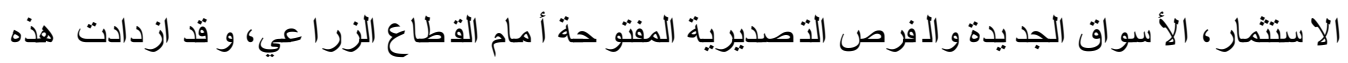

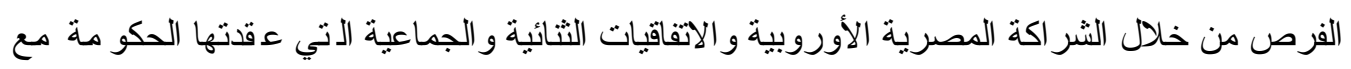

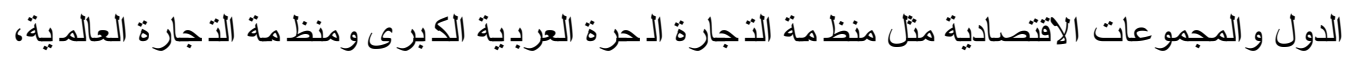

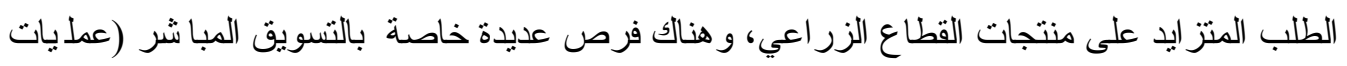

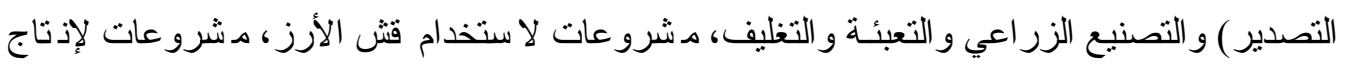

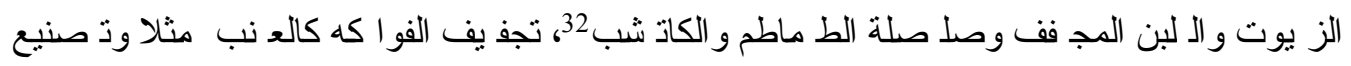

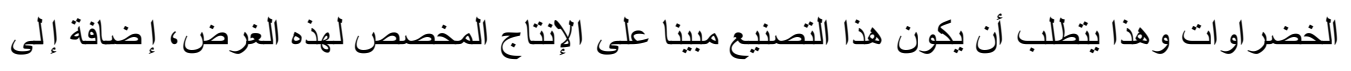

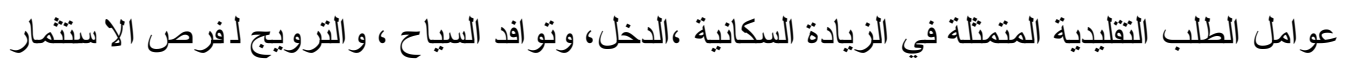
فى القطاع الزر اعى المصرى.

الجهود الترويجية لفرص الاستثمار فى مصر: لم تقتصر جهود الحكومة المصرية على الأصلاحات

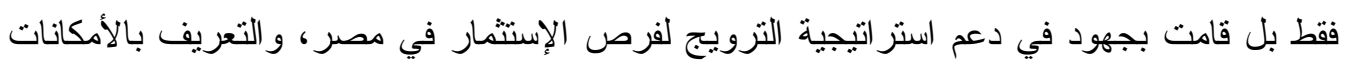

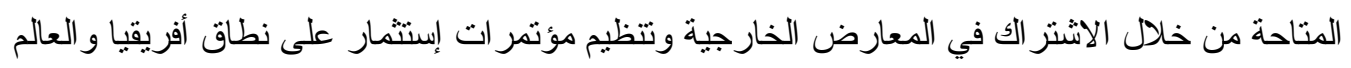

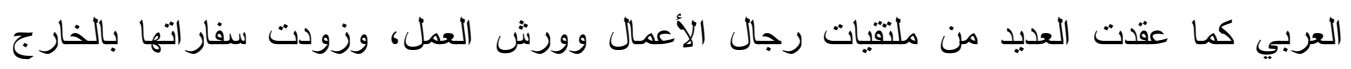

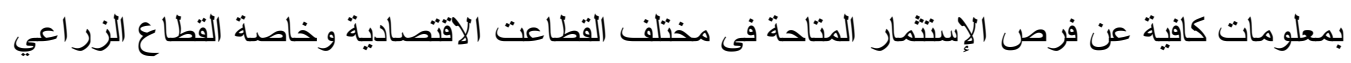

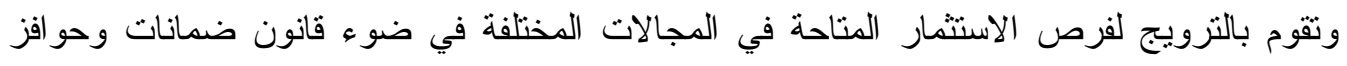

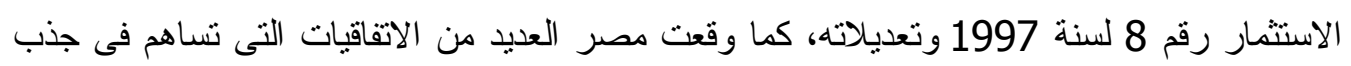

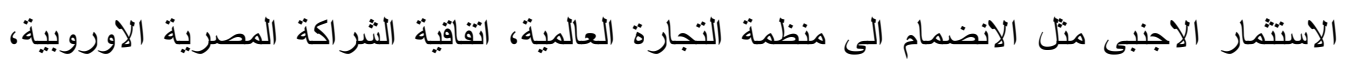

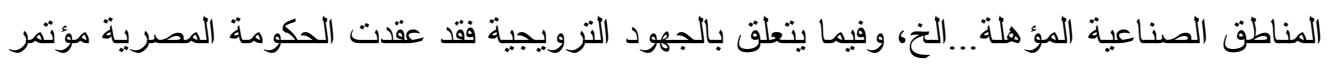

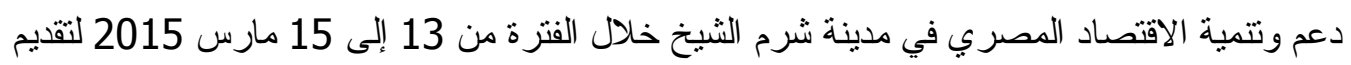
فرص استثمارية جديدة للمستثمرين في القطاعات الواعدة الرئيسية التي تتمتع بمز ايا تنافسية ومن فينة

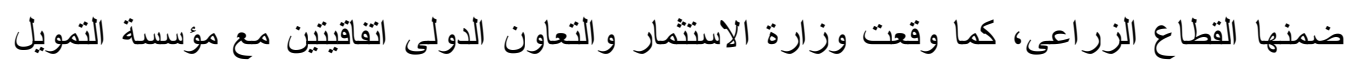

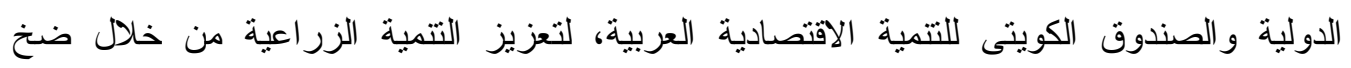

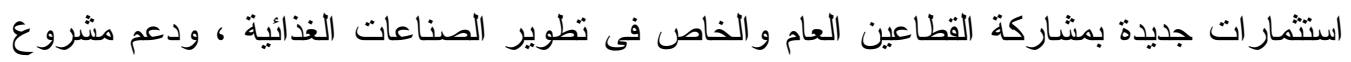

$$
\text { استصلاح } 400 \text { فدان فى شمال سيناء } 33
$$

النموذج القياسي: تبحث الدراسة في تأثثر الاستثمار فئات الاجنبية المباشرة على النمو القطاع الزراعى

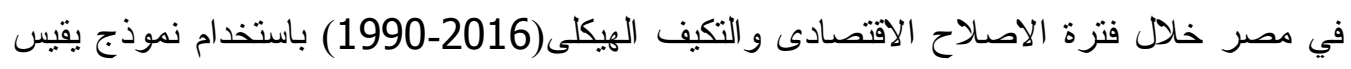

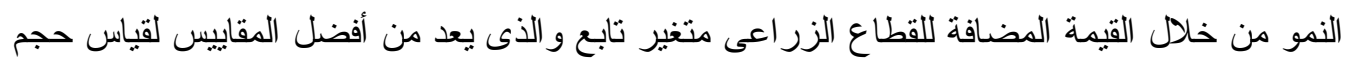

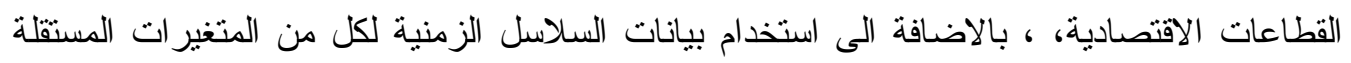

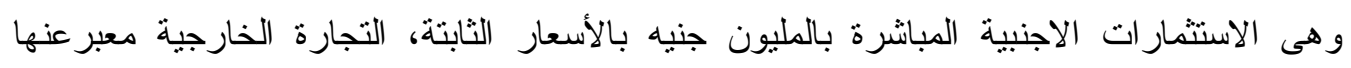

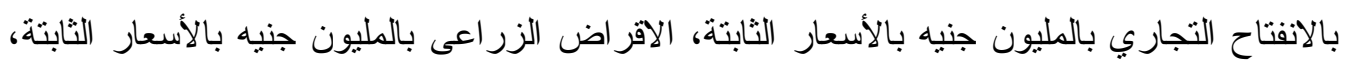

32 فرص الاستثمار المعلنة يوم 24 يناير 2008 على موقع الوزارة على شبكة الانترنت: www.investment.gov.eg

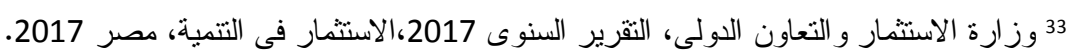




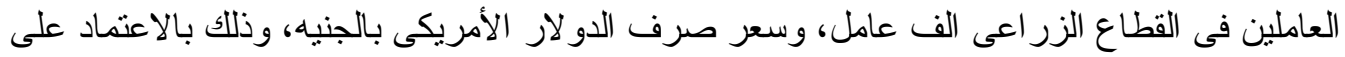

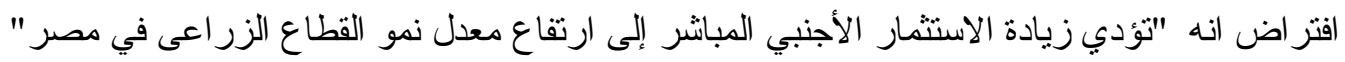

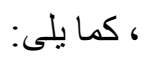

InAGI =f (In FDI, InTrade openness, In loans, In labor and In EXR)

تم تقدير النموذج باستخدام أسلوب الانحدار الخطي المتعدد ، ووجد أن الصيغة اللوغاريتمية المزدوجة (Double Log Linear Function Form)

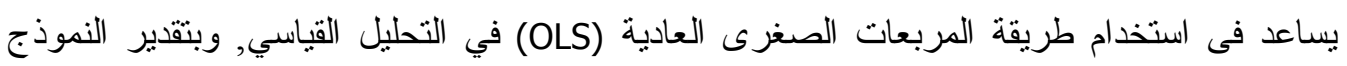
القياسي باستخدام طريقة المربعات الصغرى العادية كالاتى:

$\operatorname{Ln} \gamma=C+\beta_{1} \operatorname{Ln} X_{1 t-1}+\beta_{2} \operatorname{Ln} X_{2}+\beta_{3} \operatorname{Ln} X_{3}+\beta_{4} \operatorname{Ln} X_{4}+\beta_{5} \operatorname{Ln} X_{5}+\grave{i}$

Y= نمو القطاع الزر اعى، ويعبر عن القيمة المضافة بالمليون جنيه بالأسعار الثابتة.

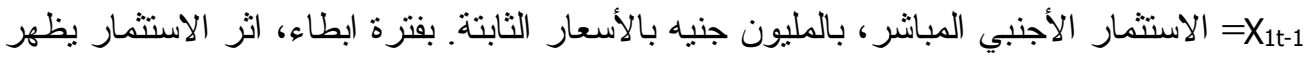

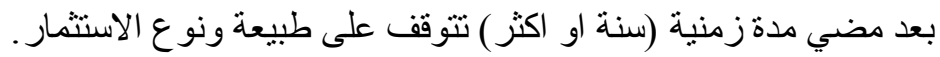
التجارة الخارجية, معبر عنه بالانفتاح التجاري بالمليون جنيه بالأسعار الثابتة. X3= الاقر اض الزر اعى, بالمليون جنيه بالأسعار الثابتة لX2=X3

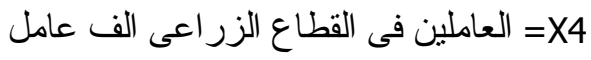
سعر صرف الدو لار الأمريكى بالجنيه =X5 الصيغة اللوغاريتمية Ln U وبتقدير النموذج القياسى كالاتى: $\operatorname{Ln} Y=5.19+0.013 \ln X_{1 t-1}+0.029 \ln X_{2}+0.117 \ln X_{3}+0.815 \ln X_{4}+0.341 \ln X_{5}$

$$
\begin{array}{ll}
\quad(2.58)^{*} & (1.16) \\
F=72 & R^{2}=0.93
\end{array}
$$

تشير قيمة (F) على أن النموذج القياسي معنوي إحصائيا، كما تعبر المعادلة(2)عن العلاقة بين المتغير

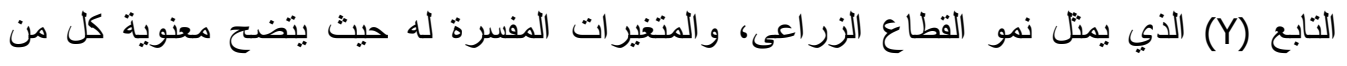

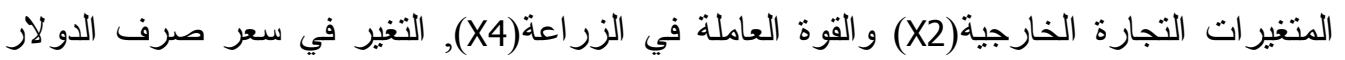

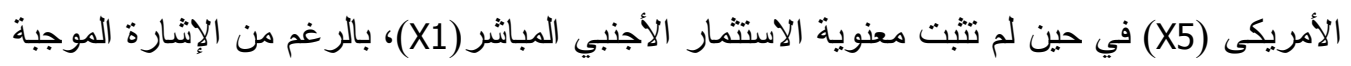

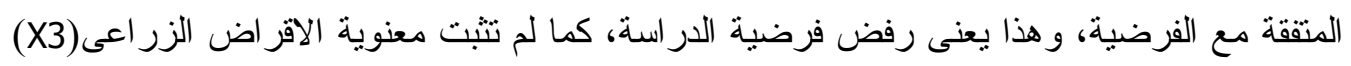

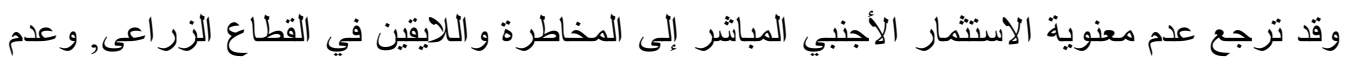

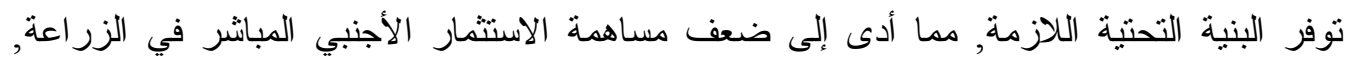

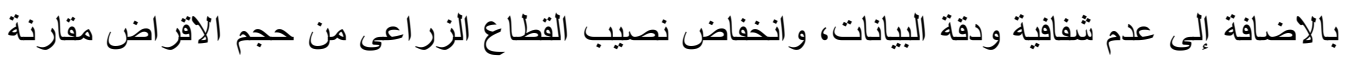

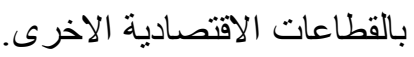

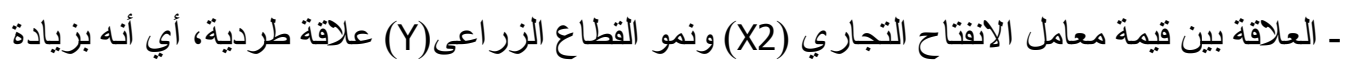
الانفتاح التجاري بنسبة 1\% تتسبب فى زيادة نمو القطاع الزر اعى بنسبة 0.029.

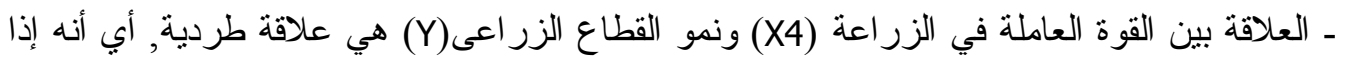

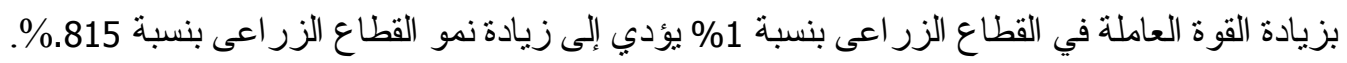

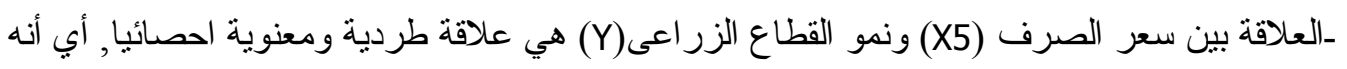
إذا بزيادة سعر الصرف في القطاع الزراعى بنسبة 1\% يؤدي إلى زيادة نمو القطاع الزر اعلى بلى بنسبة 
341\%، مع الاخذ فى الاعتبار إن التغير فى سعر صرف الدو لار يؤثر تأثثر آ موجبا على الاستثمار ات

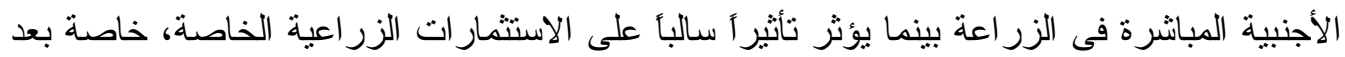

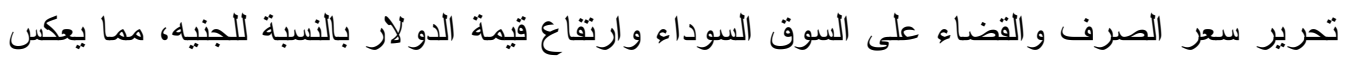

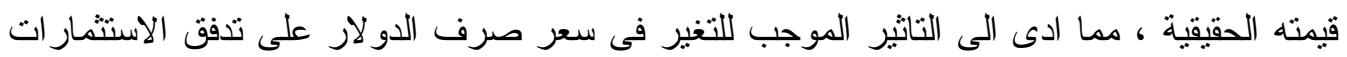

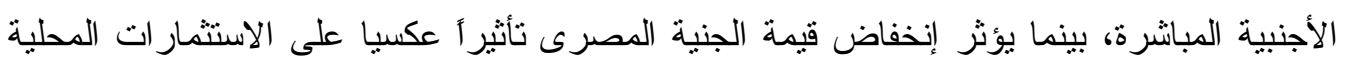

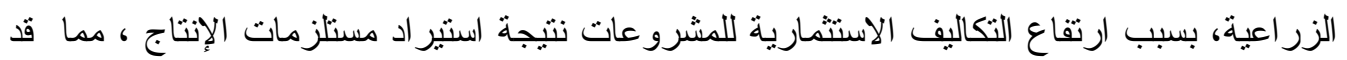

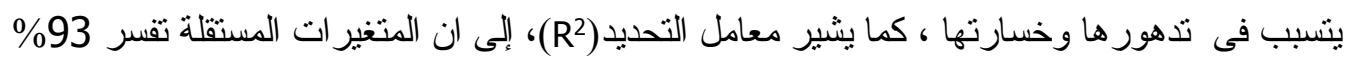

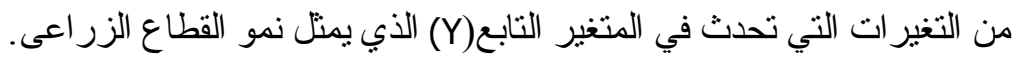

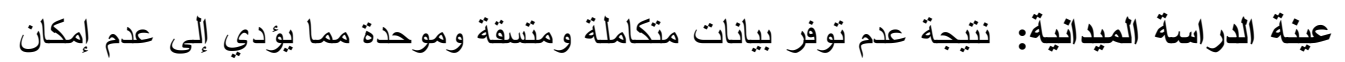

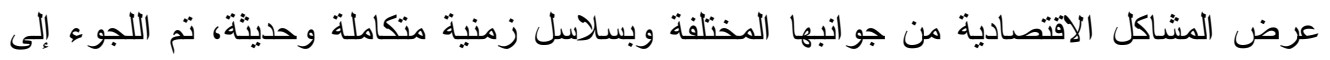
المصادر الأولية حيث أن المصادر الثانوية غير كافية لتحليل موضوع التهادية البحث، من خلال استمارة

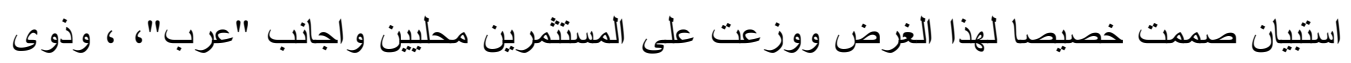

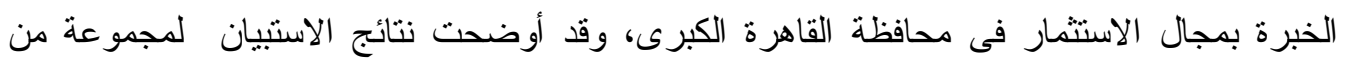

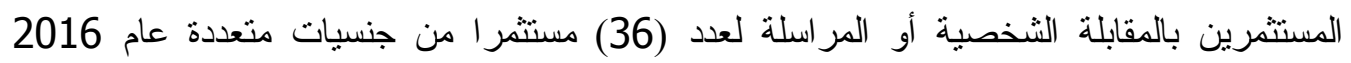

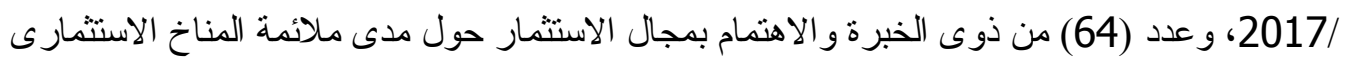

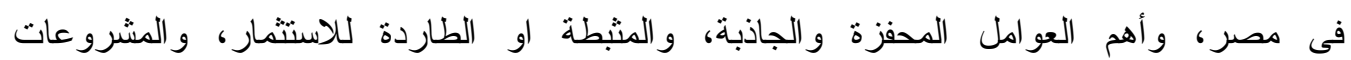
المرغوبة...الخ.

اولا: هناك العديد من التحديات والعقبات التي تواجه جذب الاستثمار الأجنبي المباثر في مصر و التي

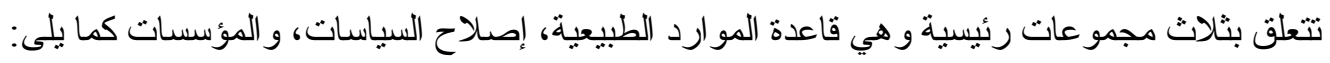

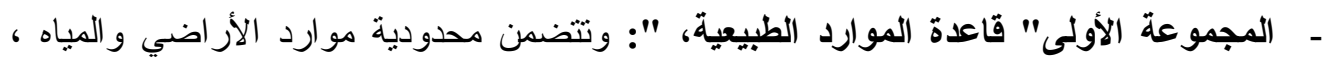
و عدد وخصائص السكان، منل ضعف المستوى التعليمى و الصحى للقوى العاملة ، اخلاقيات العمل ولاتل

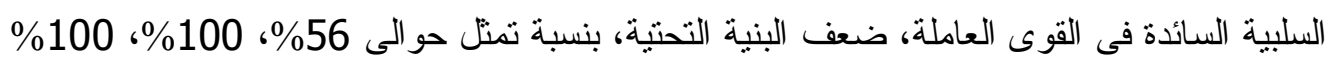

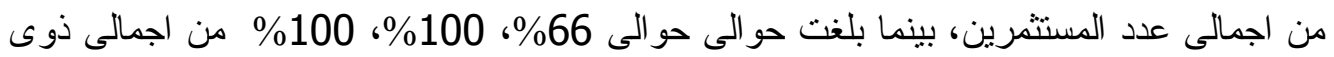
الخبرة والاهنمام بمجال الاستثمار فى عينة الدر اسة.

- أما المجموعة الثانية و الثالثة" إصلاح السياسات، والمؤسسات" الثات : فتتعلق بالإنحياز للمدن ونظم

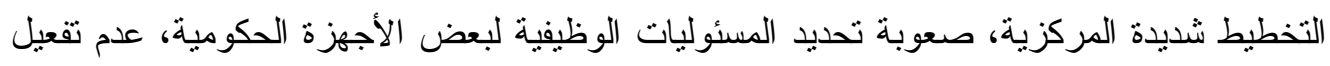

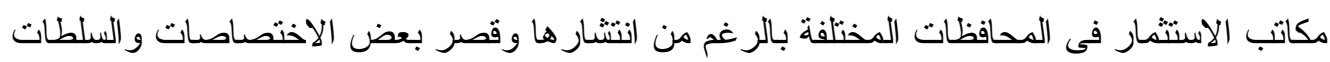

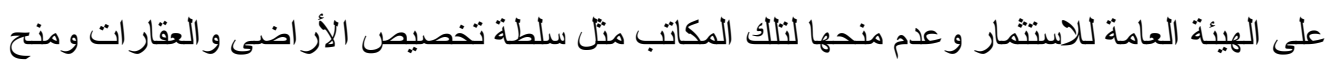
التراخيص، بعض اجراءات المصادرة وخاصة بعد ثورة يناير 2011 - اثر سلبيا على ثلقة

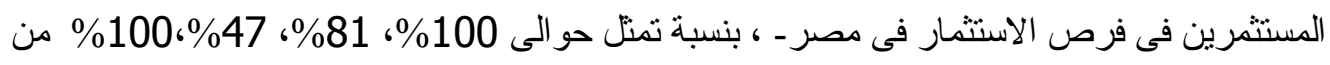

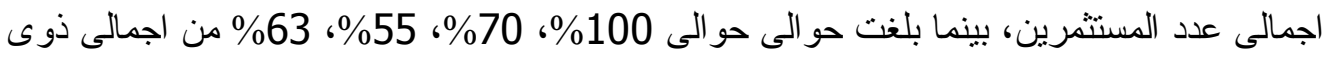

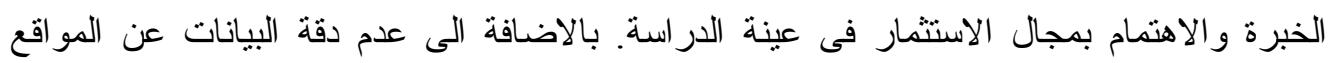

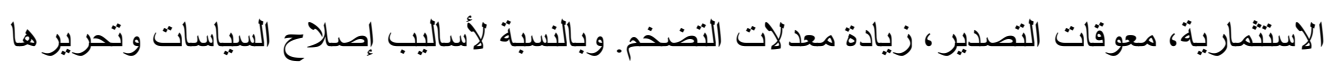
وضآلة الاستثمار في الزر اعة لارتفاع المخاطرة و اللايقين فى القطاع الزر اعى، المنافسة غير المتكافئة

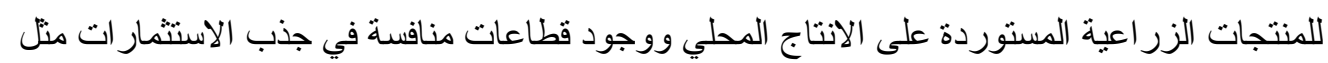

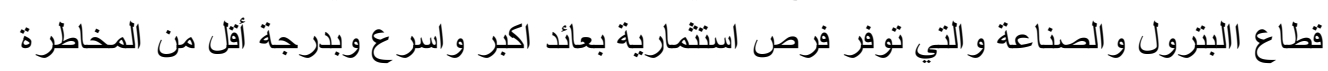

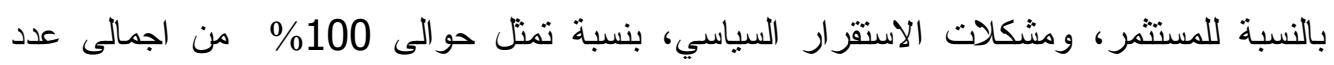




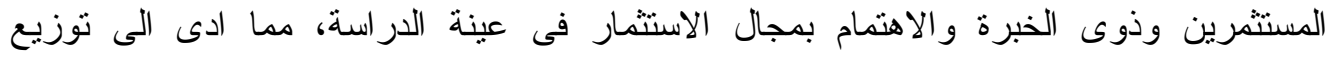

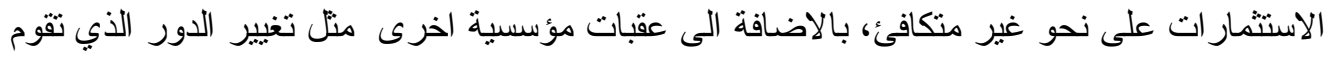

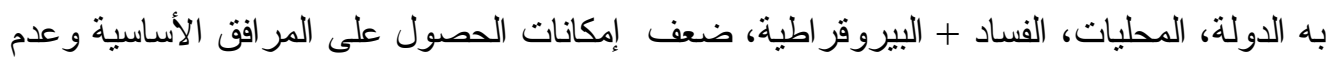
كفايتها وكذللك ضعف التمويل الريفي الفعال و الكفؤ، كما ان هناك معوقات نرجع للمستثر نفساه منل النظرة التجارية قصيرة المدى للمستثر العربي حيث ان المستثمر العربي لا يحبذ النظرة التجارية

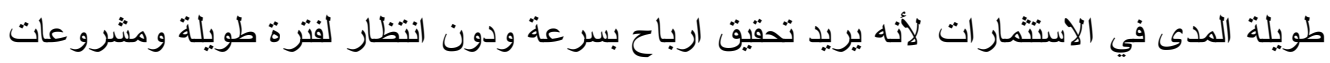

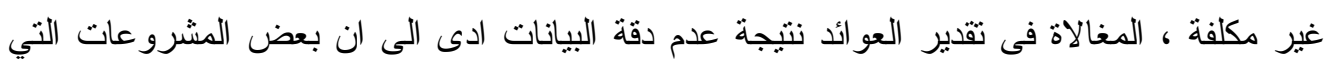

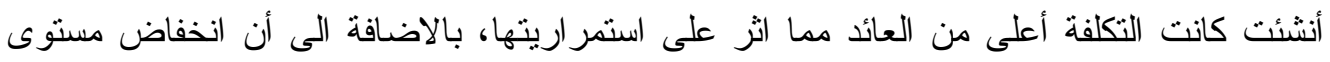

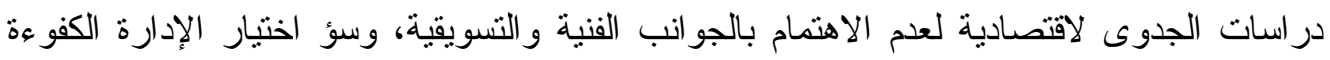
المؤهلة للتعامل مع بيئة الاستثمار ومتغير اتها، وسوء اختيار أنماط وأدوات التهات التمويل لتمويل

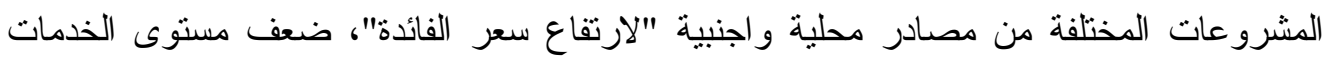
التسويقية نتيجة وجود الحواجز و القيود التي تحول دون انتقال السلع والخدمات، قصور الجهود

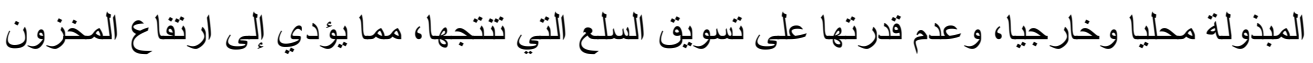

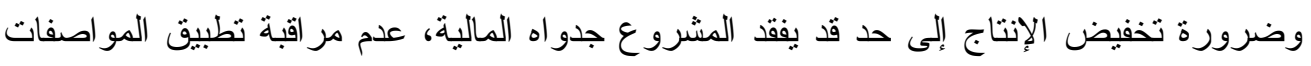

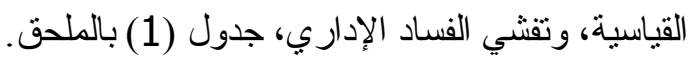

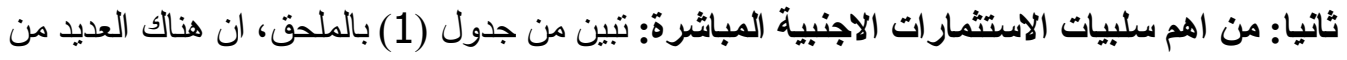

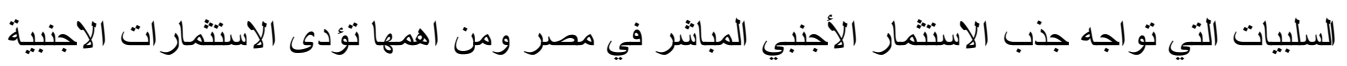

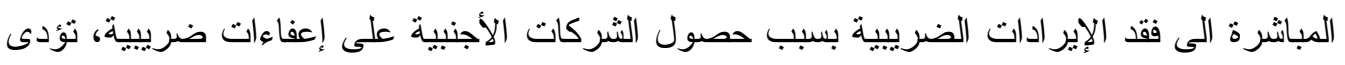

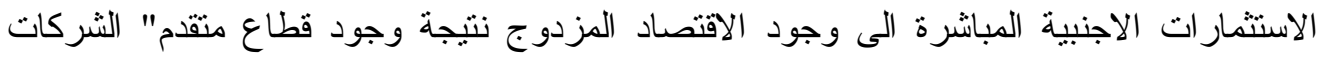

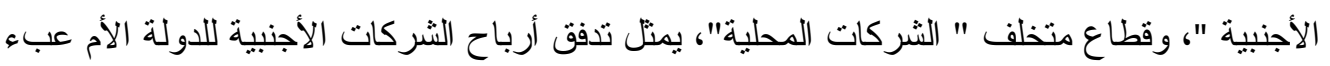

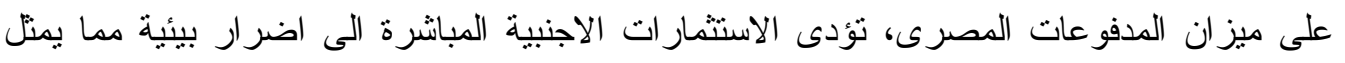

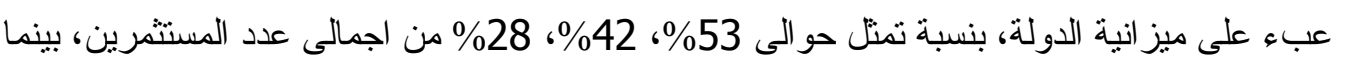
بلغت حو الى حو الى 86\%، 70\%، 36\% من اجمالى ذوى الخبرة و الاهتمام بمجال الاستثمار فى عينة

$$
\text { الدر اسة. }
$$

ثالثا: من الهم ايجابيات جذب المزيد من الاستثمارات الاجنبية المباشرة والعربية: يضفى الالتزام

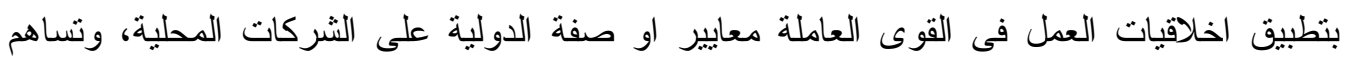

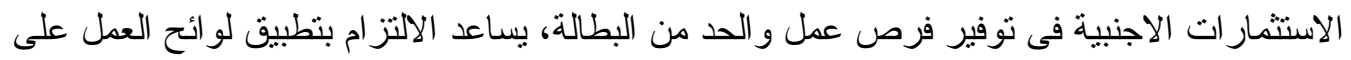

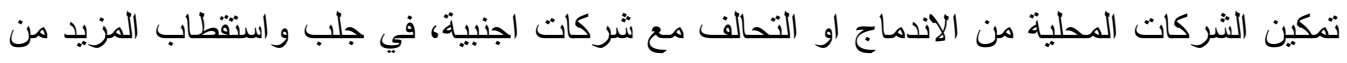

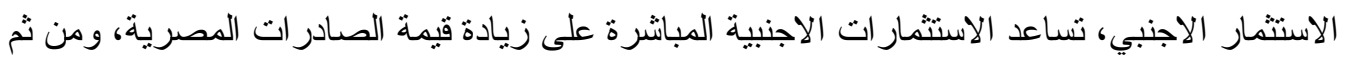

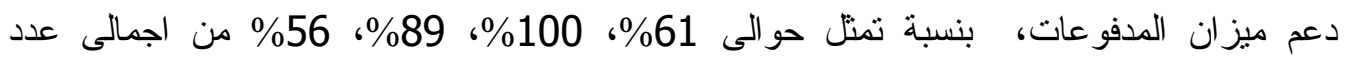

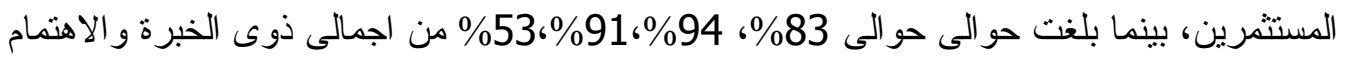

$$
\text { بمجال الاستثمار فى عينة الدر اسة، جدول (1) بالملحق. }
$$

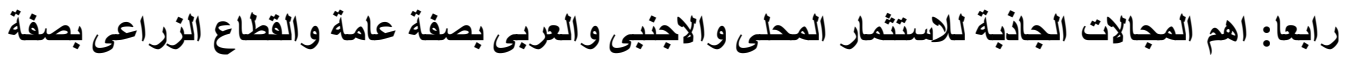

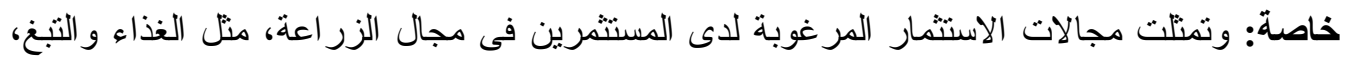

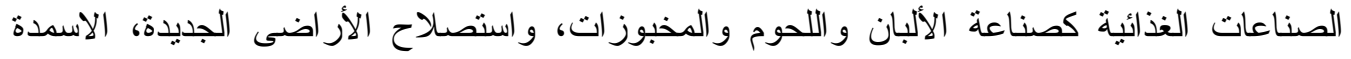

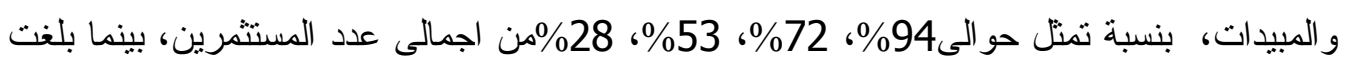


حو الى 94\%، \%7\%، 59\%36\% من اجمالى ذوى الخبرة والاهتمام بمجال الاستثمار فى عينة الدر اسة، جدول (1) بالملحق. خامسا: اهم المقترحات لاستقطاب المزيد من الاستثمارات المحلية والاجنبية والعربية فى القطاعات

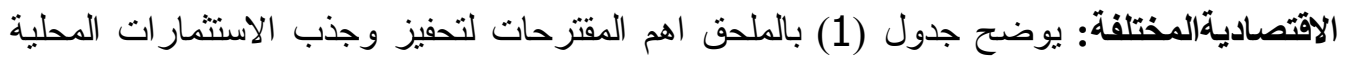

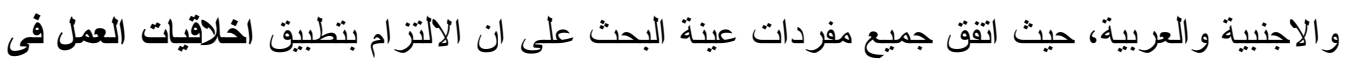

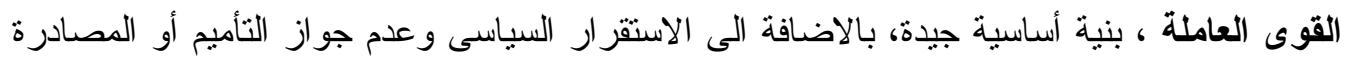

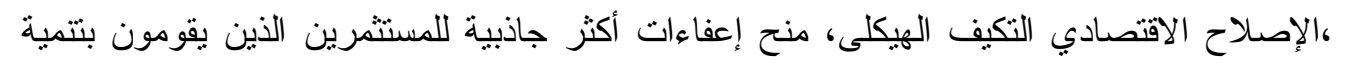

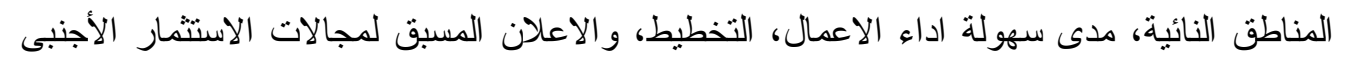

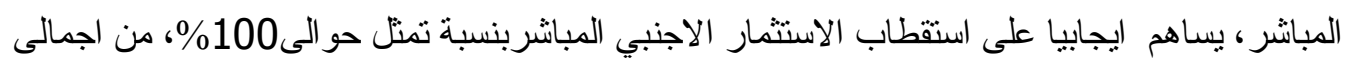

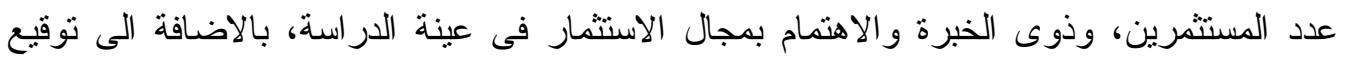

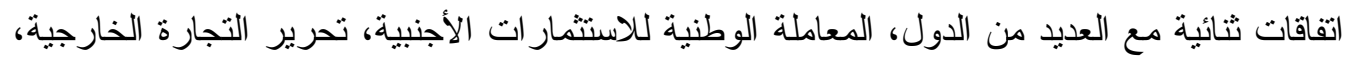

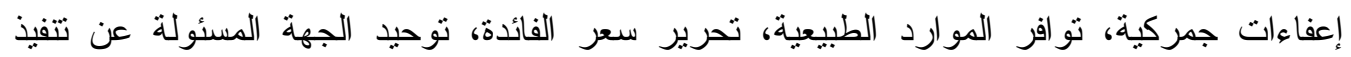

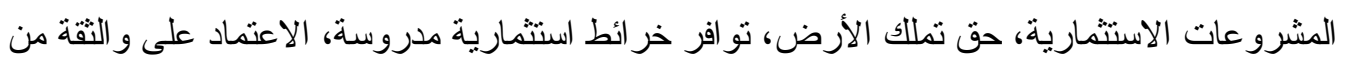

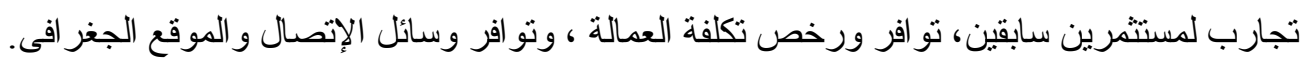

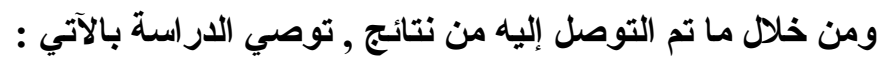

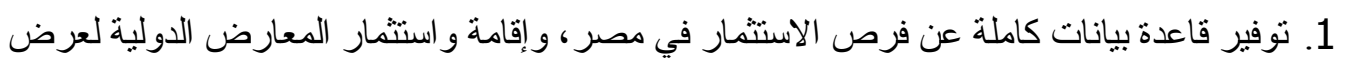

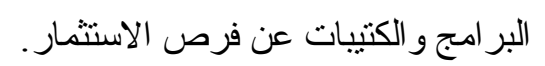

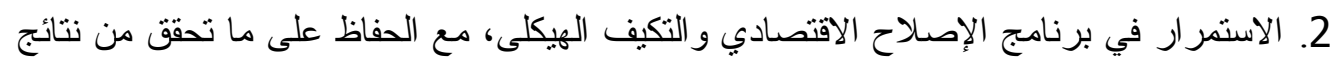

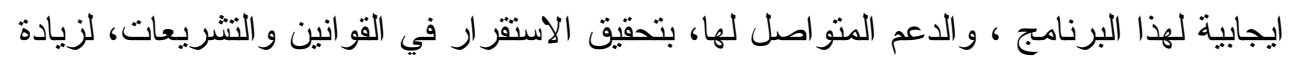

$$
\text { التقة و الامان لاى المستثمرين }
$$

3. تعزيز وتحقيق الاستقرار السياسى والاقتصادى، ونوفير بنية تحتية ضرورية للاستثمار "الماء الاهي و الكهرباء و الطرق و الاتصالات ...الخ". لاهميتهم فى جذب الاستثمار ات المحلية و الاجنبية. 4. تعزيز اطر التكامل والتعاون الاقتصادى الدولى بصفة عامة اعطاء اولوية لجذب رؤوس الأموال

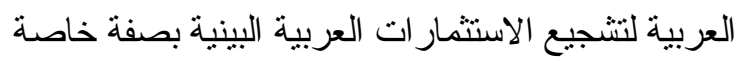

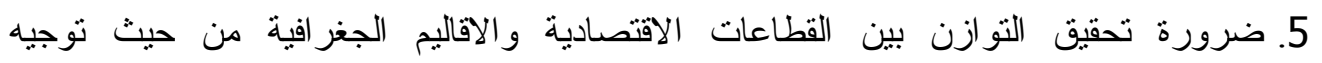

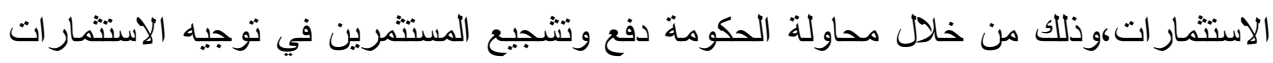

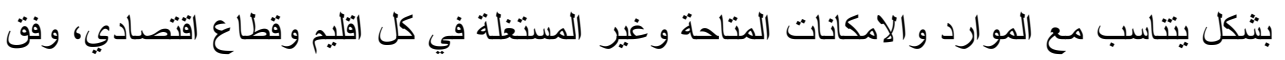

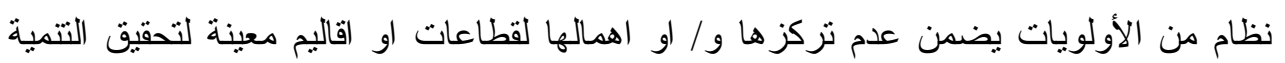

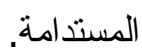

6. إنباع سباسة انتقائية في تشجيع الاستثمار الأجنبي المباشر، والاعتماد على سياسة تقديم الحوافز

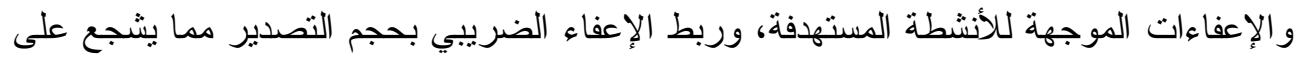

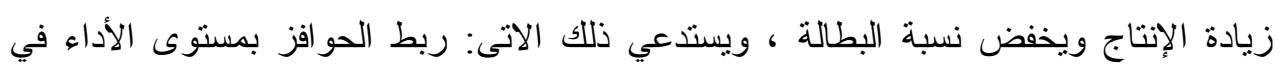

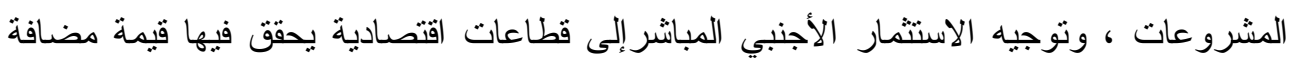

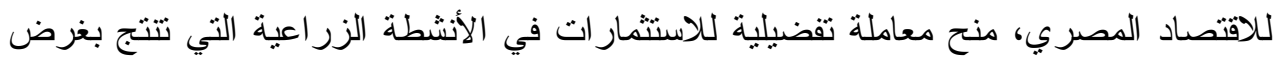

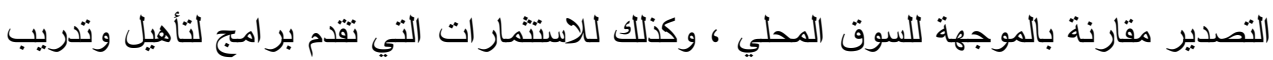

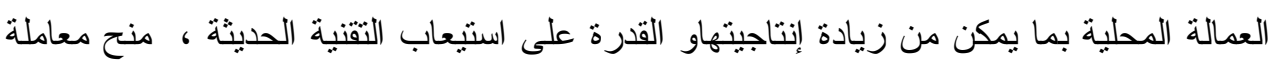


تفضيلية في الأنشطة المكثفة للعمل بما يؤدي إلى تخفيض البطالة و ايضا للأنشطة التي تعمل على

$$
\text { استخدام المو اد الخام المتوفرة محليا. }
$$

7. تنبي نماذج عمل “Inclusive Business Models" لتشجيع الاستثمار الأجنبي في مصر ، وهي تقوم

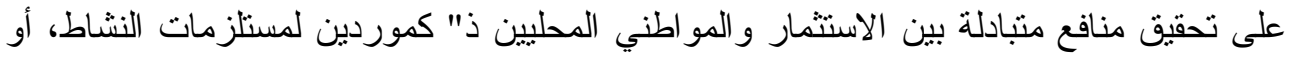
كعاملين أو كموزعين للسلع و الخدمات" مما يساعد على توفير فرص العمل وزيادة وتحسين

$$
\text { مستوى معيشتهم. }
$$

ويتم تنفيذ التوصيات السابقة من خلا العديد من الوزارات و المؤسسات المعنية المنوط بها ذلك ، منل

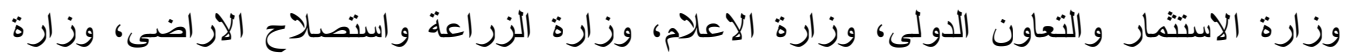

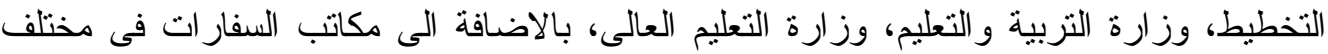

\section{المراجع}

1. احمد ابو اليزيد الرسول_السياسات الاقتصادية الزراعية "رؤى معاصرة" مكتبة بستان المعرفة للطبع و النشر -مصر - 2004.

2. احمد حسين عبدالحميد الغنيمى- الاصلاح الاقتصادى فى الزراعة المصرية ـكلية الزر اعة_قسم الاقتصاد الزر اعى-جامعة الاسكندرية-2007.

3. أميره حسب الله محمد، محدات الاستثمار الاجنبي المباشر في البنية الاقتصادية العربية دراسة

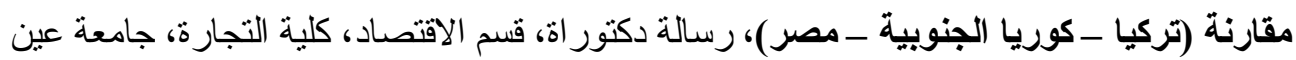
شمس، القاهرة، 2005/2004. 4. البنك الدولي، تقرير ممارسة أنشطة الأعمال في العالم العربي،اعداد مختلفة. 5. الجمعية المصرية للاقتصاد السياسي و الإحصاء و التشريع ، القاهرة ، 1991 ـ 190

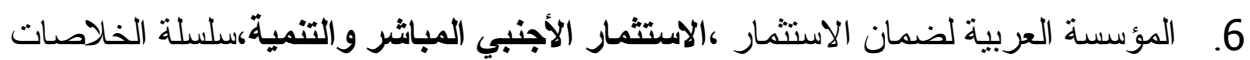

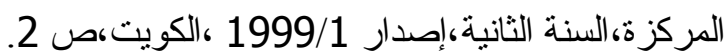
7. المؤسسة العربية لضمان الاستثمار و ائتمان الصادر ات، مناخ الاستثمار في الدول العربية

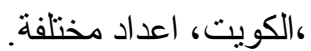
8.

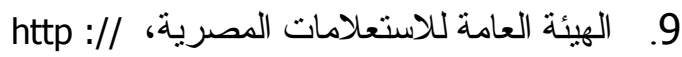
www.sis.gov.eg/Ar/lastpage.aspx/catagory-ID $=424$ 10. برنامج الأمم المتحدة الانمائي،« تقرير التنمية البشرية - 2014 المضي في التقدم :بناء المنعة

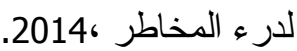

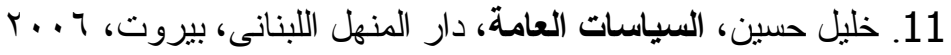
12. دريد محمود السامر ائي" الاستثمار الأجنبي المعوقات والضمانات القانونية "مركز در اسات الوحدة العربية 2006 ص48.

13. رجب ابر اهيم اسماعيل اسماعيل،اطار مقترح لسياسات جذب الثركات متعددة الجنسيات

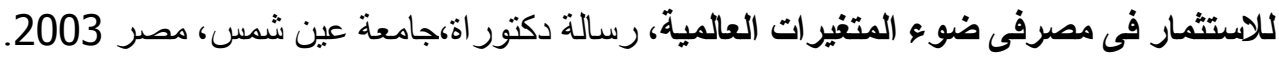

14. رئاسة الجمهورية ،المجالس القومية المتخصصة،،" موسوعة المجالس القومية المتخصصة "، المجلد الثاني و الثلاثون،الكتاب السنوي، 2005-2006. 


$$
\begin{aligned}
& \text { 15. على عبد الوهاب إبر اهيم نجا، الاستثمار الأجنبي المباشر وأثره على التتمية الاقتصادية في مصر }
\end{aligned}
$$

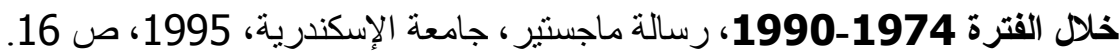

$$
\begin{aligned}
& \text { 16. فرص الاستثمار المعلنة يوم } 24 \text { يناير } 2008 \text { على موقع الوزارة على الفئرة شبكة الانترنت: } \\
& \text { www.investment.gov.eg } \\
& \text { 17. محمد سلطان أبو على (دكتور) ، تحرير الاقتصاد المصري، المؤتمر العلمي السنوي السادس عشر } \\
& \text { للاقتصاديين المصريين } \\
& \text { 18. وزارة التنمية الاقتصادية ، الخطة الخمسية السادسة(2007/208 -2011 /2012) ، ص } 60 .
\end{aligned}
$$

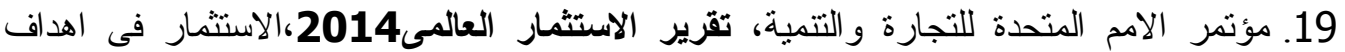

$$
\begin{aligned}
& \text { التتمية المستدامة:حطة عمل، نيويورك وجنيف، الامم المتحدة، }
\end{aligned}
$$

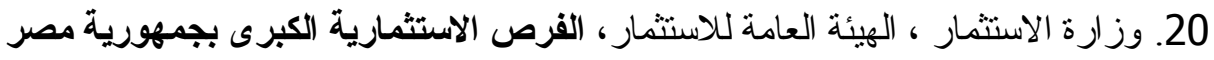

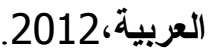

21. Alasrag, Hussien. "Foreign Direct Investment Development Policies in the Arab Countries". Munich Personal RePEc Archive, no. 2230 (December 2005), http://mpra.ub.uni-muenchen.de/2230/1/MPRA_paper_2230.pdf

22. Centre International pour le Règlement des Différends Relatifs aux Investissements CIRDI,Rapport annuel 2014, Washington, DC : Banque Mondiale, 2014, p 9-13.

23. Egypt in the global economy: strategic choices for savings,investments, and long term growth", doing business, 1st march 1998.

24. Elizabeth Asiedu (2002), "On the Determinants of Foreign Direct Investment to Developing Countries: Is Africa Different?" , World Development, Vol. 30, No. 1, P. 109.

25. FAO International investments in agriculture in the Near East. Evidence from Egypt,Morocco and Sudan. Rome: FAO. (2011).

26. Saleh S.Abdelazim, Structural Adjustment and the Dismantling of Egypt's Etatist System, Doctoral dissertation, Sociology, Faculty of the Virginia Polytechnic Institute and State University, November 15, 2002, p 22-23.

27. Unctad : World Investment Report, different issues.

28. UNCTAD, Inward FDI Performance and Potential Index Rankings,19902010,www.unctad.org/fdistatistics

29. World Economic Forum, Global Competitiveness Reports, different issuse

30. World Bank Doing Business 2013. *Ranked out of 185 economies around the world.2013.

31. World Bank ، http://data.albankaldawli.org 


\begin{tabular}{|c|c|c|c|c|}
\hline \multicolumn{2}{|c|}{ بالاستثمازرة } & \multicolumn{2}{|c|}{ المستُّنمرين } & \multirow[t]{2}{*}{ البيان } \\
\hline$\%$ & العددا & $\%$ & العدد & \\
\hline & & & & الهم معوقات الاستيّمّار من وجهة نظركم: \\
\hline 100 & 64 & 100 & 36 & ــاخلاقيات العمل السلبية السائدة فى القوى العاملة \\
\hline 66 & 42 & 56 & 20 & ـــعف المستوى النعليمى و الصدى للقوى العاملة \\
\hline 100 & 64 & 100 & 36 & ـ ـالإندياز للمدن ونظم النخطيط شديدة المركزية \\
\hline 100 & 64 & 100 & 36 & ـالاستقر ار السياسي \\
\hline 55 & 35 & 47 & 17 & ـعدم تععيل مكاتب الاستثمار فى المحافظات المختلفة بالر غم من انتشار ها. \\
\hline 42 & 27 & 33 & 12 & الاستثنمار إلىى حرفية الترويج للاستثمار الأجنبي المباشر داذل مصر وخاصة فى ظل المنافسة العالمية الكبيرة لجذب هذه \\
\hline 59 & 38 & 86 & 31 & 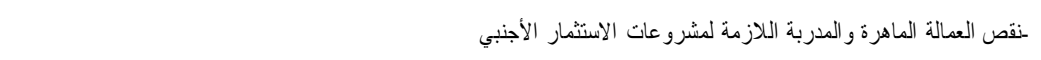 \\
\hline 52 & 33 & 72 & 26 & ـعدم وجود خريطة استثمارية للمناطق الواعدة و الجاذبة للاستثمار و إنتباع سياسات غير مرنة مع المستثر \\
\hline 56 & 36 & 53 & 19 & تنع مشكلة التعثر بالنسبة للمشرو عات الاستثمارية من أخطر المشكلات التى نو اجه الاستثمار ،لكونها أضرت بسمعة الاستثمار \\
\hline 63 & 40 & 100 & 36 & 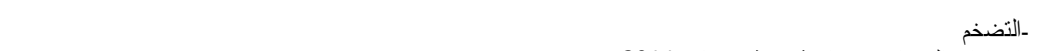 \\
\hline 63 & 40 & 100 & 36 & ـاجر اءات المصادرة وخاصة بعد ثورة يناير 2011 \\
\hline 61 & 39 & 31 & 11 & ـ ـ ـعوبة تذصيص الأر اضي وارتفاع سعر ها. \\
\hline 21 & 13 & 69 & 25 & ـ صعوبة عمليات التخليص الجمركي. \\
\hline 38 & 24 & 64 & 23 & ـالفساد. \\
\hline 50 & 32 & 94 & 34 & - إرتفاع الرسوم الجمركية على بعض المو اد. \\
\hline 70 & 45 & 81 & 29 & ـصعوبة تحديد المسئوليات الوظيفية لبعض الأجهزة الدكومية. \\
\hline 81 & 52 & 86 & 31 & 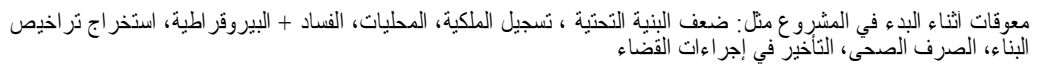 \\
\hline 86 & 55 & 86 & 31 & 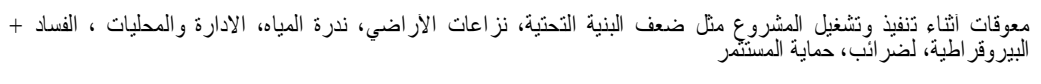 \\
\hline 100 & 64 & 100 & 36 & ـا ـارتفاع المخاطرة و اللايقين فى القطاع الزر اعى \\
\hline 100 & 64 & 100 & 36 & ـ المنافسة غير المتكافئة للمنتجات الزر اعية المستوردة على الانتاج المحلي \\
\hline 100 & 64 & 100 & 36 & 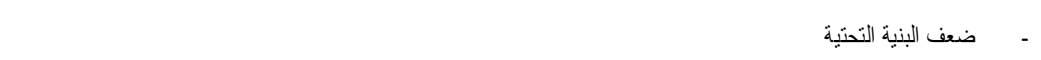 \\
\hline & & & & 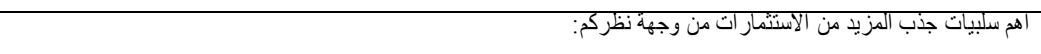 \\
\hline 86 & 55 & 53 & 19 & تؤدى الاستثمار ات الاجنبية المباشرة الى فقد الإير ادات الضريبية بسبب حصول الثركات الأجنبية على إعفاءات ضريبية. \\
\hline 91 & 58 & 81 & 29 & - ضعف القدرة التنافية للشركات المحلية، يظهر اثر المز احمة \\
\hline 70 & 45 & 42 & 15 & 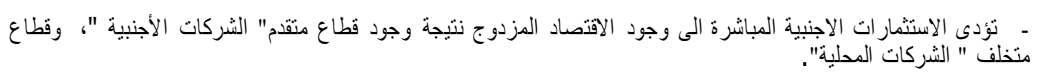 \\
\hline 36 & 23 & 28 & 10 & - ـ ت تؤدى الاستثمار ات الاجنبية المباشرة الى اضر ار بئيه مما يمثل عبء على ميز انية الدولة. \\
\hline 50 & 32 & 8 & 3 & - يمثل تدفق أرباح الشركات الأجنبية لللولة الأم عبء على ميز ان المدفو عات المصرى. \\
\hline 52 & 33 & 53 & 19 & 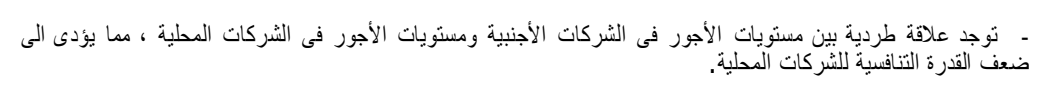 \\
\hline & & & & اهم ايجابيات جذب المزيد من الاستّمار ات المحلية و الاجنبية|المباشر مُ والعربية من وجها نظركم: \\
\hline 83 & 53 & 61 & 22 & - بضفى الالتز ام بتطبيق اخلاقيات العمل فى القوى العاملة معايير او صفة الدولية على الشركات المحلية. \\
\hline 100 & 64 & 100 & 36 & - يعد الاستقر ار الحكومى، واستقرار السياسات الاقتصادية مكملا لاتفاقيات التجارة الحرة مع دول العالم. \\
\hline
\end{tabular}




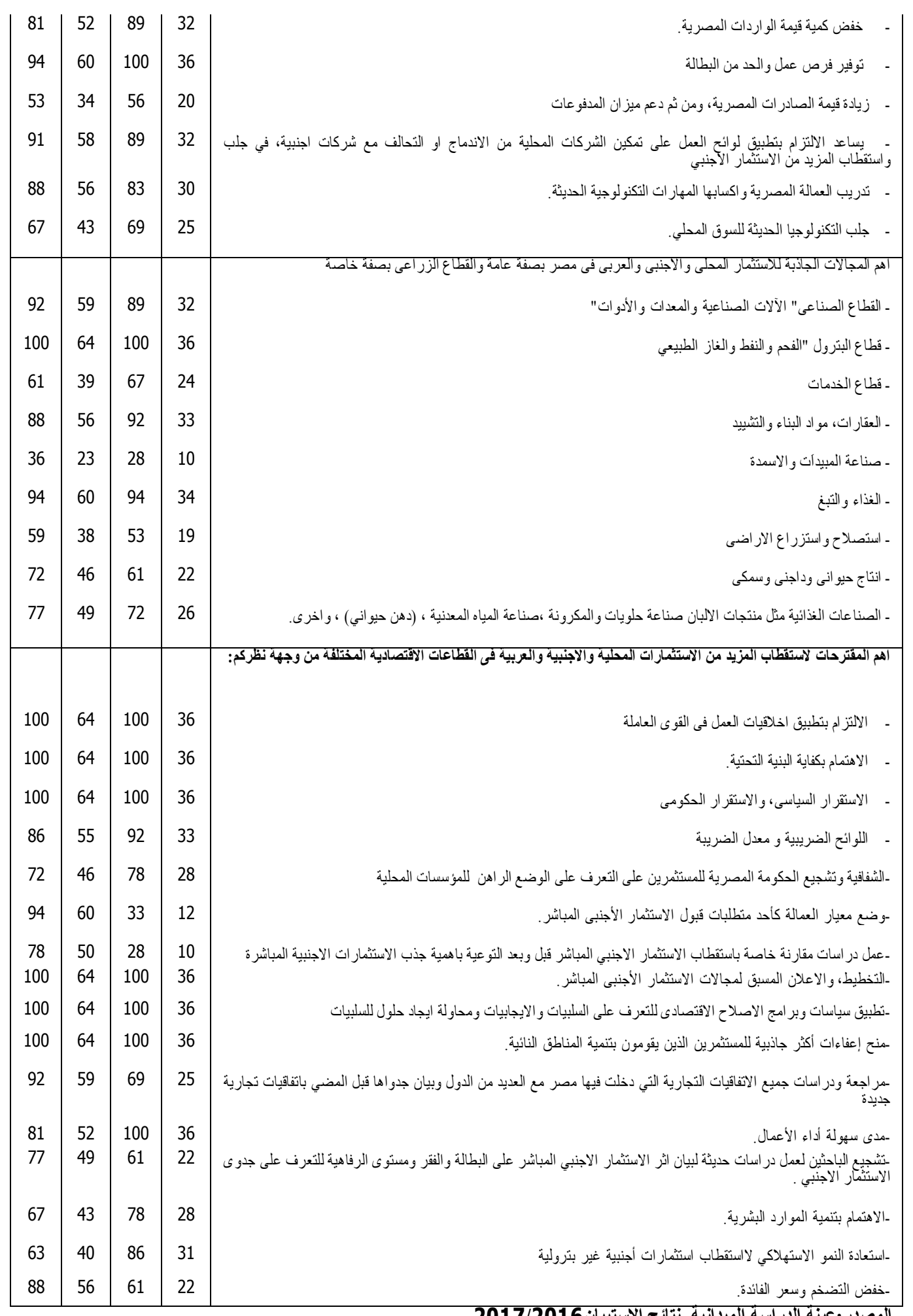

